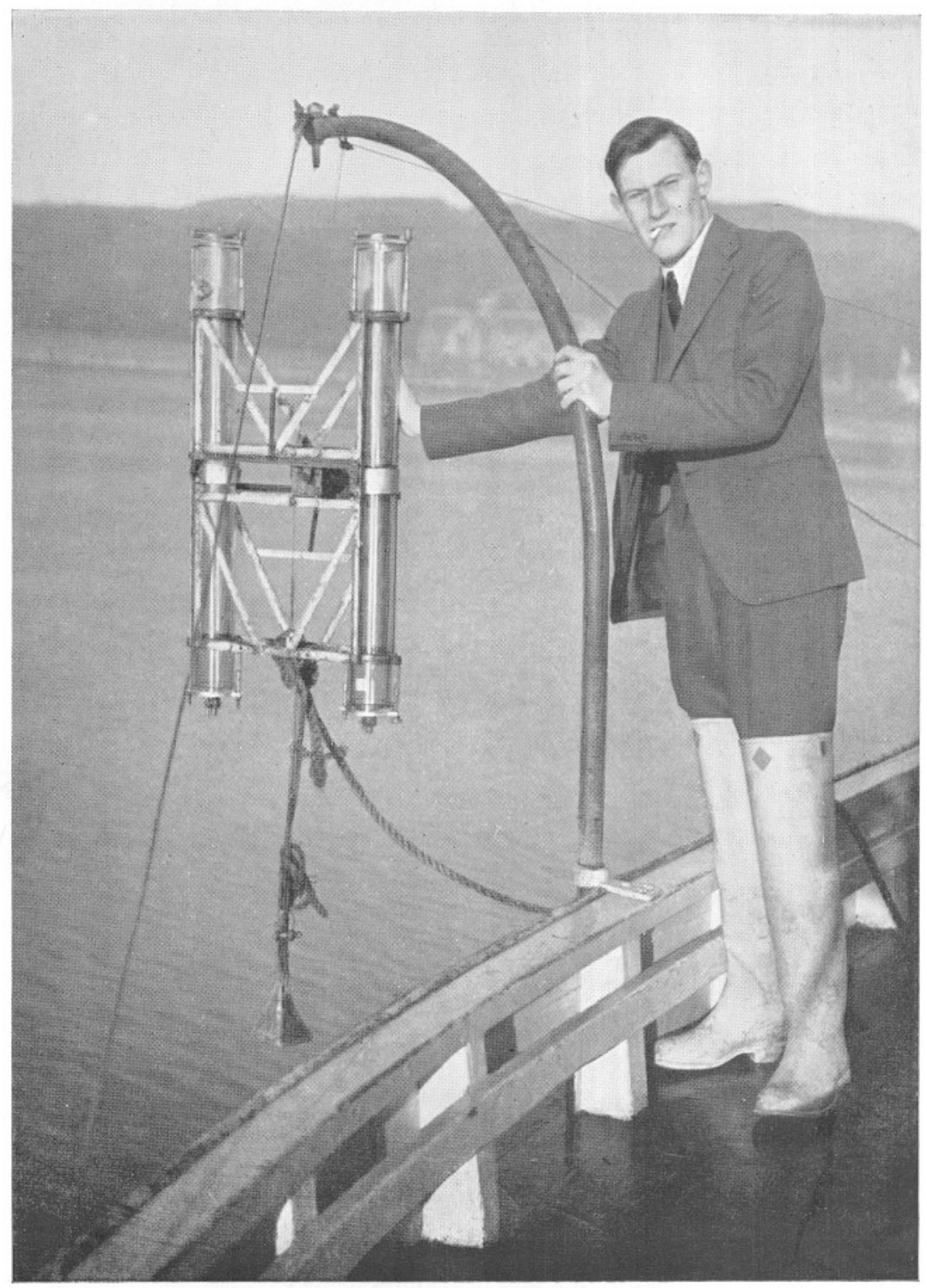

The late Lieut. W. Neil Paton, D.S.C., R.N.V.R., with Apparatus No I in the revised form. 


\title{
EXPERIMENTS ON THE VERTICAL MIGRATION OF PLANKTON ANIMALS
}

\author{
By A. C. Hardy, D.Sc., F.R.S. \\ From the Department of Oceanography, University College of Hull \\ and the late Lieut. W. Neil Paton, D.S.C., B.A., R.N.V.R. \\ Formerly Assistant Naturalist at the Marine Station, Millport
}

(Plates VIII-XI and Text-figs. I-20)

Preface by the first author. Soon after the outbreak of war Neil Paton volunteered for service with the R.N.V.R.; he received his commission in the spring of 1940 and later transferred to the Fleet Air Arm, being stationed at Malta. After many valiant aerial combats, which won him the Distinguished Service Cross and a mention in dispatches, he was reported missing in June 1942 and later officially presumed killed. Marine biology has lost a recruit of great promise and the country a very gallant officer. An appreciation of him and a brief account of his heroic battles based on Admiralty reports will be found in Nature, Vol. I5I, p. 48, I943. The present joint paper was almost complete before he left for service overseas; but there remained a few points still to be considered. Its completion has been delayed by my taking up new appointments and engaging in research in relation to the war.

\section{CONTENTS}

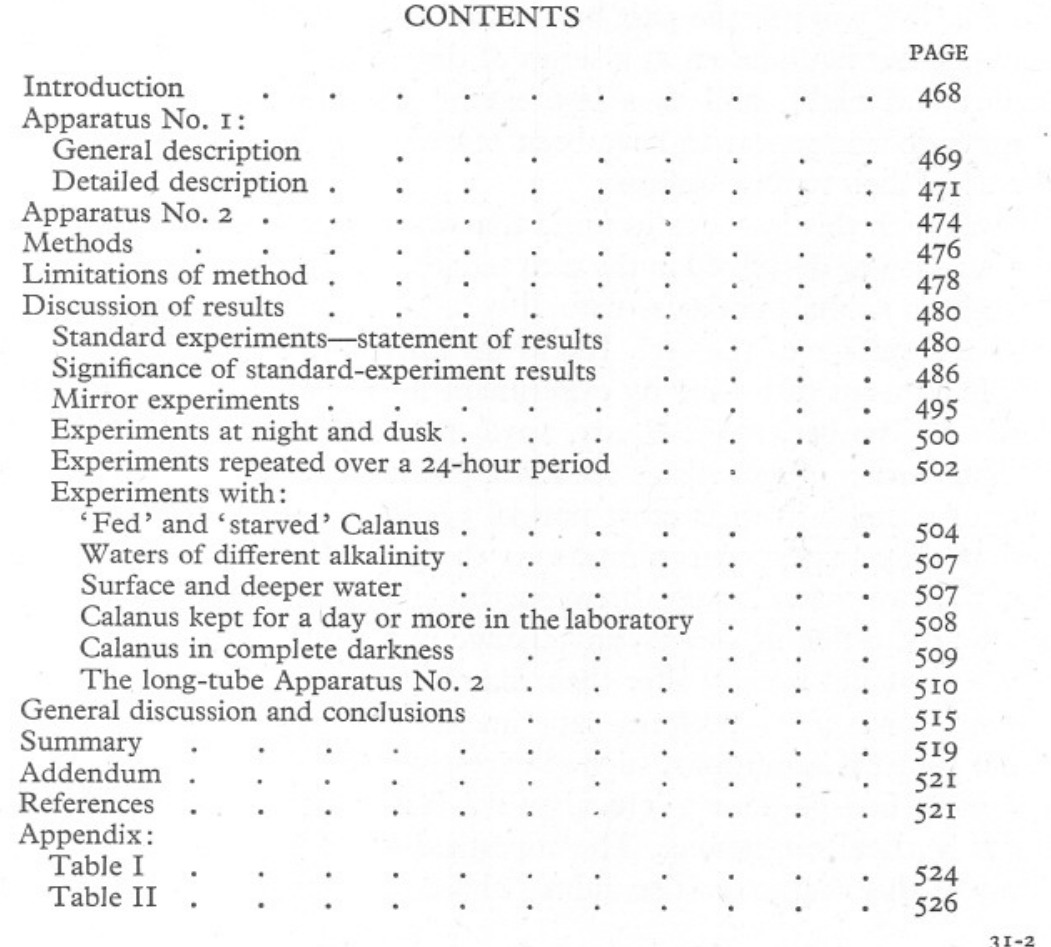




\section{INTRODUCTION}

It is well known that many plankton animals exhibit what is termed a diurnal vertical migration; they usually rise towards the surface in the evening and descend away from it in the daytime. That this behaviour should have been developed independently in so many different animal groups would seem to indicate that it is an activity of much importance in their lives; examples have been recorded among medusae, Ctenophora, Polychaeta (Tomopteris), Chaetognatha, Crustacea of many groups (Cladocera, Copepoda, Mysidacea, Amphipoda, Euphausiacea and Decapoda), Pteropoda, Cephalopoda, pelagic Tunicata (Salpa) and young fish. For a general account of its occurrence reference may be made to Murray \& Hjort (I9I2) and to a special review of the subject and its earlier literature by Russell (1927); it has been shown to be as common in the southern hemisphere (Hardy \& Gunther, 1935) as in the north.

Many investigators have made a special study of this diurnal vertical migration, for example, Esterly (I9II, I9I2, I9I7 and I9I9), Michael (I9II, I9I3), Rose (1925), Russell (1925-34), Clarke (1930-4), Gardiner (1933), Southern \& Gardiner (1932), Worthington (I93I), Nicholls (1933) and others. The concensus of opinion holds that light is a very important, if not the most important, factor controlling these changes in the vertical distribution of the animals. The work in the past has for the most part involved the analysis of many tow-net hauls taken at a series of different depths at different times of the day and night, and to a less extent laboratory experiment. Hitherto attempts do not appear to have been made to perform experiments with the animals in their natural habitat.

It was with this last idea in mind that the senior author designed a special apparatus (to be described in the next section) to study the vertical movements of plankton animals under as natural conditions as possible at various depths below the surface of the sea. It was his intention that the apparatus should provide a means of testing by experiment his hypothesis of animal exclusion (Hardy \& Gunther, I935; Hardy, 1936, I938). In this he has suggested that the distribution of animals as seen in a plankton survey might in part be the result of changes in their more normal vertical migrations brought about by dense phytoplankton concentrations in the upper layers. He pointed out that, since the two water layers, between which they migrate, are nearly always travelling at different speeds, any change in the animals' vertical migrational behaviour would usually alter their distribution as seen in plan. Before proceeding, however, to perform experiments designed to reveal the effects of various unusual conditions, such as excessive phytoplankton, it was clear that work must first be done to elucidate the factors governing the animals' more normal vertical migrations. The investigations described in this paper are mainly of this character. The animal chosen for experiment was the copepod 
Calanus finmarchicus (Gunner.), upon the vertical migration of which much analytical work has already been done (Esterly, I9II; Russell, I925, I926, 1928 b, I934; Gardiner, 1933; Nicholls, I933; Clarke, 1934a).

Through the generosity of the Leverhulme Trust a grant was provided to start the research which was later continued at Millport. We express our great indebtedness to the Leverhulme Trustees who, in addition, made a contribution towards the cost of constructing the apparatus. We are also most grateful to Mr Richard Elmhirst, Director of the Millport Laboratory, for his interest in the experiments and the excellent facilities he gave for them, and to the two boatmen $\mathrm{Mr}$ R. Kerr and Mr D. Burnie who throughout, on the motor research boat Nautilus, helped in the manipulation of the apparatus with so much care and devotion to the work.

Because the research has been suspended on account of the war, and since it is not known when it may be continued, we have thought it desirable to publish the results as far as they have gone. ${ }^{1}$ It must be understood that the experiments are preliminary in character, and consequently no attempt is made at present to elaborate a theory to cover the results; a number of hypotheses suggested by the work must be tested by further experiment. It is hoped, however, that the publication of the results as far as they go may invite comment and criticism which will be helpful in planning the future development of the investigations. The results of all the experiments are given, but many are indicative rather than conclusive.

\section{APPARATUS No. I \\ General description}

The essential nature of the apparatus will be understood with the aid of the diagram in Text-fig. I. It consists of two glass cylinders, $A B$ and $\alpha \beta$, each I $\mathrm{m}$. tall and with an internal diameter of 3 in., mounted in a frame so that they may be suspended vertically in the water and lowered by a wire rope to any desired depth. The frame is so made that it cuts off as little light as possible from the cylinders. A weight, $W$, hanging below, provides stability. The ends of the cylinders are closed at the top and bottom by glass and metal plates respectively; these are removable and interchangeable. Swivelling disks, which will be called trapdoors, are placed half-way down each cylinder at $X$ and $Y$ and fixed to spindles passing through watertight bearings in the cylinder walls. They are arranged so that they may be turned through $180^{\circ}$ to take up any one of three positions. At 'position I' they are each at right angles to the axis of their cylinders, so that, fitting closely, they form partitions dividing their respective cylinders into two compartments, $A$ and $B$ in one cylinder, and $\alpha$ and $\beta$ in the other. At 'position 2' the trapdoors have been

1 This was written before Lieut. Paton was killed on active service: see my prefatory note. A. C. H. 
turned through $90^{\circ}$ so that they now allow free communication between $A$ and $B$, and $\alpha$ and $\beta$. A further turn of $90^{\circ}$ brings them into 'position $3^{\text {', so }}$ that they again form a partition between the two compartments as in 'position I'. The spindles of the two trapdoors, being linked together by cranks and connecting rods, are turned by a spring and trigger mechanism $T$ which may be operated at any depth below the surface by messenger weights $M_{1}$ and $M_{2}$ slid down the supporting wire from above.

At the beginning of an experiment the cylinders are filled with sea water and the trapdoors are set in 'position I': plankton animals are then introduced into one only of the two compartments in each cylinder. When the machine has been lowered to the required depth, the first messenger weight $M_{1}$ is sent down to turn the trapdoors to 'position 2'. The plankton animals are now free to move up or down the whole length of the cylinders. After a certain time has elapsed the second messenger weight $M_{2}$ is dispatched to close the trapdoors again, to 'position 3', and so divide each cylinder once more into its two compartments; now the machine may be brought to the surface and the contents of each compartment extracted and preserved separately for laboratory examination and counting. If, for example, the plankton had been placed at the start in $A$, but not in $B$, and yet at the end of the experiment we find some animals in $B$, we can then estimate the percentage of those which have moved downward in $A B$, and similarly in $\alpha \beta$.

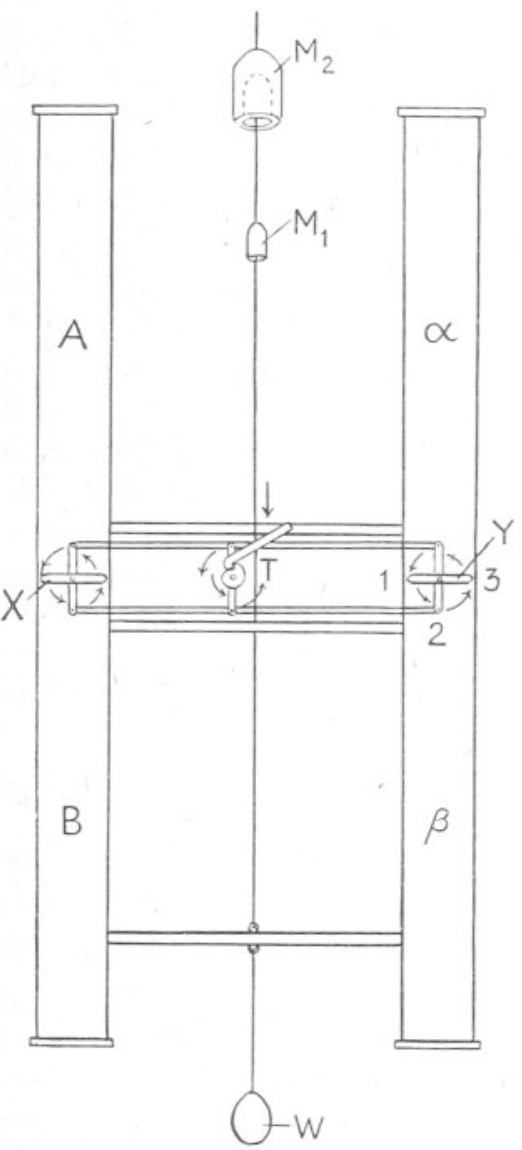

Text-fig. I. Diagram of Apparatus No. I; for explanation see text.

Vice versa starting with the animals in $B$ but not in $A$ we can estimate the percentage of those which have moved upwards in $A B$ and similarly in $\alpha \beta$. A sketch and photographs showing the details of the structure of the apparatus are given in Text-fig. 2, Pl. IX, and Pl. X, fig. 3 .

It will be seen that the apparatus can be used for a number of different purposes. The animals may be introduced into the corresponding compartments of each side to give comparative dual experiments. At other times they may be introduced into the top compartment of one side and into the bottom 


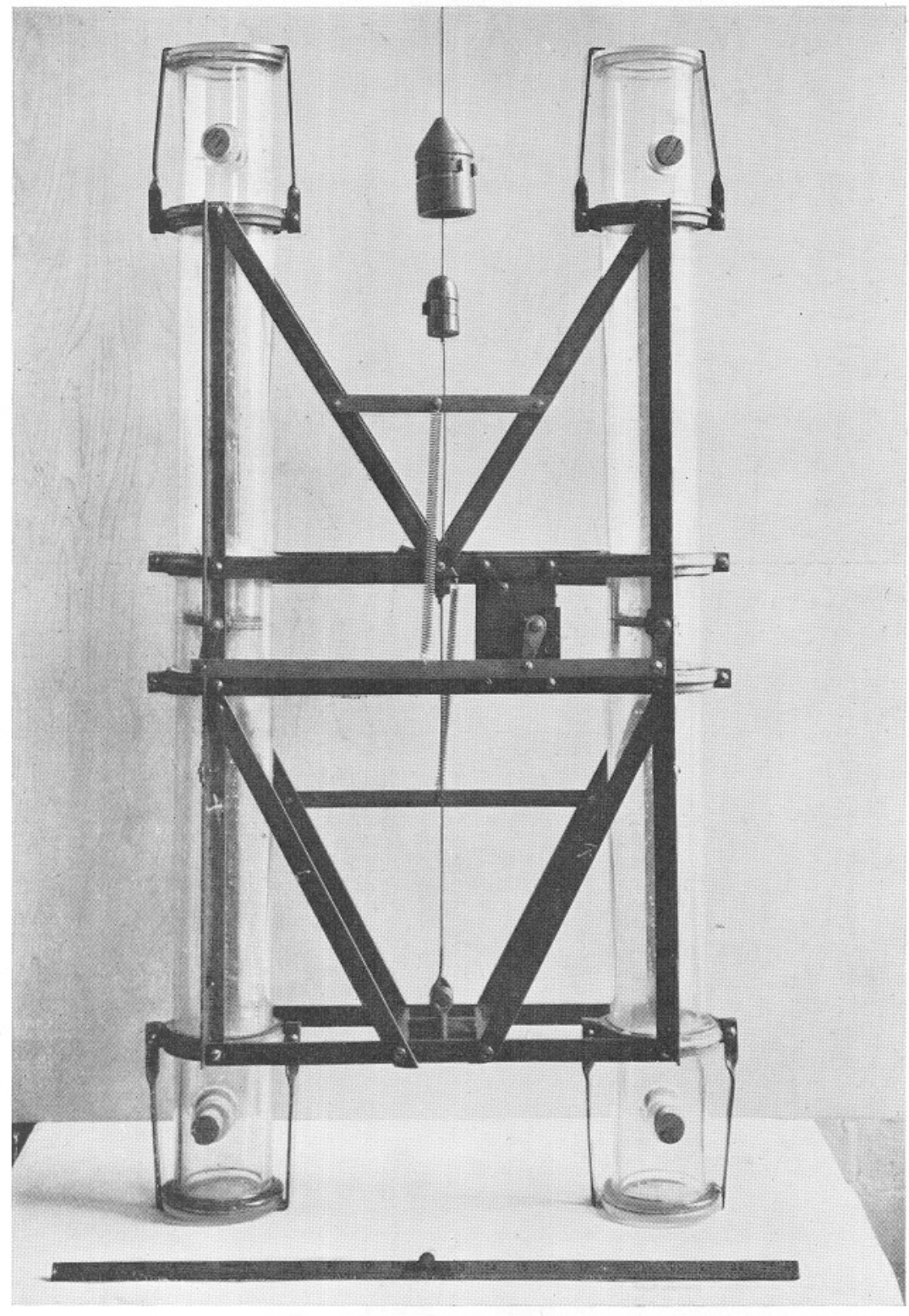

Apparatus No. I in its original form. 


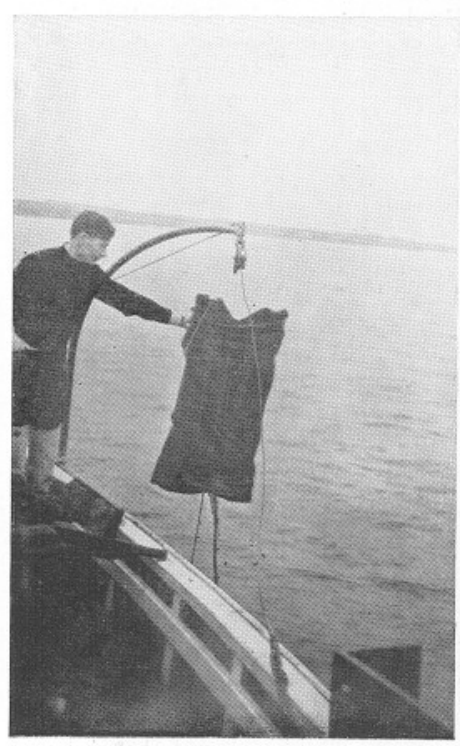

Fig. I.

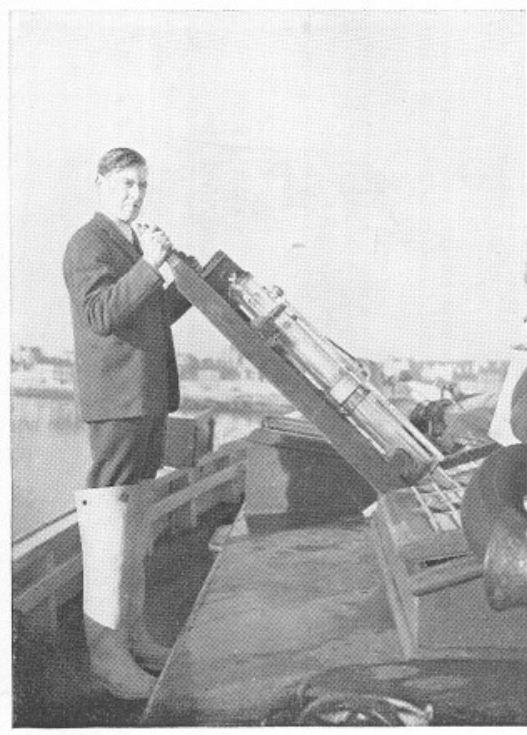

Fig. 2.

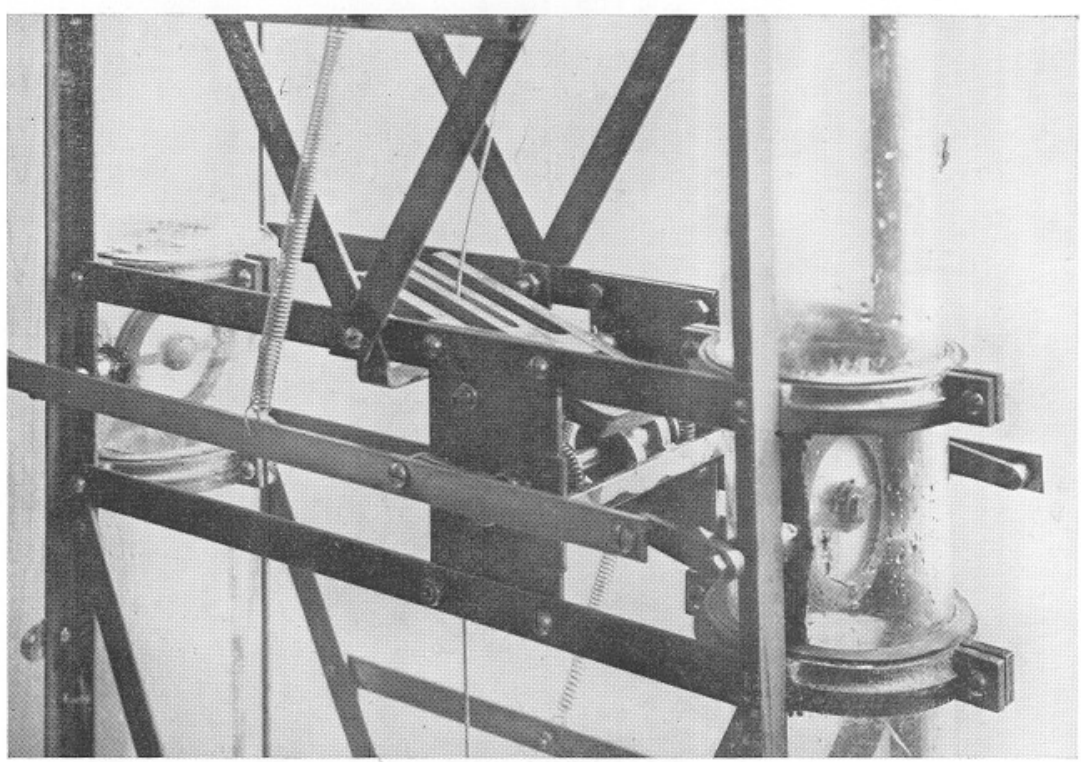

Fig. 3 . 
compartment of the other, so that the numbers moving up or down under similar conditions may be compared. The experiments described here are mainly of this nature. Again, and this is the ultimate object of the apparatus, we may use one side as a control, keeping the conditions as far as possible constant for a number of experiments, and alter one by one the conditions of the environment on the other side (e.g. $p \mathrm{H}$, oxygen content, light and shade,

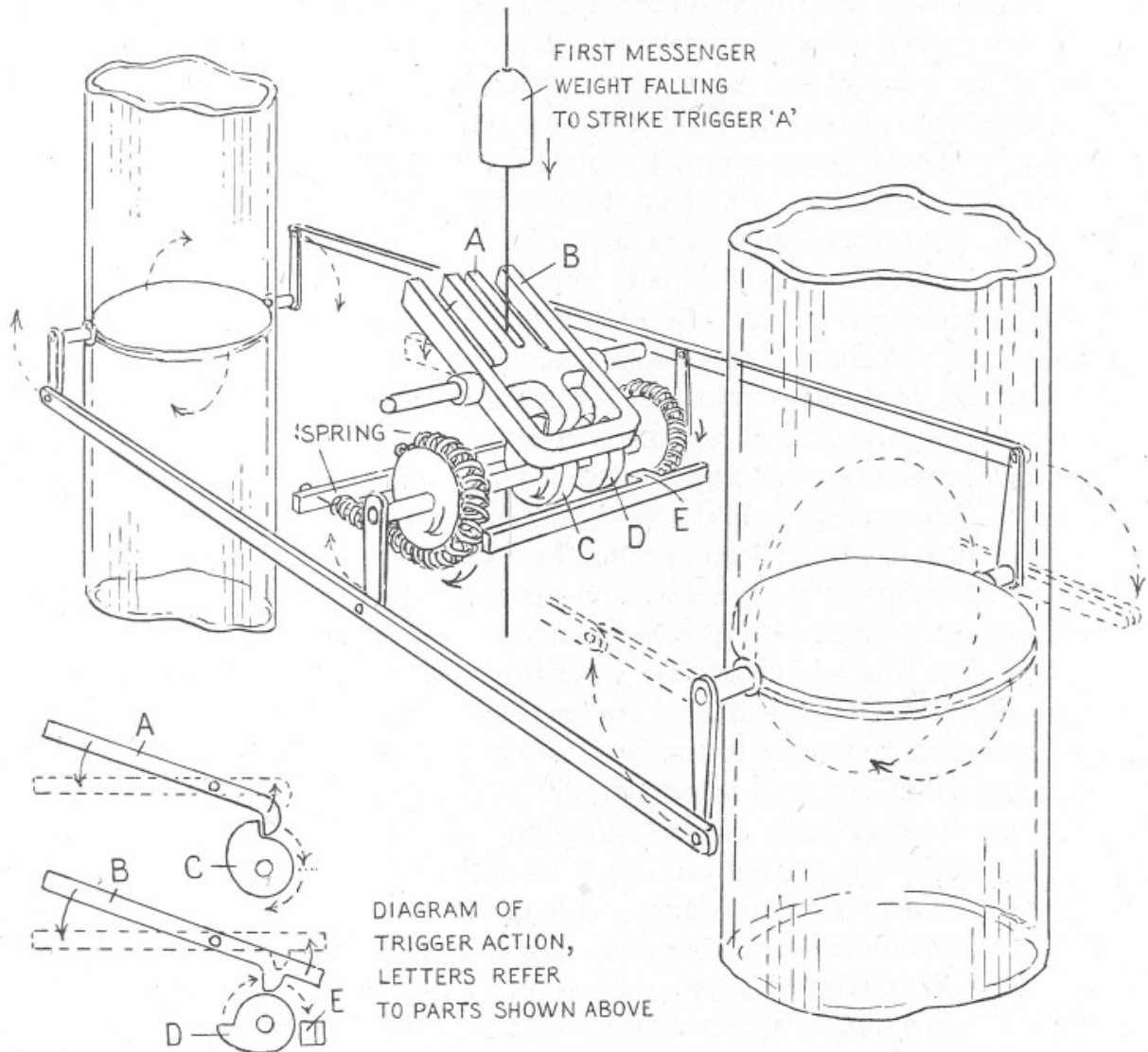

Text-fig. 2. Sketch of trigger and spring mechanism of Apparatus No. I, with parts of the steel supporting frame omitted.

phytoplankton concentration, etc.) until the different factors which may affect the vertical migrations of the animals have been analysed. As yet only a small beginning has been made in this direction.

\section{Detailed description}

The cylinders have an internal diameter of 3 in. and are each made in three sections, two 18 in. long of glass $\frac{1}{4}$ in. thick and a short centre-piece which 
holds the trapdoor and its spindle. This centre-piece was originally of glass, 4 in. long, as shown in Pl. X, fig. 3; but later it was made of metal ( 3 in. long) to ensure a better fit for the trapdoor, provide better bearings for the spindles and avoid the danger of cracking. Formerly the three sections were held together by metal clamping pieces lined with thick rubber, but latterly the two glass sections fitted into sockets at either end of the metal centre-piece. The distal ends of the glass cylinders are flanged to a thickness of $\frac{5}{8}$ in. to make broad seats (covered with rubber washers) against which are held the glass plates at the top and the metal plates, fitted with stopcocks, at the bottom. (Originally glass plates like those at the top were used also at the bottom, and the contents of the lower compartments were drained out through the corked bottle-necks shown in Pl. IX; the substitution of metal plates with stopcocks was a great improvement.) The two tripartite cylinders are held in position in parallel, II in. apart, by a metal frame. The apparatus in its original form is shown in Pl. IX, while Pl. VIII shows it fitted with the metal centre-pieces and the draining cocks below.

The frame, as already explained, is made as open as possible. Angled steel strips run along the greater part of the length of the cylinders at the back and front; being bolted to the centre-piece and to metal clamps round the upper and lower sections, they hold the three parts of each cylinder securely together. The two strips of angled steel are then held in parallel by horizontal steel tie bars, two pairs about their centre and one pair towards the bottom. Other strips are added diagonally to give rigidity as shown in P1. IX.

The trigger and spring release mechanism, illustrated in Text-fig. 2, is mounted between the horizontal tie bars about the centre of the machine. The connecting rods, one to the back and one to the front, linking together the cranks which turn the trapdoors, are in addition each linked to a crank turned by the main axle of the spring mechanism. On this axle are two cams, $C$ and $D$, with angled cam-stops into which fit the teeth of the trigger mechanism. There are two triggers, $A$ and $B$, each with paired release arms and each with a tooth at its other end. One lies between the arms of the other (inner and outer triggers), and each is pivoted about two-thirds along its length. The supporting wire passes between their arms (to a clamping shackle below), and so they form the striking points for the messenger weights which slide down the wire. The main axle with its two cams is turned by two springs; these stretch over and are attached to drums on the axle, their other ends being fixed to a stationary bar a short distance away. When the trapdoors are set at 'position I' for the beginning of an experiment the springs are at their maximum tension and held by the inner trigger tooth which is caught in its cam-stop $C$. When the first and smaller messenger strikes, the inner trigger $A$ is depressed and its tooth raised; the axle immediately rotates through $90^{\circ}$ and a second cam-stop $D$ is caught by the tooth of the outer trigger. The trapdoors, being linked with the cam axle by connecting rods, 
are also turned through $90^{\circ}$ into 'position 2' giving free passage between the upper and lower parts of the cylinders. At the end of the experiment the second messenger is allowed to slide down the wire; being hollowed out to fit over the first messenger, and being so much larger, it strikes and depresses the arms of the outer trigger $B$. This raises the second tooth; the springs turn the axle through a further $90^{\circ}$ bringing the trapdoor to 'position 3', and so close once more the passage between the two halves of the cylinders. Extra springs were added stretching between the connecting rods and the steel frame (see Pl. X, fig. 3). The two messengers are shown suspended on the wire in Pl. IX.

The trapdoors were originally made of two half circles of plate glass held on a metal spindle by circular metal rings (see Pl. X, fig. 3). The edges of the trapdoors were of rubber which bedded against the glass sides of the centrepiece. This proved to be an unsatisfactory arrangement, and in the winter of I938-9 a modified centre-piece was introduced. The trapdoors and spindles are now all metal in one piece, with the edges of the doors bevelled to give a good fit against the inside of the centre-piece. This is also of metal, but where the trapdoor edges fit against it, there is a ring of rubber let into its walls. By the introduction of this modification each trapdoor is now watertight when closed, and there is no danger of the centre-piece becoming strained owing to the impact of the rotating trapdoors. The metal was brass, which was found to be highly toxic to Calanus. A good deal of time was spent in discovering why the Calanus died, but finally the trapdoors and centre-piece (as well as the metal bottom plates) were silver-plated, and the toxic effect was overcome.

The top plates are of $\frac{1}{4}$ in. plate glass; they rest on the flanged lip of the cylinders with a flat rubber washer interposed, and are held in position by an open metal ring with two slotted wings opposite each other on the circumference, into which fit threaded arms with butterfly nuts. These arms are attached to the metal framework of the apparatus, and the nuts can be screwed down till the joint is watertight. There is essentially the same fitment at the lower end of each cylinder, but here the bottom plates are of silver-plated brass with centrally placed stopcocks. The inside of each of these is slightly concave so that the water and plankton may more easily be washed through the draining cock. The metal bottom plates and glass top plates with their metal rings are interchangeable end for end.

In the general set up the apparatus is suspended on a thin steel wire which is threaded between the trigger arms and attached by a shackle to a central bar at the base of the frame. Attached also to this bar is a heavy weight on a length of line, to keep the apparatus vertical and to prevent swinging due to water currents.

The whole apparatus is lowered over the side of the boat, and the wire let out over a recording sheave slung on a davit. A rope 'life line' is always attached to the frame in case the wire should break. 


\section{APPARATUS No. 2}

A modification of the original apparatus was made in the winter of $1938-9$; it is shown in Pl. XI, figs. I and 2. A number of glass cylinders, in the present instance seven (but the number might be very much increased), each I 8 in. long with an internal diameter of 3 in., is connected in series with intervening metal pieces (cylinders only 2 in. in length) which are not unsimilar to the centre-pieces of Apparatus No. I. The ends of the glass cylinders butt up against the rims of these metal connecting pieces and a broad rubber band fits over the junction. This rubber band is in turn clasped above and below the joint by narrow bands of brass which may be tightened by thumbscrews. In each connecting piece is a circular trapdoor mounted on a spindle which passes through its walls to be attached to levers fixed at $45^{\circ}$ to the plane of the trapdoor. Each trapdoor, which is of phosphor-bronze gauze set in a flat
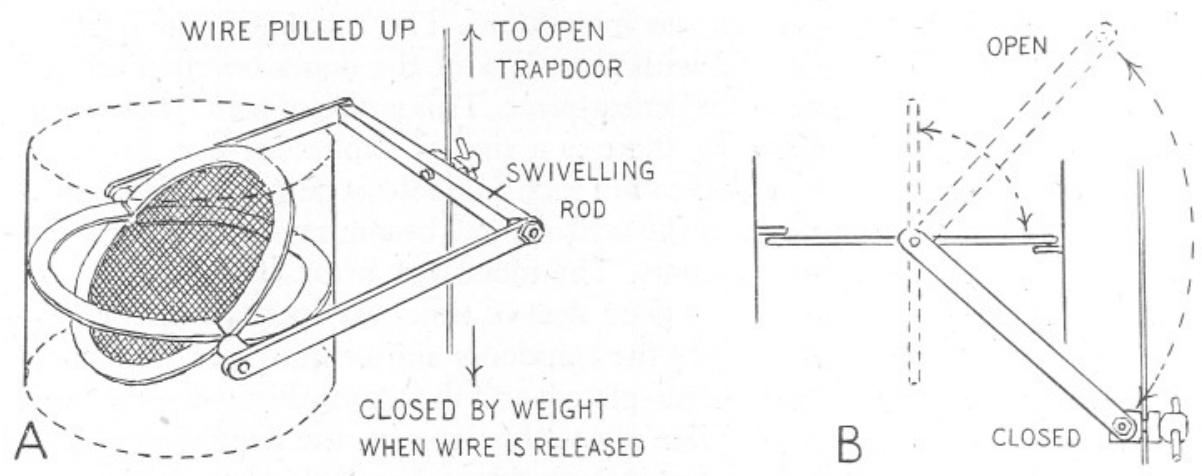

Text-fig. 3. Trapdoor mechanism of Apparatus No. 2. A is a sketch showing the trapdoor in half open position; B is a diagrammatic side view.

metal ring, beds itself down against two semicircular flanges running round the inside of the connecting piece: one above the one-half of the trapdoor and to one side of its spindle, and the other below the other half and on the opposite side of its spindle (see Text-fig. 3). By lifting the levers through $90^{\circ}$ the trapdoor is turned from its closed position, at right angles to the axis of the cylinder, to its open position in line with the axis. It can be turned no further. All the metal parts were silver plated to avoid the toxic effects which had been observed in Apparatus No. I before a similar remedy was applied (see above, p. 473).

The whole system of alternate glass and metal connecting pieces is suspended vertically in the water attached to a stout wire cable by means of thumbscrew clamps situated on the side of the connecting pieces (Pl. XI, fig. 2). A heavy weight on the end of the cable keeps the whole in alignment, while the rubber bands allow just sufficient flexibility to prevent any strain upon the glass pieces. The whole forms one cylinder nearly $\mathrm{I} 2 \mathrm{ft}$. long containing six gauze 


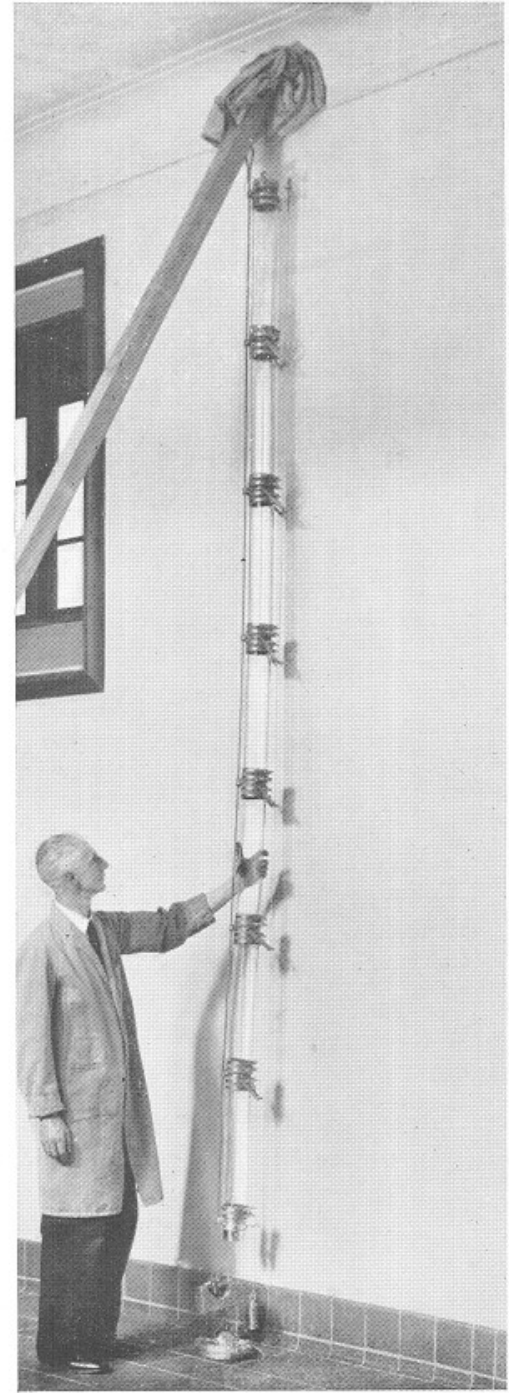

Fig. I.

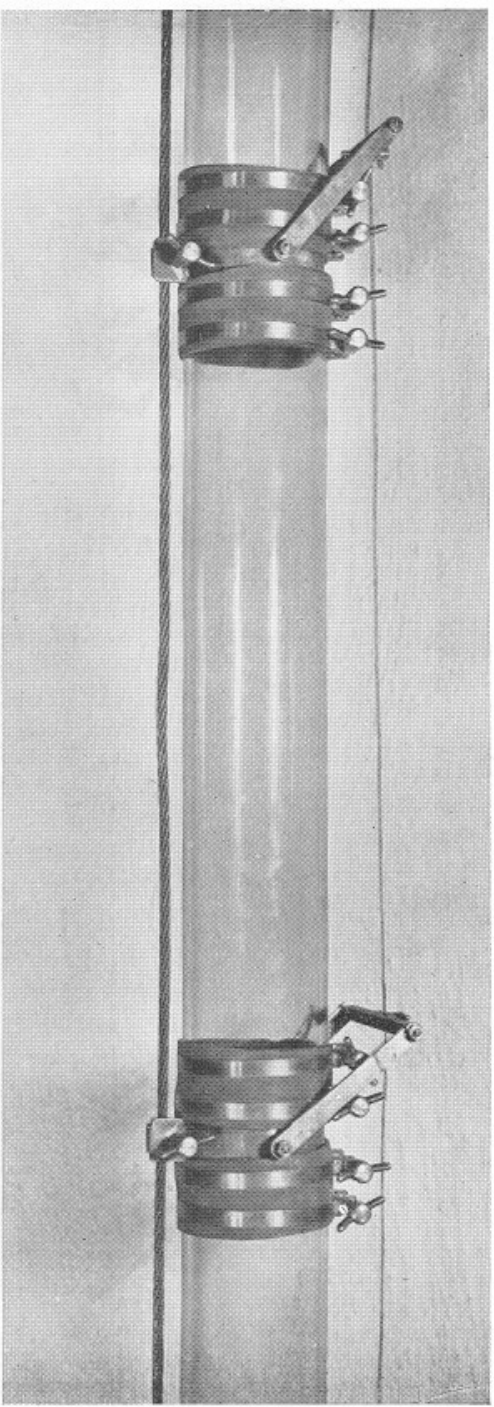

Fig. 2 
trapdoors at intervals down its inside: its top and bottom are closed respectively by a glass plate and a metal gauze disk held in metal pieces. Into the sides of the top metal piece are let panels of phosphor-bronze gauze. Now if the whole apparatus (when it has been assembled as described below) is lowered slowly into the sea, the water will rise in it, passing up through the bottom gauze, through all the gauze trapdoors and out through the gauze side panels in the top piece. Thus by lowering it from a boat we enclose within it an actual column of the sea itself.

One other device must be described. All the levers which will turn the gauze trapdoors are secured by little swivelling screw clamps to a thin wire which has a small weight attached to its lower end and hangs down beside the apparatus (see Pl. XI, fig. 2). The upper end of this wire passes up to the boat above. As this wire is paid out the weight at its end holds all the levers hard down so that each gauze trapdoor is closed at the beginning of an experiment. Plankton (as will be explained below) may be introduced into any one of the compartments (top, bottom, or perhaps one of the intervening ones) cut off from the rest of the cylinder by the gauze trapdoors. When the apparatus has been lowered to the desired depth, the end of the thin wire is pulled up so that each of the levers rotates through $90^{\circ}$ and all the trapdoors open in unison. The wire is secured in this position and the plankton animals are now free to travel vertically up or down the whole length of the cylinder. After a prearranged interval of time the wire is slackened so that the weight falls, and all the levers are pulled down; this closes all the trapdoors again and divides the cylinder as before into a series of separate compartments. The apparatus is now hauled up and as the water drains out through the gauzes so the plankton from each section is found on the gauze immediately below it, and is washed off and preserved separately as the cylinders are dismantled.

The whole device can readily be assembled or taken apart. In assembling, section after section is clamped to the supporting cable as it is lowered over the side of the boat; at the same time the trapdoor levers are secured one by one to the weighted operating wire which keeps them pressed down in the closed position. The plankton is introduced by a long rubber siphon when the appropriate section is partially submerged. When the plankton is placed in any but the top section care must be taken in lowering lest the surge of the water, as the apparatus fills, should cause the animals to be pressed against the gauzes and so damaged; the apparatus must be lowered very slowly.

Only five experiments with Calanus have so far been performed with this apparatus, and in each the top of the apparatus was sunk only about 6 in. below the surface $;^{1}$ the results are discussed on pp. 510-I5.

${ }^{1}$ In experiments with fresh-water plankton animals made in Lake Windermere the apparatus was at times lowered to a depth of $10 \mathrm{~m}$. and worked just as satisfactorily as near the surface. There is no reason why it should not be worked at much greater depths. 


\section{Methods}

It will be most convenient to describe the procedure adopted in the preparation and carrying out of one typical experiment (with Apparatus No. I) and later to give the modifications of this method in particular instances.

The plankton was usually caught between 8 and 9 o'clock in the morning by means of stramin ring nets ( $\mathrm{I} \mathrm{m}$. diameter) fished at a depth of between 60 and $90 \mathrm{~m} . ;^{1}$ it was known that the Calanus were generally most abundant at this range of depth at this time of the day. Usually two nets were attached to the towing warp about Io ft. apart and towed horizontally for $\frac{1}{2} \mathrm{hr}$. The nets would fish very little on the way down because they were veered out at almost the same speed as the forward motion of the boat. They would, however, fish on the way up; but the time involved is small compared with that of the haul proper $(7-10 \%)$. Occasionally more than one haul was necessary to secure sufficient animals, but generally the catches in the Clyde sea area are remarkable for the numbers of Calanus they contain.

It was desirable to interfere with the animals as little as possible, so that except in certain special experiments the Calanus were not individually picked out, but part of the plankton sample was used just as it was caught. This was possible because in most cases, being caught with a coarse-mesh net of stramin which let the smaller animals escape, the sample was composed almost entirely of this one species of copepod.

Since light was considered from the results of earlier workers to be the most important factor influencing the behaviour of the animals, precautions were taken to avoid exposing them at any moment to the above-surface daylight. The apparatus was always filled in the cabin of the boat with the skylights covered with cardboard screens. The cabin was so dark that it took the operator 2 or $3 \mathrm{~min}$. to discern objects even dimly. It was found that no reading was given on a Cambridge Unipivot ' $L X$ ' galvanometer when coupled direct to a Weston photocell, even with appreciably brighter conditions in the cabin. When the nets were hauled to the surface, the cod-end, with its opaque (zinc) bucket attached, was lowered into this darkened cabin through the skylight which was then closed. The contents were then transferred to glass jars (breffits) from which they were later siphoned into the apparatus; care was always taken not to include the animals at the very bottom, since these might be in a moribund condition.

In a typical experiment the plankton (mainly Calanus) was introduced into the top compartment $A$ of one side of the apparatus and the lower compartment $\beta$ of the opposite side; the other two compartments $B$ and $\alpha$ were filled with sea water filtered to exclude all plankton.

1 Tests made with a depth recorder attached to the line just above the nets are described on p. 49r. They show that the depth was usually between 60 and $70 \mathrm{~m}$., but sometimes as deep as $90 \mathrm{~m}$. 
When loaded the apparatus was placed on a wooden frame with handles at either end just like a stretcher (Pl. X, fig. 2); it was necessary to have some such device to enable the machine to be handled easily without fear of breakage. As it was placed on the stretcher it was covered with a black cloak of calendered linen. The stretcher was then passed up through the skylight of the cabin, the apparatus taken off it and lowered to just below the surface of the sea (Pl. X, fig. I). Only then was the black cover removed (by pulling a system of cords) and the machine lowered quickly to the required depth, say 5, Io or perhaps $50 \mathrm{~m}$. Though these precautions against abnormal illumination could not be continued to the depth of the experiment, it was felt that the protection afforded till the apparatus was below the surface would considerably reduce the stimulation from light to which the animals would otherwise be exposed. From the moment of capture to the time when they were lowered again below the surface of the sea the animals were never exposed to above-surface illumination.

The experiment was now begun by the first messenger weight being sent down the suspending wire to open the trapdoors. The animals were now free to move up and down the whole length of the cylinders. Usually at the end of an hour the second messenger was sent down to close the trapdoors again and prevent further migration between $A$ and $B$ and $\beta$ and $\alpha$. Very occasionally the experiment was of only half an hour's duration, and such exceptions will be specially noted.

The apparatus was then hauled up to the surface, taken below to the cabin, and the populations of Calanus in each compartment extracted, and preserved separately. Those from the top compartments were siphoned off; those in the lower compartments drained through the stopcocks. The samples were taken to the laboratory where they were counted, separated into sexes and developmental stages, and examined for food remains in the gut. The total of the animals found in $A$ and $B$ reveals the number introduced into $A$ at the beginning of the experiment, and the number found only in $B$ gives the number of those which have migrated downwards during the experiment. Similarly, the total found in $\alpha$ and $\beta$ gives the number originally introduced into $\beta$, and the number in $\alpha$ alone shows those which have migrated upwards during the experiment. The numbers which have moved upward and downward can now each be expressed as a percentage of the total population in the appropriate side of the experiment. The results of all the experiments, together with particulars of date, time, position, weather, etc., are given in tables in the Appendix (pp. 524-6).

In all the experiments the general plan of procedure was as outlined above, but in some, as will be described later, certain modifications were introduced for special purposes.

All the experiments were made in the months August to November: Exps. I-39 between 2 August and II November 1938, and 40-75 between 
2I August and 22 November 1939. It had been hoped that the early summer months of 1939 could be used, but certain technical difficulties (see p. 473) as well as limitations of opportunity for sea work interfered.

\section{Limitations OF METHOD}

The main purpose of these experiments was to examine the behaviour of Calanus under as natural conditions of illumination as possible. It is realized that the methods employed do hold considerable artificialities; yet it is felt that they are nearer to natural conditions than experiments in the laboratory. This contention is supported by the results of Exps. 68-75, in which individuals of the same original stock of Calanus showed a marked change of behaviour after being kept in the laboratory for 3 days. This does not seem to be due merely to a lowering of their vitality, since the whole of the remainder of the stock lived healthily for a fortnight, and many for 6 weeks, afterwards in the laboratory.

We have no means at present of telling how far the precautions taken, e.g. darkening of the cabin, cloaking of the apparatus, etc., are effective or necessary. The Calanus must have experienced some abnormal conditions during capture. The results of the experiments at any one depth, however, are with a few exceptions remarkably consistent.

The water used for the experiments was, nearly always, taken either from the surface or pumped from just below it. The fact that Calanus are thus introduced into water which may differ considerably (e.g. salinity, oxygen content, $p \mathrm{H}$, etc.) from that from which they were caught may be a source of error. It would appear not to be great however, as on two occasions experiments were conducted using surface water in one side of the apparatus and water from $30 \mathrm{~m}$. (drawn with a water bottle) in the other, and the difference in behaviour in the two sides was only slight (see p. 507).

Usually we attempted to use just over roo Calanus in each side of the apparatus to allow the calculation of a true percentage. This was very difficult to judge in the dark, and the numbers used range between 20 and I 400. Each side of the apparatus holds about 2.8 litres of water which gives a range of population density from 7 to 500 Calanus per litre. The lowest figure probably fairly represents a density to be found in the sea (catches of Calanus in a water bottle have on occasions contained 6 per litre), but the higher value must represent abnormally crowded conditions. However, even at this high figure, such physical conditions as oxygen tension in the cylinder would probably not be significantly different at the end of I hr. Marshall, Nicholls \& Orr (1935) show that the maximum respiration rate of female Calanus was $0.75 \mathrm{ml} . / 1 . / \mathrm{hr}$. up to $3 \mathrm{hr}$. after capture. Using this figure the highest density in our experiments would produce a fall in oxygen tension of 
$0.39 \mathrm{ml}$. $/ 1$. $/ \mathrm{hr}$. Probably the actual value was below this, as a large proportion of our Calanus were Stage V, whose respiration rate is below that of adults, but in any case Marshall et al. found that Calanus were affected only after the tension had fallen by over $2 \mathrm{ml}$./1. Other chemical factors might be involved and, further, the population density in the tube might have a purely mechanical effect due to obstruction. However, when the results at any one depth are plotted against a scale of population density there is no correlation: a random distribution of the points is found.

There are various other ways in which these experimental conditions might affect the behaviour of the Calanus. In the first place they might be disturbed by bumping into the sides of the apparatus, or obstructed by the trapdoor in its vertical position. Again the surge produced by the rotation of the trapdoor might introduce a false distribution. Whether the first type of interference occurs to any extent can easily be ascertained. If the sides of the cylinder or the trapdoor do interfere with the movements of the animals, then, in standard-type experiments in which the plankton was introduced into $A$ on one side and $\beta$ on the other, one would expect at the end of an experiment to find a higher percentage in $\beta$ than in $B$. Omitting experiments below $30 \mathrm{~m}$. in which another factor (referred to later) may arise, there are eighteen such standard experiments performed between depths of $\mathrm{I}$ and $20 \mathrm{~m}$.; in eight the percentage is higher in $B$ and in ten it is higher in $\beta$ : there is clearly no significant difference.

The 'surge' effect was examined in the laboratory. There is certainly some disturbance set up by the opening trapdoors, but it is felt that any result of this momentary effect would be counteracted by the stimulus of light or other factors operating for an hour. Also the effect would be the same on both sides of the apparatus.

The possible effects of shadow produced by the metal parts must be considered. The most important of these must be the shading from the trapdoors and centre-piece. If this was a considerable factor in the final distribution of Calanus in the cylinders, one would expect it again to show as a difference in the results of the two sides when the original place of introduction in each differed. We have just seen that in the upper $20 \mathrm{~m}$. this is not so. The effects of shadow would seem to be too fine to be shown by these experiments. In I938 the apparatus had a cylindrical glass centre-piece, while in I939 this was replaced by a metal one. It was feared that this metal centre-piece would possibly create a shadow past which the Calanus might not move or in which they might collect. The results, however, from the two years are quite consistent; the illumination came of course vertically down the tube.

Such factors as are discussed above do not appear to have concealed the main outlines of behaviour. 


\section{DISCUSSION OF RESULTS}

In the following discussion only the results of the behaviour of the fifth copepodite stage are treated in detail. The other stages, including adults, occur in too small numbers to give comparable pictures, but in some cases there are sufficient males and females to give a rough comparison, and these are included in the discussion. A few results with the copepod Euchaeta norvegica Boeck are also given (p. 502). Unless otherwise stated the Calanus figures throughout will refer to Calanus Stage V.

The preliminary nature of the work so far accomplished is again emphasized; but for the outbreak of hostilities the experiments would have been carried much further before the publication of results. It is realized that there are too few experiments as a whole and that the special ones require further development. The main results, however, are felt to be of sufficient interest to record, and the more special side issues have been included as they indicate useful lines for future inquiry.

The results of sixty-five experiments with Apparatus No. I are here considered: Exps. I-2I, 23-39 and 49-75. Exp. 22 was made with Thysanoessa and, offering insufficient evidence, is excluded; Exps. 45-48 are also excluded because of the toxic effect of the new metal centre-pieces and bottom plates referred to on p. 473 and overcome in subsequent experiments by silver plating. Exps. 40-44 were made with Apparatus No. 2.

\section{Standard experiments-statement of results}

It will be convenient to deal first with the standard experiments which formed the main part of the work and were designed to study the behaviour of Calanus under the different light conditions met with at different depths in the sea. All those considered in this section were performed between 0800 and I600 hr. (G.M.T.); other similar experiments made in the evening or hours of darkness will be described separately.

In these preliminary experiments it was felt that only relative light conditions need be considered; we had not the equipment to measure the exact intensity of light at each experimental depth. The relative light intensity at any given depth will not only vary from hour to hour, but also from day to day at the same hour according to various weather conditions. An indication of light penetration, however, was obtained by the use of the Secchi disk ${ }^{1}$ with each experiment.

Under the heading 'Standard experiments' there are two kinds, which may be termed double- or single-standard experiments.

1 The Secchi disk is a white disk used to measure the transparency of water. It is lowered below the surface on a line at the end of which it is suspended by three cords of equal length running to its circumference; below, supported by three similar cords, hangs a weight which keeps the disk horizontal and the line vertical. A measure of the transparency of the water, and so an indication of the relative light penetration, is obtained by lowering the disk and noting the depth at which it just disappears. 
A double standard experiment is one in which both cylinders of the apparatus are subjected to the same conditions, but the Calanus are usually introduced into the upper compartment $(A)$ of one side and into the lower compartment $(\beta)$ of the other. The carrying out of such an experiment has already been described under the section on methods.

A number of other experiments have been performed in which the conditions in one cylinder are normal, as a control, but those of the other have been altered as part of the experiment. The results of the normal control cylinders will be considered along with those of their more special partners when these are dealt with later; but by themselves they may also be considered here as single-standard experiments.

Double-standard experiments were conducted at depths of I, 5, IO, 20, 30, 40,50 and $100 \mathrm{~m}$. and single-standard experiments at similar depths down to $30 \mathrm{~m}$.

To make quite clear the nature of the experiments and the kind of results obtained, three examples of typical double-standard experiments may first be considered: one made at a depth of $\mathrm{I} \mathrm{m}$. below the surface, another at $\mathrm{IO} \mathrm{m}$. and the third at $30 \mathrm{~m}$. The experiments, Nos. 6, 56 and 15 respectively, are compared in diagrammatic form in Text-figure 4 . Each experiment started with the Calanus placed in the upper compartment $(A)$ of the left-hand cylinder and in the lower compartment $(\beta)$ of the right-hand cylinder; the other two compartments ( $B$ and $\alpha$ ) had no Calanus, being filled with filtered sea water. At the end of each experiment (i.e. after I hr. had elapsed) some, but not all, of the Calanus had moved downward in the left-hand cylinder and some, but not all, had moved upward in the right-hand cylinder. For each experiment the percentage value for those which had moved down on the one side corresponds, either closely or fairly closely, with that for those which had stayed down on the other side. Further it is seen that the proportion of those which had moved down or stayed down varies inversely with the depth at which the experiment was performed. The percentage values for the proportions found in the lower compartments, $B$ or $\beta$, for all experiments are given in the Appendix, Table II.

Text-figure 5 shows graphically in the form of similar percentage diagrams the results of all standard experiments, double and single, averaged for each depth at which they were made. The left-hand column of each pair represents the cylinder of which the Calanus were introduced into the upper compartment, and the right-hand column that of which the Calanus were introduced into the lower compartment at the beginning of each experiment. The number of experiments of each kind averaged for each depth are shown by figures below each column. The use of average percentages gives a clear indication of the general change over in the proportions of the Calanus population which move up or down as the experiments are performed at different depths. The actual numbers for all experiments cannot be summed and averaged because 
the totals used in different experiments vary widely and the experiments are performed over different dates under a range of different weather conditions.

Text-figure 6 shows the individual results of all double-standard experiments. The positions of the blacked-in circles represent the percentage values
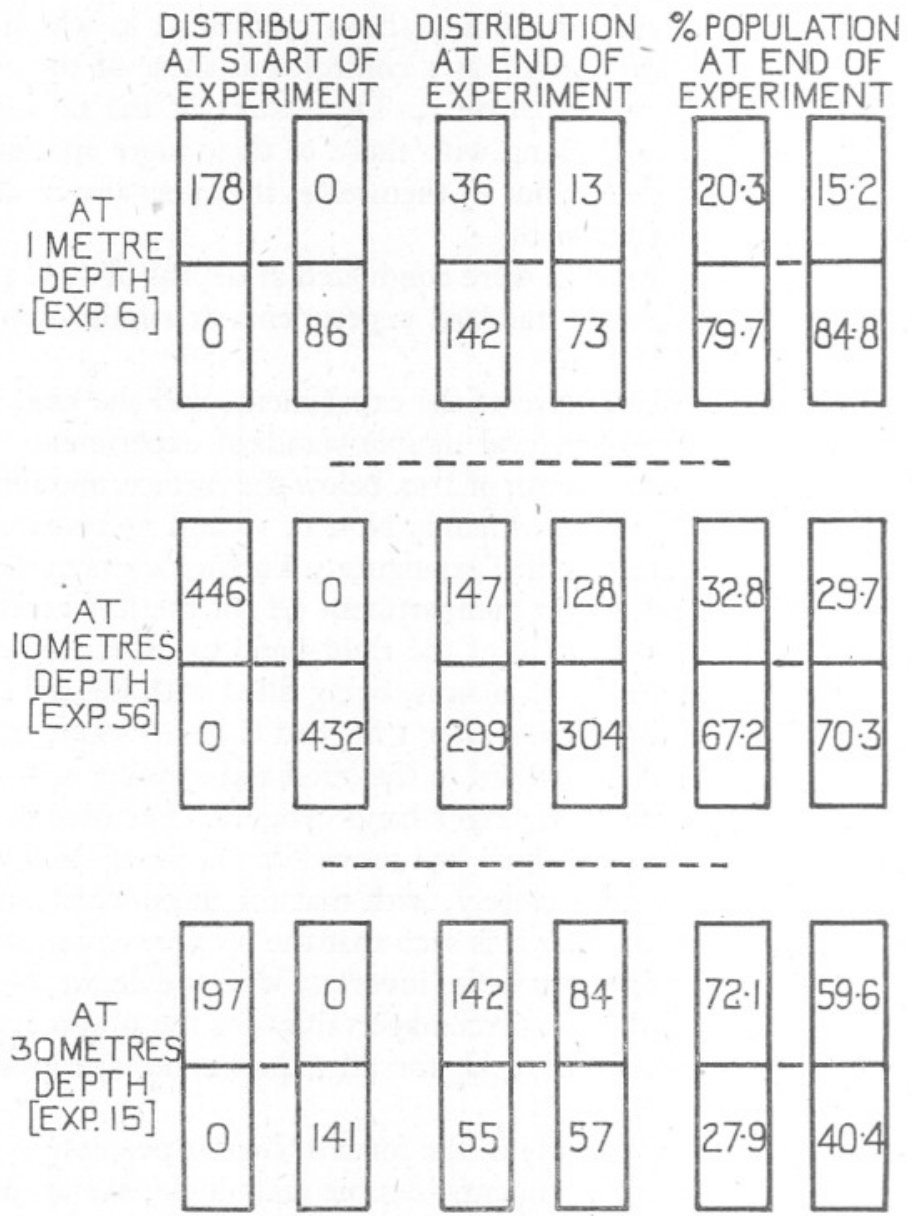

Text-fig. 4. Diagram of results of three standard experiments, Nos. 6, 56 and I5, performed respectively at depths of $\mathrm{I}, \mathrm{IO}$ and $30 \mathrm{~m}$.

for the Calanus which have moved down and the positions of the open circles the percentage values for those which have stayed down in the opposite cylinder of each experiment. The results from the two cylinders in any one experiment are linked together.

Text-figure 7 shows the percentage values of those which have moved down for all standard experiments, both double and single. The percentage values 


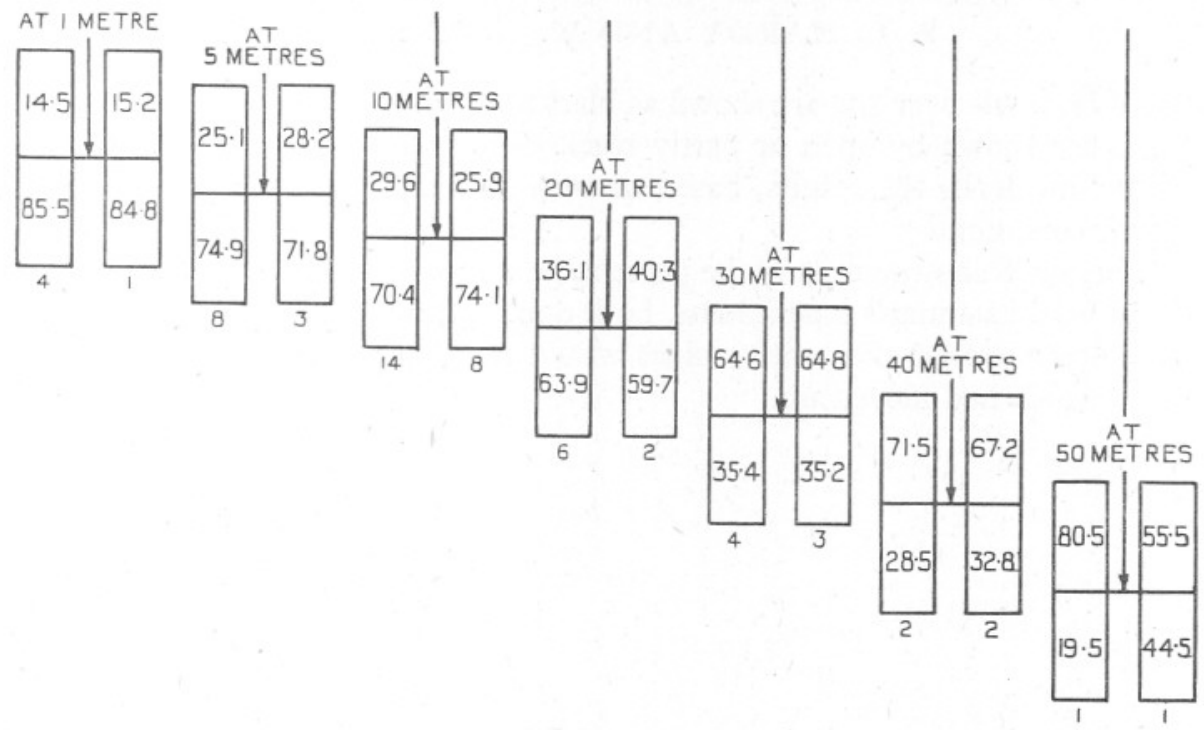

Text-fig 5. Diagram of the averaged results of all standard experiments performed between 0800 and $\mathrm{I} 600 \mathrm{hr}$. at depths of $\mathrm{I}-50 \mathrm{~m}$. For full explanation see text.

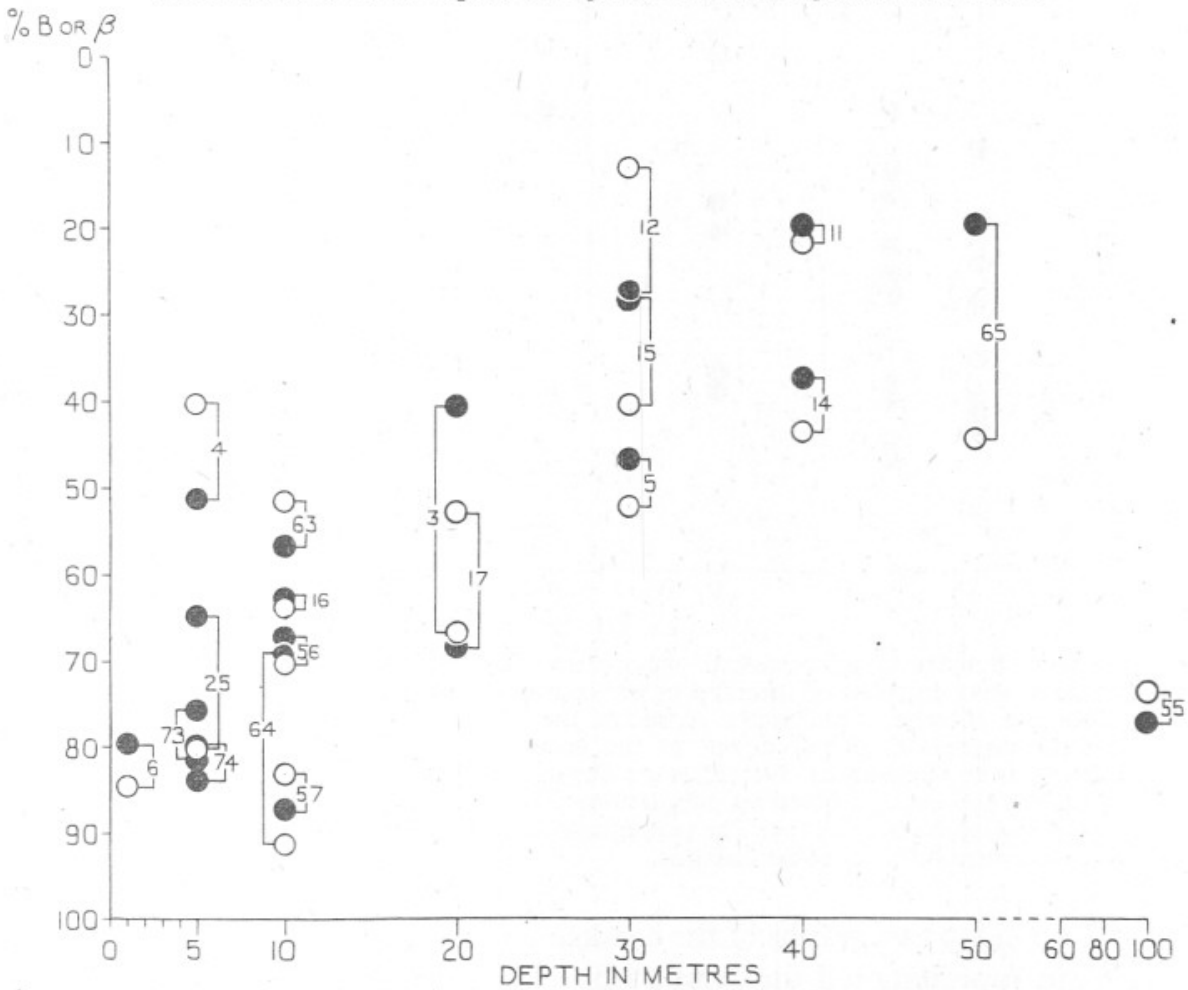

Text-fig. 6. Results of double-standard experiments with Calanus Stage V introduced into $A$ on one side and $\beta$ on the other (except in Exps. 73 and 74 , in which they were introduced into $A$ and $\alpha$ ) carried out in daylight between 0800 and $\mathrm{I} 600 \mathrm{hr}$. The blackedin circles represent the percentage Calanus which have moved down (into $B$ ) and the open circles the percentage Calanus which have stayed down (in $\beta$ ). The two results for each experiment are linked together with its reference number. 
based on totals over 100 are shown as blacked-in circles, those based on lesser totals are shown by open or partly blacked-in circles (see legend to figure). At $100 \mathrm{~m}$. depth the results, based on only two experiments, are seen to be very inconsistent.

Text-fig. 8 shows similarly the percentage values of those which have stayed down for all standard experiments, both double and single. If the percentage scale was reversed then their values would naturally give the percentage of those which had moved up.

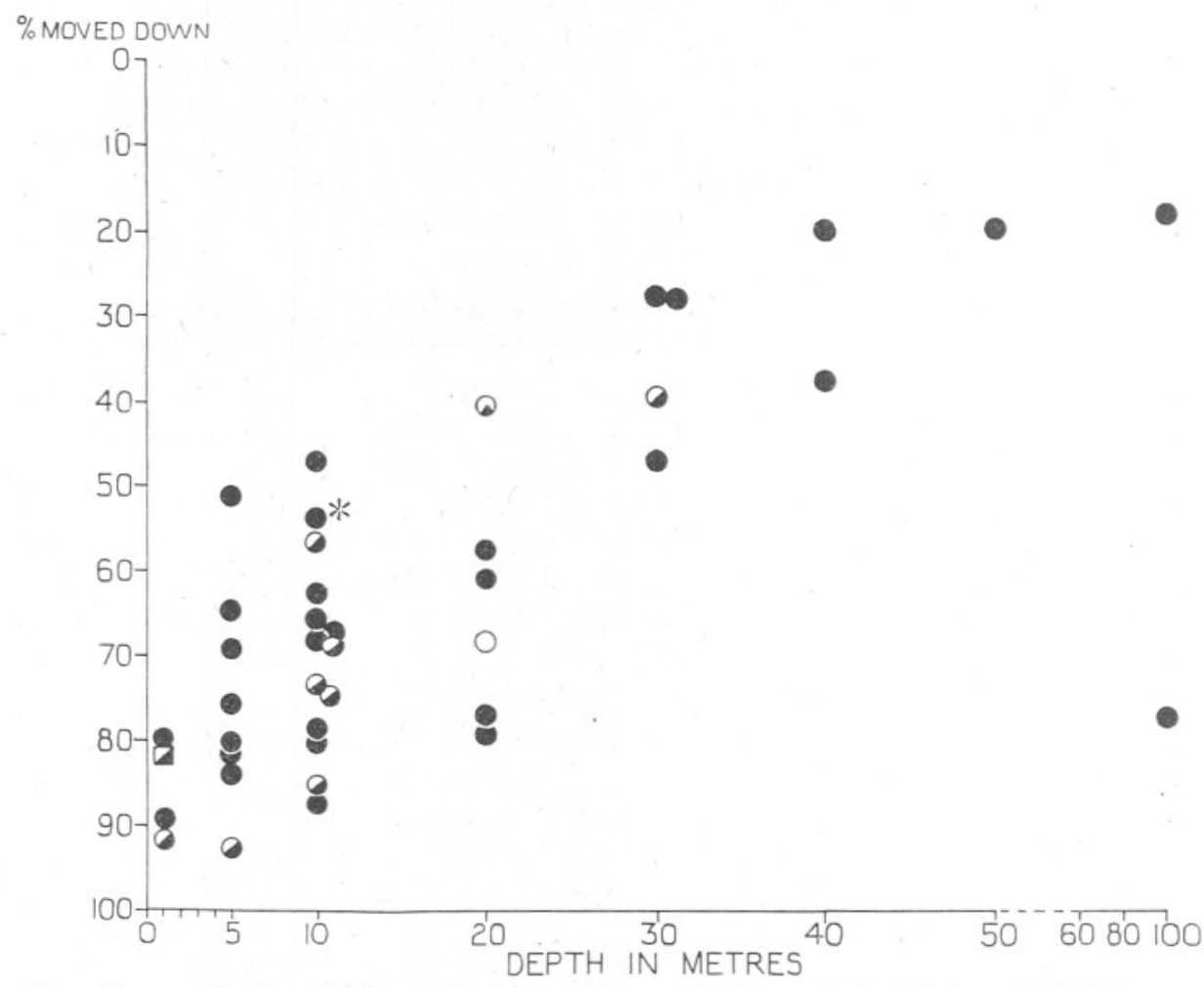

Text-fig. 7. Results of all standard experiments (double and single), in which Calanus Stage V were introduced into the upper compartment, carried out in daylight between 0800 and $\mathrm{I} 600 \mathrm{hr}$. The circles represent the percentage Calanus found in the lower compartment (i.e. moved down) at the end of each experiment. The single square represents an experiment (No. 40) with Apparatus No. 2 (see p. 513). Blacked-in circles represent percentages based on populations $>$ I00, half-blacked $5 \mathrm{I}-\mathrm{I00}$, quarter-blacked $26-50$ and open circle $2 \mathrm{I}-25$. The percentage result with an asterisk is a little too low due to an accidental loss of some Calanus.

In Text-fig. 9 two graphs of the average percentage values from Text-figs. 7 and 8 are superimposed for comparison. The numbers against the points on the graphs show the number of experiments averaged. The percentage values are also shown in Table I. At $50 \mathrm{~m}$. there is only one experiment of each kind 
(one double experiment); while it is unwise to draw conclusions from just one experiment there is a suggestion, for future investigation, that at this depth more Calanus tend to remain in the compartment into which they were introduced. Against this latter suggestion is the result of the double experiment at $100 \mathrm{~m}$. (Text-fig. 6), where the percentages of those moved down and stayed down are closely similar.

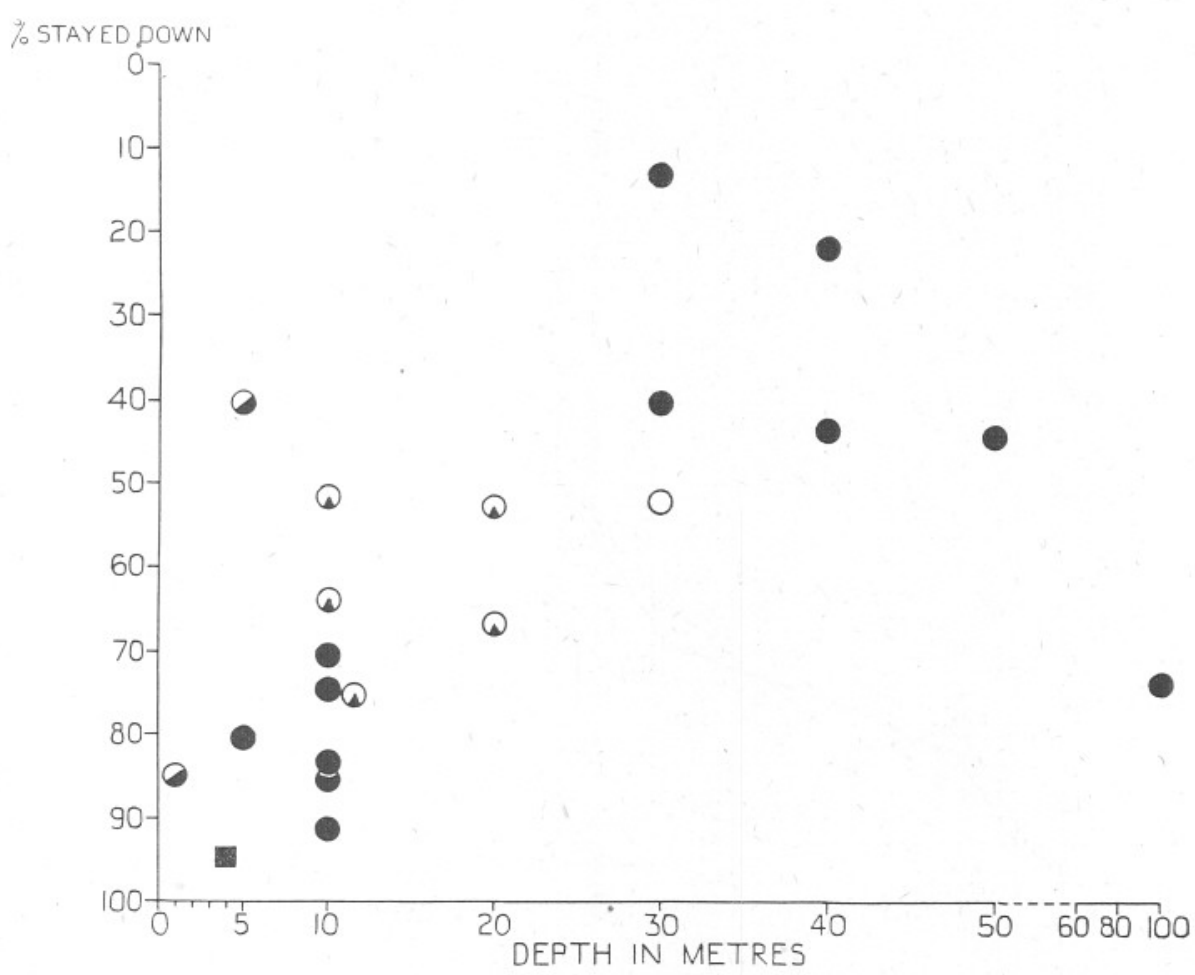

Text-fig. 8. Results of all standard experiments (double and single), in which Calanus Stage V were introduced into the lower compartment, carried out in daylight between 0800 and $\mathrm{I} 600 \mathrm{hr}$. The circles represent the percentage Calanus found in the lower compartment (i.e. stayed down) at the end of each experiment. The single square represents an experiment (No. 4I) with Apparatus No. 2 (see p. 5I3). Blacked-in circles represent percentages based on populations $>$ IOO, half-blacked $5 \mathrm{I}-\mathrm{roO}$, quarter-blacked 26-50 and open circle $21-25$.

Text-fig. Io shows together the percentage values of male and female Calanus which have moved down or stayed down for the limited number of experiments in which there were numbers worth considering (over twenty, see reference in figure legend). The percentage values of those moved down are shown as circles and of those stayed down as squares. Clearly the number of experiments and the number of adult Calanus available are too small to point to any definite conclusion, but there is a suggestion that the trend of 
their behaviour is in the same direction as that for Stage $\mathrm{V}$ but in a much less marked degree. Where there are sufficient males to be included their percentages are usually very similar to those of the females in the same experiments.

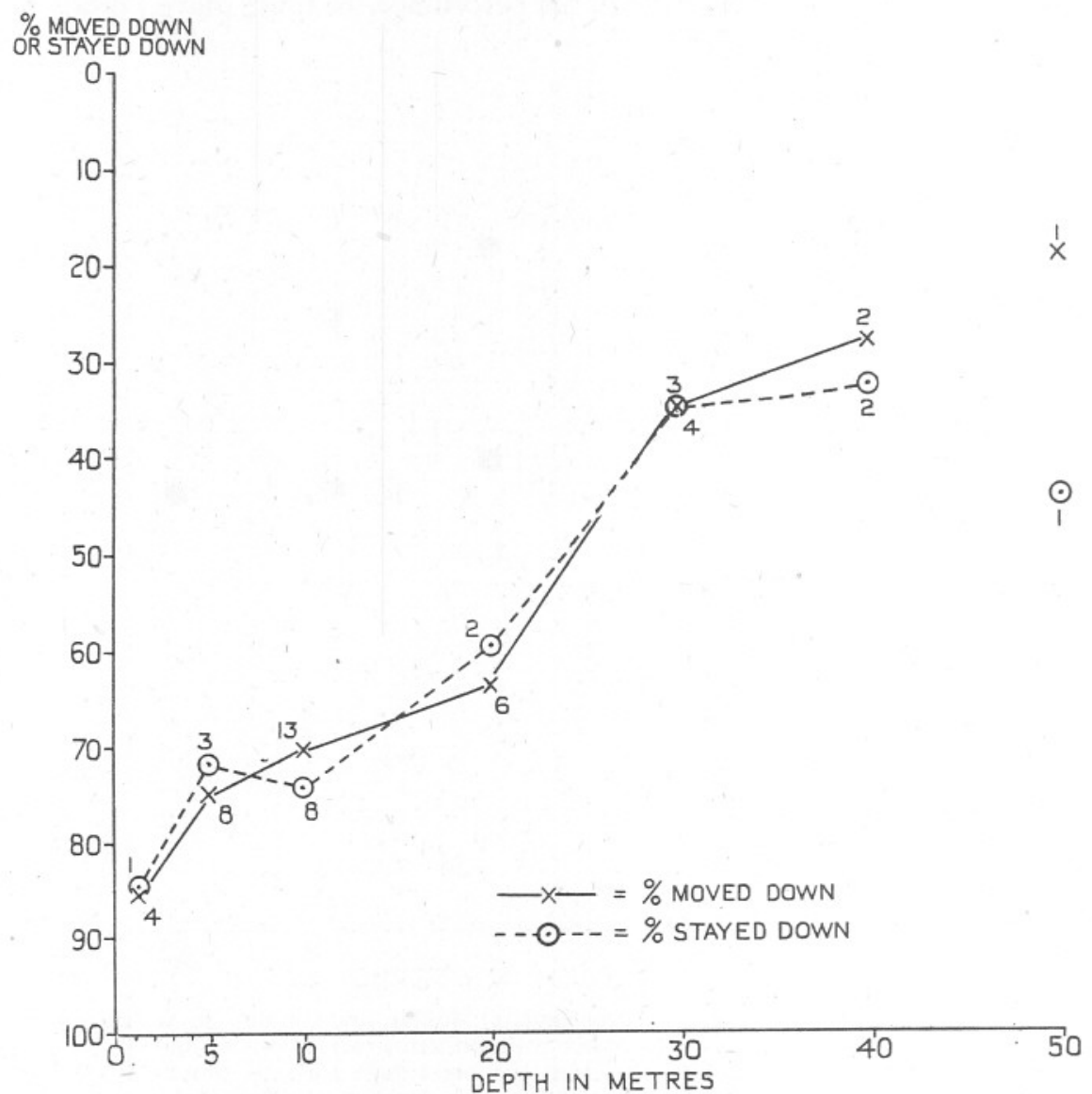

Text-fig. 9. The crosses, connected by a continuous line, represent the average percentage values of Calanus Stage V moved down in all standard experiments (i.e. the average of the values shown in Text-fig. 7), and the points within circles, connected by a broken line, represent the average percentage which have stayed down (i.e. the average of the values shown in Text-fig. 8). The number of results averaged is shown in each case. The diverse results at $50 \mathrm{~m}$. depth are based on only one experiment of each kind.

\section{Significance of standard-experiment results}

After this brief digression to look at experiments with male and female Calanus we may return to consider further the results obtained with Calanus Stage V, and now, as before, unless otherwise stated the term Calanus will always refer to Stage V only. 
Table I. The Average Percentages of Calanus Stage V which have Moved Down or Stayed Down IN STANDARD Experiments at DIFFERENT DEPTHS IN THE DAYTIME (BETWEEN 0800 AND I600 HR.)

$\begin{array}{cccc}\begin{array}{c}\text { Depth } \\ \text { of exps. }\end{array} & \begin{array}{c}\text { Average \% } \\ \text { moved down }\end{array} & \begin{array}{c}\text { Average } \% \\ \text { Average } \% \\ \text { stayed down }\end{array} & \begin{array}{c}\text { both moved } \\ \text { and stayed } \\ \text { down }\end{array} \\ 0 \cdot 5-1 & 85 \cdot 5^{4} & 84 \cdot 8^{1} & 85 \cdot 4^{5} \\ 3 \cdot 5-5 & 74 \cdot 9^{8} & 71 \cdot 8^{3} & 74 \cdot 0^{11} \\ \text { IO } & 70 \cdot 4^{13} & 74 \cdot 1^{8} & 7 \mathrm{I} \cdot 8^{21} \\ 20 & 63 \cdot 9^{6} & 59 \cdot 7^{2} & 62 \cdot 9^{8} \\ 30 & 35 \cdot 4^{4} & 35 \cdot 2^{3} & 35 \cdot 3^{7} \\ 40 & 28 \cdot 5^{2} & 32 \cdot 8^{2} & 30 \cdot 6^{4} \\ 50 & 19 \cdot 5^{1} & 44 \cdot 5^{1} & 32 \cdot 0^{2} \\ \text { IOO } & 47 \cdot 4^{2} & 73 \cdot 7^{1} & 56 \cdot 1^{3}\end{array}$

Note. The index numbers refer to the number of experiments averaged.

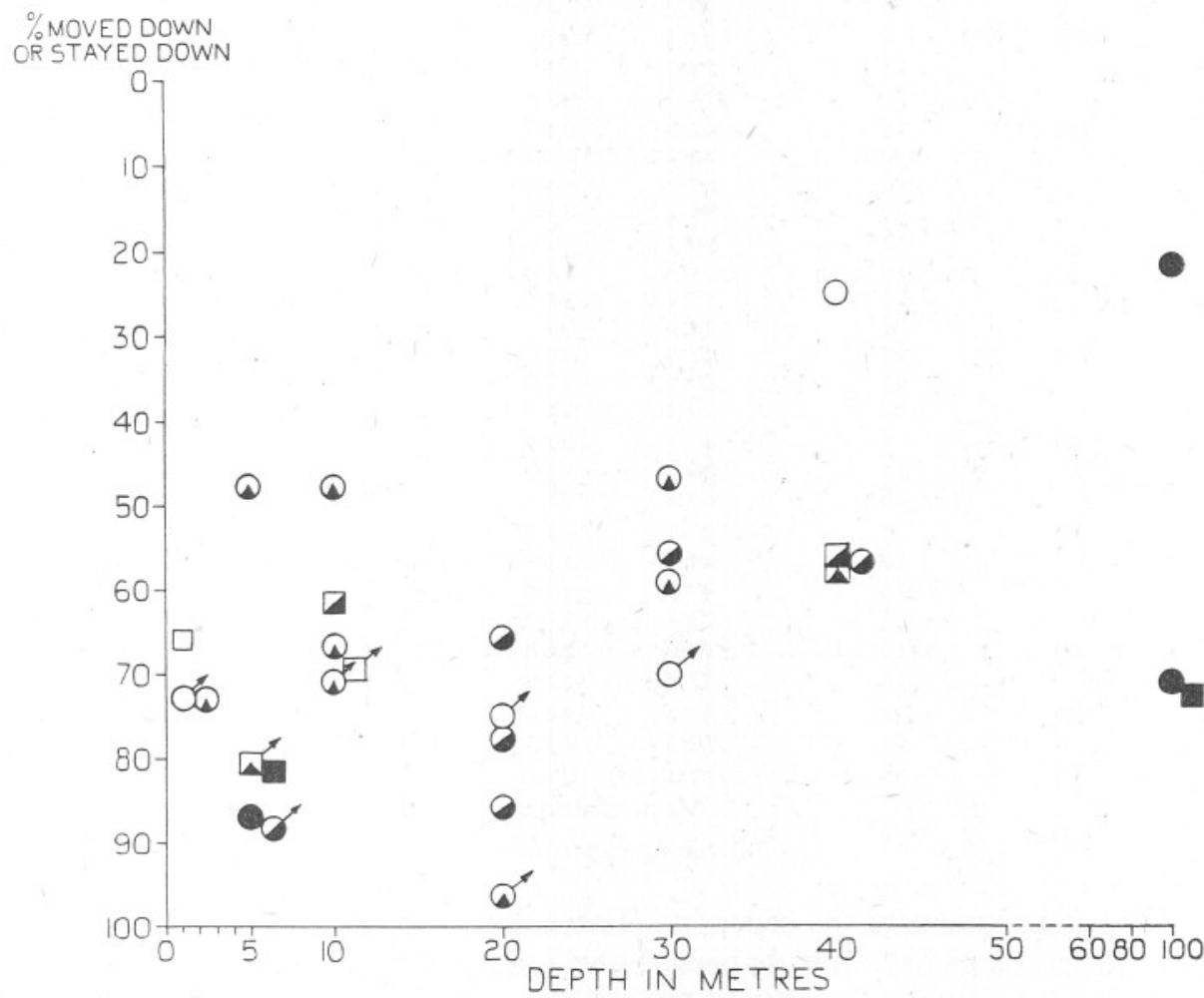

Text-fig. Io. Results of standard experiments in which male and female adult Calanus were introduced into the upper compartments (shown as circles) or into lower compartments (shown as squares) carried out in daylight between 0800 and $1600 \mathrm{hr}$. The circles and squares represent the percentage Calanus found in the lower compartment (i.e. moved down or stayed down respectively) at the end of an experiment. The arrows attached to the symbols distinguish the male results from the female results. Blacked-in circles or squares represent percentages based on populations $>$ I00, half-blacked 5I-I00, quarterblacked $26-50$ and open circles or squares $21-25$. 
Here will be a convenient place at which to discuss the nature of the difference that is found between the results of the two sides of the apparatus, in such double-standard experiments as we have been discussing, where the conditions on the two sides have been the same except that the Calanus have been introduced into the upper compartment of one side $(A)$ and into the

Table II. Showing the Difference between the Results of the two SIDES $(A B$ AND $\alpha \beta)$ OF ALL DOUble-STANDARD EXPERIMENTS IN WHICH CALANUS WERE INTRODUCED INTO THE UPPER COMPARTMENT $(A)$ OF ONE SIDE AND INTO THE LOWER COMPARTMENT $(\beta)$ OF THE OTHER

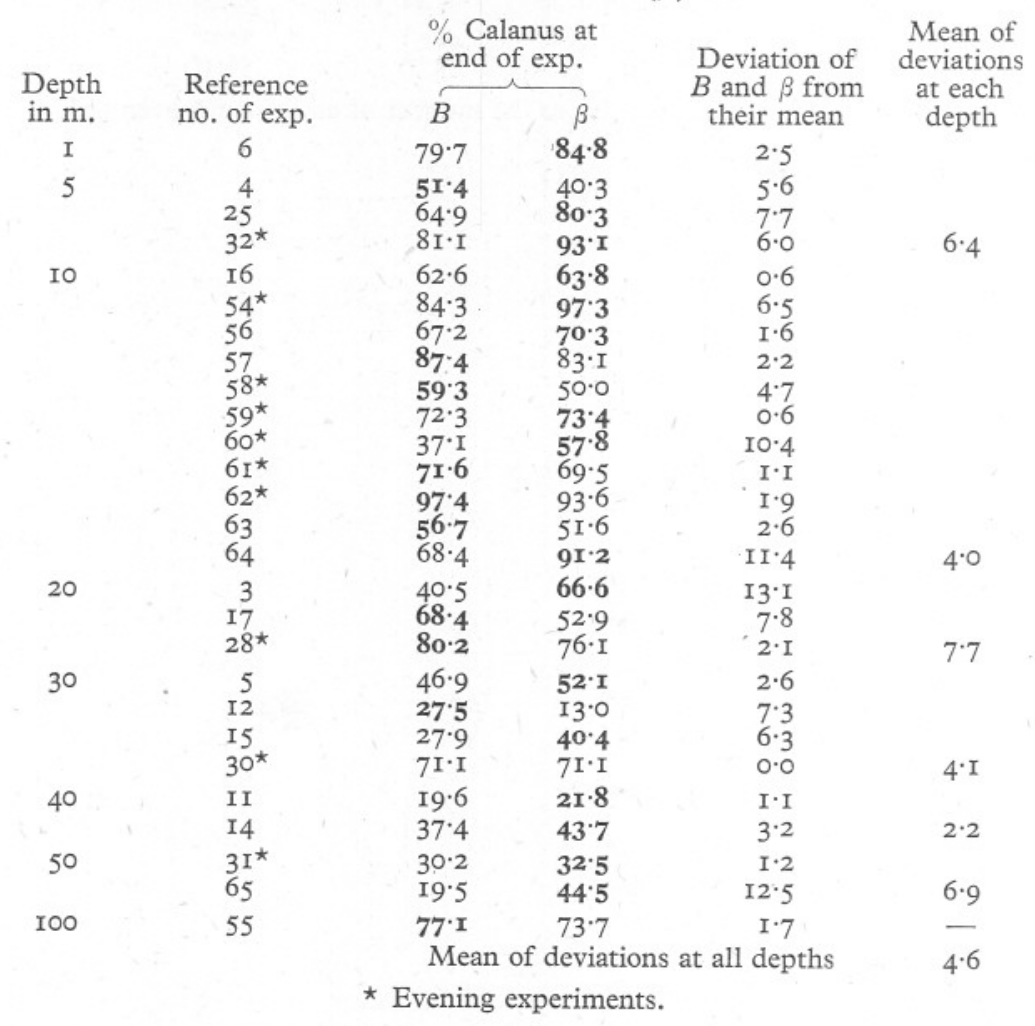

lower compartment of the other $(\beta)$. These differences for the standard daylight experiments have already been shown graphically in Text-fig. 6. Table II gives the percentages found in the two lower compartments $(B$ and $\beta)$ at the end of all these experiments together with those of other similar ones (marked with an asterisk) taken in the evening. The latter, which will be discussed in a later section (pp. 500-4), are here included because, although taken in dusk or darkness, the conditions of the two sides of the apparatus are the same in any one experiment. The table also gives the deviations of the percentages 
on the two sides of each experiment from their mean; these range from

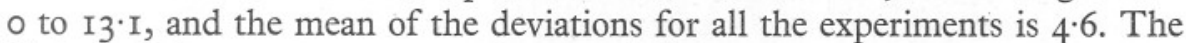
higher of the two percentages (in $B$ and $\beta$ ) in each experiment is shown in heavy type; we see that down to and including $20 \mathrm{~m}$. there are eighteen experiments of which eight have the higher percentage in $B$ and ten have it in $\beta$. For $30 \mathrm{~m}$. and below there are nine experiments, and out of these six have the higher percentage in $\beta$. It may be that at the greater depths there is a slight tendency for more Calanus to remain in the compartment in which they were placed at the beginning of the experiment, but there are too few results to warrant any conclusion on this and the one result at $100 \mathrm{~m}$., the deepest of all, is against it.

At the end of the season in 1939 a series of experiments (68-75), in which the Calanus were introduced into the top compartment of both sides of the apparatus, were made for the special purpose of $(a)$ comparing the differences in the results found on the two sides of these experiments with those of the standard experiments just discussed, and $(b)$ providing a comparison for later experiments in which the conditions on one side of the apparatus would be modified. Unfortunately, these experiments were left until very late in the programme, I8-22 November 1939; then it was difficult to collect Calanus in sufficient numbers off Millport, so that all but two were performed with stocks of Calanus which had been collected in Loch Striven, brought to the laboratory and kept in large containers for I, 2 or 3 days. The effects of being so kept are discussed in a later section (p. 508) $;^{1}$ here we are simply considering the differences in the percentages of Calanus, with exactly the same history, introduced into the top compartments of the two sides of the apparatus and subjected to exactly the same conditions. The Calanus used were always selected from the same level in the containers to eliminate individual differences as far as possible. The results are shown in Table III. The deviations of the two percentages from their mean in each experiment range from 0.9 to $12 \cdot 8$, and the mean of these deviations is $4 \cdot 8$; these figures compare very closely with those just given above for the standard experiments. It is seen that the position of introduction at the beginning of the experiment on either side makes little difference to the result.

We are working with a population in which a certain proportion of the individuals shows a tendency to move upward and a certain proportion to move downward at a particular depth and time. Taking two random samples from such a population for purpose of experiment it is not surprising that we do not get exactly similar results on the two sides; rather is it remarkable that they differ so little from one another. The difference seen between the results of the two sides of any experiment is clearly of the nature of an experimental error due to sampling. Out of the total of thirty-five experiments given in

\footnotetext{
${ }_{1}$ The results of these experiments, because of the effects described later, have not been included with the standard experiments just described.
} 
Tables II and III, twenty-one show deviations between 0 and 4.9 , nine between 5 and 9.9, and only five between Io and I3.I (the highest).

Having obtained some measure of this experimental error we can now look more closely at the standard experiments performed in daylight, i.e. between 0800 and $\mathrm{I} 600 \mathrm{hr}$.

Neglecting the experiments at 50 and $100 \mathrm{~m}$. which are too few to offer conclusive results, it is seen from Table I and Text-fig. 9 that the deeper the experiments are made, from I to $40 \mathrm{~m}$., then the smaller is the average proportion of the population which has moved down or stayed down at the end of each experiment; and the larger is the average proportion which has moved up or stayed up in the apparatus.

Table III. Showing the Difference Between the Results of the two SIDES $(A B$ and $\alpha \beta)$ OF DOUble Experiments IN Which CALANUS Were INTRODUCED INTO THE UPPER COMPARTMENTS ( $A$ AND $\alpha$ ) OF EACH SIDE

\begin{tabular}{|c|c|c|c|c|c|}
\hline \multirow{2}{*}{$\begin{array}{l}\text { Depth } \\
\text { in } \mathrm{m} .\end{array}$} & \multirow{2}{*}{$\begin{array}{l}\text { Reference } \\
\text { no. of exp. }\end{array}$} & \multicolumn{2}{|c|}{$\begin{array}{l}\% \text { Calanus at } \\
\text { end of exp. }\end{array}$} & \multirow{2}{*}{$\begin{array}{l}\text { Deviation } \\
\text { of } B \text { and } \beta \\
\text { from their } \\
\text { mean }\end{array}$} & \multirow{2}{*}{$\begin{array}{c}\text { Mean of } \\
\text { deviations } \\
\text { at each } \\
\text { depth }\end{array}$} \\
\hline & & $B$ & $\beta$ & & \\
\hline 5 & $\begin{array}{l}73 \\
74\end{array}$ & $\begin{array}{l}8 \mathrm{r} \cdot 5 \\
80 \cdot 0\end{array}$ & $\begin{array}{l}75^{\circ} 6 \\
84^{\circ} \cdot\end{array}$ & $\begin{array}{l}3 \cdot 0 \\
2 \cdot 0\end{array}$ & 2.5 \\
\hline IO & $\begin{array}{l}68^{\star} \\
69^{\star} \\
70^{\star} \\
71 \dagger \\
72 \dagger \\
75^{\star}\end{array}$ & $\begin{array}{r}63 \cdot 2 \\
69 \cdot 8 \\
74 \cdot 1 \\
18 \cdot 4 \\
3 \cdot 5 \\
35 \cdot 6\end{array}$ & $\begin{array}{r}75 \cdot 7 \\
86 \cdot 8 \\
81 \cdot 1 \\
15 \cdot 0 \\
29 \cdot 0 \\
33 \cdot 8 \\
\text { Mean o }\end{array}$ & $\begin{array}{r}6.3 \\
8.5 \\
3.5 \\
1.7 \\
12.8 \\
0.9 \\
\text { eviations }\end{array}$ & $\begin{array}{l}5 \cdot 6 \\
4 \cdot 8\end{array}$ \\
\hline
\end{tabular}

(See discussion of these experiments on p. 508.)

If nothing definite had been known about the actual depth from which the Calanus were originally collected, a very simple explanation of these results could be suggested. At $\mathrm{I} \mathrm{m}$. depth it was found that on an average $14.6 \%$ of the population in the apparatus moved upward or stayed up; it might be suggested that this $14.6 \%$ of the population had in fact been collected from just below the surface as the nets came up. At $5 \mathrm{~m}$. depth experiments showed $26 \%$ of the population up in the apparatus, so it might be suggested that there would on an average be $\mathrm{Ir} \cdot 4$ (i.e. $26-\mathrm{I}_{4} \cdot 6 \%$ ) of the population caught between depths of 5 and I $\mathrm{m}$. So on as we pass to lower depths; at $30 \mathrm{~m}$. an average of $64 \%$ moved up or stayed up in the experiments, suggesting that this proportion of the population was actually caught above $30 \mathrm{~m}$. Such a simple explanation, however, is not possible; we know from what follows that the majority of the Calanus were collected at a much greater depth.

It became a matter of the utmost importance to have an exact record of the depth at which the nets fished when the Calanus were collected for the 
experiments. A depth recorder, similar to that used by Russell (I925) for determining the depths of his nets when studying vertical migration at Plymouth, was kindly lent by the Admiralty. A graph of the depth at which the recorder is towed is traced on a paper mounted on a clockwork drum in a watertight chamber within its streamline body. The tests were made at the same place, in the Cumbrae Deep (the deep water between Garroch Head and Kilchattan Bay) from which the Calanus were usually collected for the experiments. The two I $\mathrm{m}$. diameter tow-nets were used just as they had always been used: placed on the towing rope Io ft. apart with a weight just below the lower net and 60 fathoms of rope let out. The only addition was the depth recorder placed between the weight and the lower net; being small and streamlined, and having neutral buoyancy, it would make little difference to the normal path of the nets when towing. The boat and windlass were handled

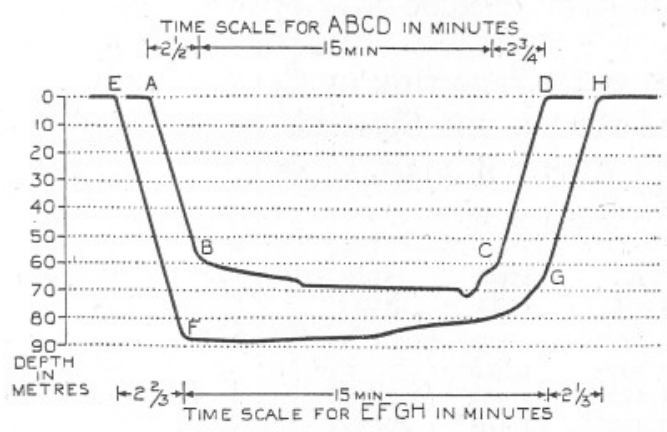

Text-fig. II. Two tracings from an Admiralty Depth Recorder showing the path of the collecting tow-nets below the surface on two occasions: curve $A B C D$ is a tow against the tide (as was the custom whenever possible) and curve $E F G H$ is a tow at slack water. $A B$ and $E F$ represent the path of the nets while the towing rope is being veered out, $B C$ and $F G$ their path during the actual tow, and $C D$ and $G H$ while being hauled in. The duration of the collecting period (i.e. between the time when the rope was fully out and the time when hauling in began) was exactly $15 \mathrm{~min}$. in each case; a separate time scale is given for $A B C D$ above the figure and for $E F G H$ below, a difference in scales due to the varying rate of turning of the recorder clockwork.

by the same two boatmen who always worked them so that the nets were towed and hauled up at the same speed as usual. A first tow was made against the tide as had been the practice whenever possible in the past; a second test was then made in the opposite direction, but by that time it was almost slack water and the nets fished deeper. The two curves traced by the recorder are shown superimposed in Text-fig. II with the depth scale alongside. Curve $A B C D$ is the first tow: that against the tide. $A B$ represents the descent of the net while the rope is being veered out; $B C$ is the path of the net during the tow and is seen to lie (except for a very small fraction) between depths of 60 and $70 \mathrm{~m}$.; $C D$ is the net being hauled to the surface. In the same way the curve $E F G H$ represents the path of the net during the second test, that at slack water; the depth during tow was now deeper, starting at about $87 \mathrm{~m}$. 
and rising to about $62 \mathrm{~m}$. at $G$, where the transition to the regular steep climb during hauling can be seen. The haul $F G$ appears to be of longer duration than $B C$, but actually this is due to an acceleration in the clockwork mechanism ${ }^{1}-$ the two were timed to be $15 \mathrm{~min}$. each. The tests show conclusively that the nets were fished during towing at a depth of between 60 and $90 \mathrm{~m}$. and more usually between 60 and $70 \mathrm{~m}$., because they were towed against the tide whenever possible.

The nets, being veered out at almost the same speed as the forward motion of the boat, would hardly fish on the way down; they would, however, fish well while being hauled up, but the time taken in hauling is less than $3 \mathrm{~min}$. In the tests the duration of the tow was $15 \mathrm{~min}$., but in actual collecting it was always half an hour; thus the time taken in hauling was just under $10 \%$ of the fishing time. It is almost inconceivable that nets fishing for $90 \%$ of the time below $60 \mathrm{~m}$. should capture some $70 \%$ of their Calanus above $40 \mathrm{~m}$. in the

Table IV. Vertical Distribution of Calanus in the Cumbrae Deeps in THE DAYTIMe DURING THE SUMmers OF 1942 AND I943 AS SHOWN BY I5 MIN. HAUlS WITH I M. DiAM. COARSE MESH NetS at VARIOUS DEPTHS

\begin{tabular}{|c|c|c|c|c|c|c|c|c|c|}
\hline \multirow[b]{2}{*}{$\begin{array}{l}\text { Depth } \\
\text { in } m .\end{array}$} & \multicolumn{4}{|c|}{ Average nos. in } & \multicolumn{4}{|c|}{ Same results as percentages } & \multirow{2}{*}{$\begin{array}{c}\text { Average } \\
\% \text { at } \\
\text { each } \\
\text { depth }\end{array}$} \\
\hline & $\begin{array}{l}\text { July } \\
\text { I } 942\end{array}$ & $\begin{array}{l}\text { Aug. } \\
1942\end{array}$ & $\begin{array}{l}\text { Sept. } \\
1942\end{array}$ & $\begin{array}{l}\text { July } \\
\text { I } 943\end{array}$ & $\begin{array}{l}\text { July } \\
\text { I } 942\end{array}$ & $\begin{array}{l}\text { Aug. } \\
\text { I942 }\end{array}$ & $\begin{array}{l}\text { Sept. } \\
\text { I } 942\end{array}$ & $\begin{array}{l}\text { July } \\
\text { I } 943\end{array}$ & \\
\hline I & $400^{1}$ & $672^{4}$ & $\mathrm{II}^{2}$ & $0^{1}$ & $2 \cdot 8$ & $\mathrm{I} \cdot 2$ & 0.7 & 0 & $\mathbf{r} \cdot \mathbf{2}^{8}$ \\
\hline 30 & 470 & $697^{12}$ & I, $618^{5}$ & $72^{1}$ & 2 & & & 0.4 & $3 \cdot 9^{22}$ \\
\hline 55 & $5,010^{4}$ & $\mathrm{I}_{5}, 882^{12}$ & $I, 967^{8}$ & $2,253^{3}$ & $34 \cdot 5$ & $27 \cdot 2$ & 13.0 & $9 \cdot 9$ & $2 \mathrm{I} \cdot \mathrm{I}^{27}$ \\
\hline 90 & $8,603^{3}$ & $4 \mathrm{I}, 202^{8}$ & II, $425^{6}$ & $20,600^{3}$ & $59 \cdot 5$ & $70 \cdot 4$ & $75 \cdot 6$ & $89 \cdot 7$ & $73^{\cdot} 8^{20}$ \\
\hline
\end{tabular}

The index figures indicate the number of samples averaged.

short interval of time during which they are hauled up. They are hauled at a speed of just over I $\mathrm{m}$. in $3 \mathrm{sec}$. The Calanus would have to be exceedingly rich near the surface to yield $14.6 \%$ of the catch in the top metre (in $3 \mathrm{sec}$. tow). In fact we know that this is not so except on very rare occasions. Repeatedly it has been found impossible to collect heavy samples of Calanus in the daytime except by fishing below $50 \mathrm{~m}$.

During the summers of $1942-3$ the senior author carried out a study of the yield of Calanus in the Clyde Sea area $;^{2}$ a number of horizontal tow-net hauls were made with I m. diameter nets at depths from I to $90 \mathrm{~m}$. in the area of the Cumbrae Deeps, just where the Calanus were collected for the present experiments. Table IV shows the results of these hauls for the months of July, August and September. From 60 to $90 \%$ of the Calanus were below $55 \mathrm{~m}$. depth in the daytime with less than $10 \%$ in the upper $30 \mathrm{~m}$.

${ }^{1}$ Similar variations in the recorder clockwork are also shown by Russell (I925).

${ }^{2}$ This was part of an investigation into the possibility of harvesting the plankton as a means of increasing the country's protein supply for livestock food in wartime; it was not found to be a practical proposition (as will be recorded in a later paper). 
These two lines of evidence make it clear that the bulk of the Calanus used in the standard experiments had in fact come from depths of some $60 \mathrm{~m}$. or more. One is presented with an unexpected result; when samples of this deep population are taken for purposes of experiment nearer the surface, between I and $40 \mathrm{~m}$., there is a regular change in the proportions of the population which move upwards and of those which move downwards. We will return to this problem in the general discussion at the end.

Regarding the upper levels it might perhaps be argued that one need not assume that there were some which actively moved upwards, but rather that there might be a proportion of the population unaffected and moving at random and only some which actively moved down. Thus at $\mathrm{I} \mathrm{m}$. depth it might be said there were $29.2 \%$ moving at random, i.e. twice the $14.6 \%$ appearing to have migrated actively upward ( $14.6 \%$ having moved at random into the upper compartment as well as a similar percentage having moved at random into the lower compartment). This would leave $70.8 \%$ actively moving down at $\mathrm{I} \mathrm{m}$. depth. Similarly, at $10 \mathrm{~m}$. depth it might be suggested that $56.4 \%$ were moving at random and only $43.6 \%$ actively moving down. However the evidence of the long tube (Apparatus No. 2) experiments to be described on p. 510 is against this view of random movement and when one comes to consider events at $30 \mathrm{~m}$. one would have to assume that there had been a change over with $29.4 \%$ actively migrating upwards and $70 \cdot 6 \%$ moving at random (i.e. twice the $35.3 \%$ appearing to have migrated downwards).

If it should be assumed that the Calanus in the top compartment are photopositive and the remainder photonegative, it would mean that each individual would have, for that particular time, its own threshold of light intensity below which it is positive and above which it is negative in action. If this was so then the populations we are considering must be characterized by nicely graded threshold values: a few Calanus would be photopositive under all experimental conditions, and more and more would reach their positive threshold at each successive reduction in light intensity with increasing depth. So far no direct evidence has been presented to show that these changes in behaviour in relation to different depths are due to differences in the light intensity at all. All that has been demonstrated so far is that there is a change of behaviour in the population varying with depth.

In the next section under the heading of 'Mirror experiments' evidence will be given to show that light is truly a factor of importance; but before passing to these there is other evidence from those experiments already described which must be considered and which, together with the mirror experiments, suggest that differences in light intensity have but little to do with the changes in behaviour observed at different depths. Two lines of evidence from the present experiments are available.

In Text-figs. 7 and 8 it is seen that the results of different experiments at any given depth spread over a considerable range of values. If the differences 
in the intensity of the light were an important factor in determining the animals' behaviour at different depths, then it might be expected that differences in behaviour at the same depth, but on different days, might in part be due to differences in the light conditions on these different occasions. At the one depth it would be expected that the brighter the intensity of light then the smaller the proportion of the population moving upward in the apparatus. With each experiment readings were taken with the Secchi disk (see p. 480)

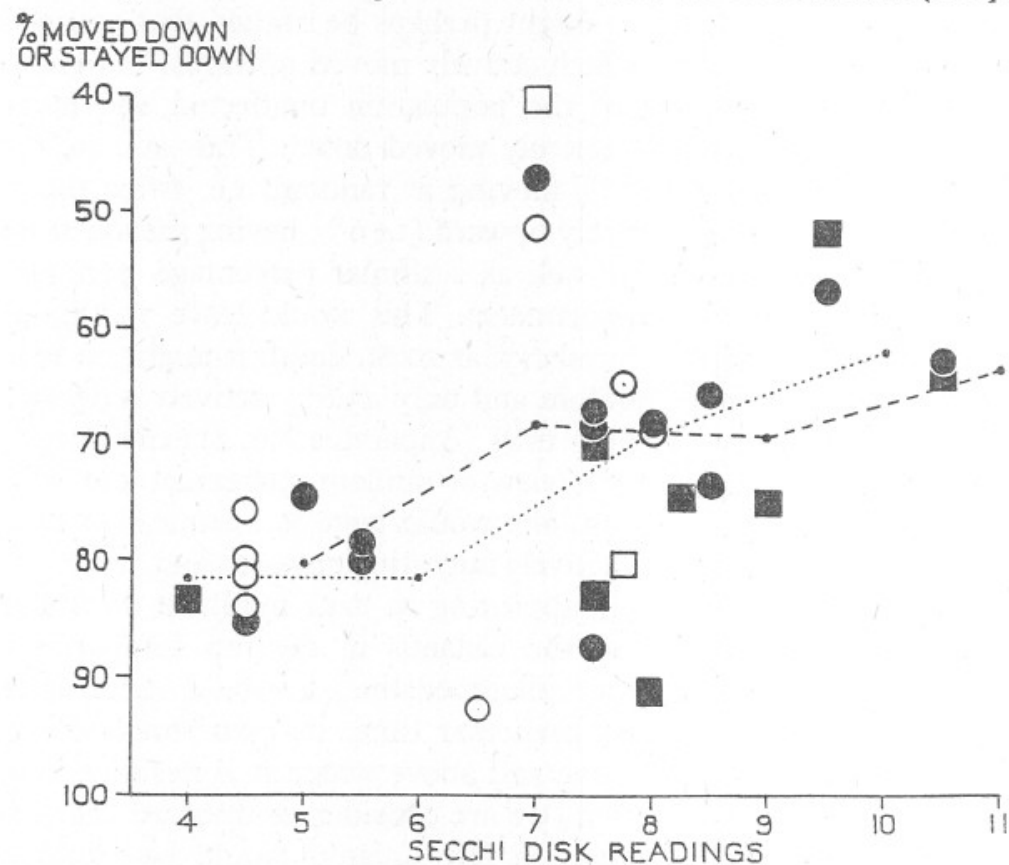

Text-fig. I2. Percentages of Calanus Stage V in the lower compartments of the apparatus at the end of standard experiments at 5 and $10 \mathrm{~m}$. between 0800 and $1600 \mathrm{hr}$. plotted against Secchi disk readings. Percentages of Calanus which have moved down are shown as circles and those which have stayed down as squares; the observations at 5 and $10 \mathrm{~m}$. depth are distinguished by open and blacked-in symbols respectively. The broken line connects points which are the averages of the percentage values falling between Secchi disk readings of $4-5.9,6-7 \cdot 9,8-9 \cdot 9$ and IO-II.9; similarly, the dotted line shows the averages when the Secchi disk readings are grouped as $3-4.9,5-6.9,7-8.9$ and $9-10 \cdot 9$.

to give some measure of the transparency of the water and hence the relative penetration of light. The full set of readings will be found in the Appendix, Table I. A greater number of standard experiments were made at 5 and $10 \mathrm{~m}$. than at any other depths. In Text-fig. I2 the percentage values of Calanus which were in the lower compartments at the end of these experiments (i.e. either moved down or stayed down) are plotted against their Secchi disk readings. The Secchi disk method is undoubtedly a crude one; but, while not a measure of light intensity, in general a shallower disk reading indicates a poorer penetration of light due to increased opacity on that particular day. 
If there is any correlation shown here between the behaviour of the Calanus and the differences in the penetration of light it is only a slight one-and if so, then it is a correlation in the unexpected direction. The broken line and dotted line graphs in the figure connect the points which represent the average percentage values for each two degrees of the Secchi disk readings grouped either as $4-5 \cdot 9,6-7 \cdot 9$, etc., or $3-4 \cdot 9,5-6 \cdot 9$, etc. It suggests that on an average the greater the light penetration the larger is the proportion of photopositive individuals in the population. It will be seen from other experiments to be described later that there are indications that there are other factors (possibly physiological conditions dependent upon the amount of food taken) which may affect the proportions of the population moving up or down at any one depth so that any marked correlation with light penetration at one depth would not be expected. This possible correlation must be investigated by future experiments with an exact means of measuring absolute light intensity; for the moment it is sufficient to have shown that the reverse correlation does not hold here: there is no sign of a larger number of Calanus moving downward when the Secchi disk indicates a greater light penetration.

The second line of evidence has more weight. In Text-fig. I3 are plotted the average percentage values of Calanus which have either moved down or stayed down in the standard experiments at different depths. As already pointed out it is virtually a straight line correlation with depth; it becomes so if we omit two double experiments (Exp. 4 at $5 \mathrm{~m}$. and Exp. I2 at $30 \mathrm{~m}$.) which gave exceptionally low percentages. Now in the same figure, using the same percentage scale, there is plotted for comparison the curve of relative light intensity below the surface as determined by Poole \& Atkins (I926) off Plymouth expressed for each depth as a percentage of the light intensity immediately below the surface (see also the figure in Russell, I927, p. 248). Although the actual subsurface light intensity in the Clyde sea area may differ somewhat from that off Plymouth, its percentage reduction with depth will be of the same general order as that shown by Poole \& Atkins. It seems quite clear from this that the progressive alteration in the behaviour of the population of Calanus as one goes deeper is in direct linear correlation with depth and not in such direct correlation with diminution of light intensity. This is further emphasized in Text-fig. I4 where the same average percentages of Calanus, moved down and stayed down, are plotted directly against the scale of percentage light intensity, e.g. the results at I m. are plotted opposite the value of the percentage light intensity found at that depth by Poole \& Atkins $(82.5 \%)$, those at $5 \mathrm{~m}$. opposite the percentage light intensity at that depth $(46 \%)$ and so on.

\section{Mirror experiments}

In these experiments the sides of one whole cylinder of the apparatus were tightly covered with black opaque paper and its metal bottom plate 
interchanged with its top glass plate. Thus in one cylinder all light was excluded except from below, and here mirrors at right angles to one another were arranged to reflect the daylight from above vertically up the cylinder from below as shown in the diagram in Text-fig. I5. In this way light was played

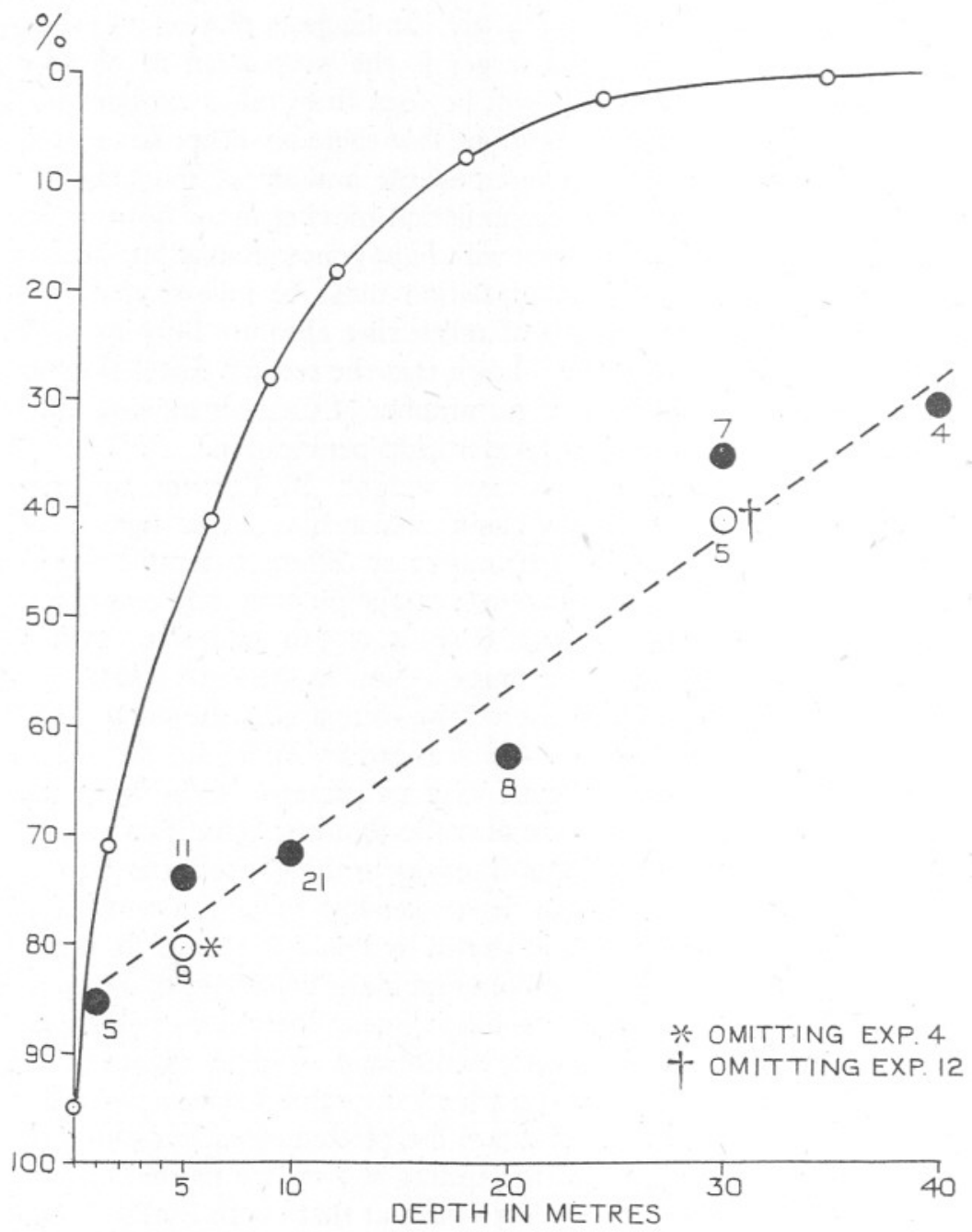

Text-fig. I3. The blacked-in circles show the average percentage values of Calanus which have either moved down or stayed down in standard experiments at depths of $\mathrm{I}-40 \mathrm{~m}$. (i.e. the two graphs in Text-fig. 9 combined). The figures against them indicate the number of experiments averaged at each depth. Their distribution suggests a straight-line correlation with depth. The continuous line curve indicates the relative light intensity below the surface as determined off Plymouth by Poole \& Atkins (I926) expressed for each depth as a percentage of the light intensity immediately below the surface. See discussion in text. 
upwards against gravity on one side of the apparatus while the cylinder on the other side was normal and acted as a control.

In Text-fig. I6 the right-hand graph shows the percentage of Calanus which moved down (circles) or stayed down (squares) in the normal side of the apparatus according to whether they were placed in the upper or the lower half of the cylinder at the start. This graph is therefore that of a selected

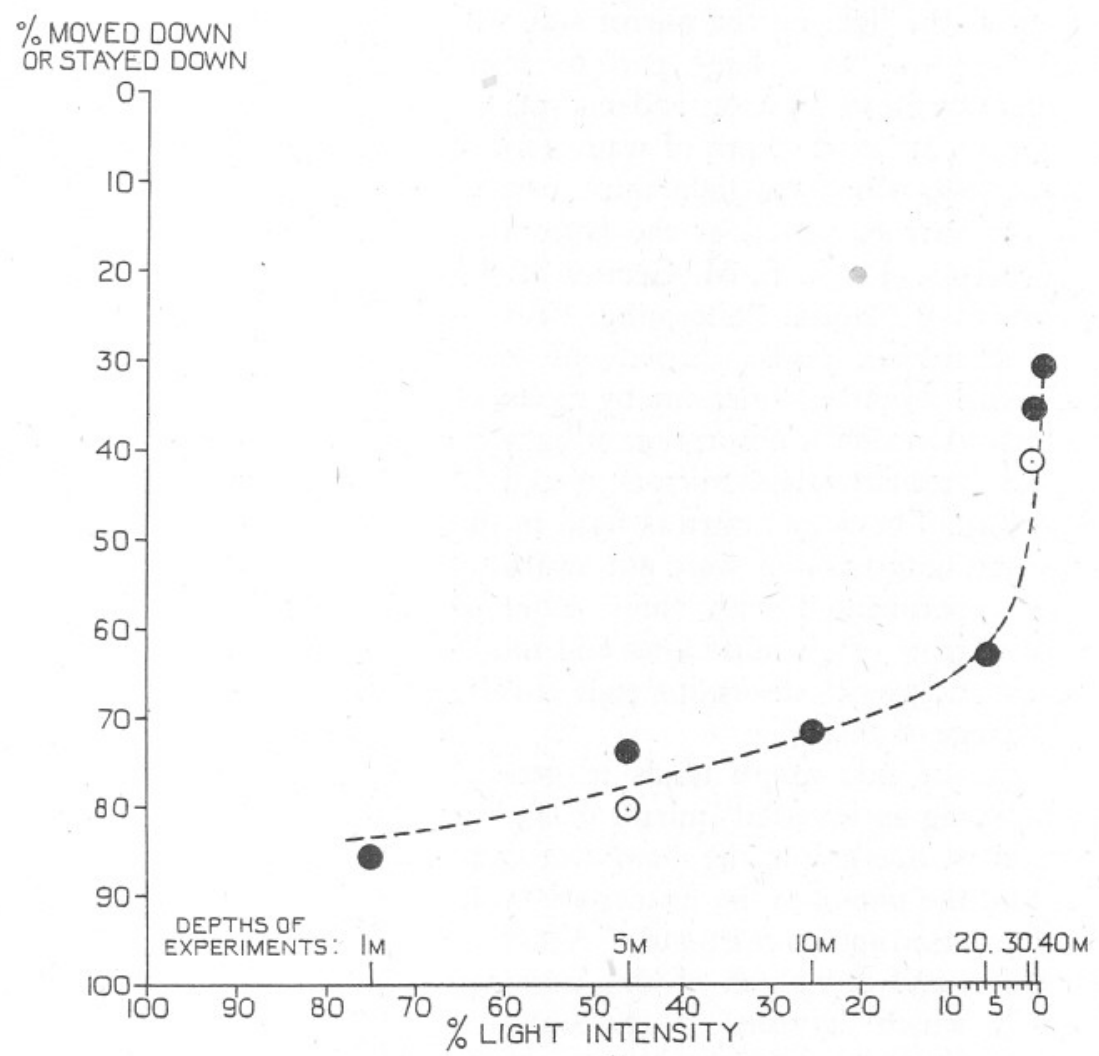

Text-fig. I4. The same percentage values of Calanus moved down or stayed down as shown in Text-fig. I3 but plotted against a scale of percentage light intensity. They are plotted against points on the scale corresponding to the light intensities found by Poole \& Atkins (I926) at the same depths at which the experiments were performed. See discussion in text.

number of single-standard experiments, and their results conform closely with the general trend of those shown by the total of such standard experiments (compare with Text-figs. 7-9). In the left-hand graph are shown the percentages of Calanus that have moved down or stayed down in the mirror side of the apparatus in the same number of experiments. The reference number of each experiment is given so that the members of each pair of experimental results may be compared. In both sides of the apparatus the majority of the 
Calanus in the experiments at the lesser depths of $\mathrm{I}$ and $5 \mathrm{~m}$. have been found at the end of the experiment in the compartment away from the direction of the light, but to do this in the mirror side they have had to go up (or stay up) against gravity. This clearly shows that light is playing an important part.

The only difference in the conditions of the two sides of each experiment relate to light: first, the direction of the light is reversed, and secondly, the intensity of the light on the mirror side will be the less, due in a large part to some absorption by the two mirrors and in a smaller part due to the extra depth of water (about I m.) through which the light must pass to reach the mirrors placed at the bottom of the apparatus. Dr A. E. M. Geddes of the Department of Natural Philosophy, University of Aberdeen, kindly carried out some experiments recently to measure by means of a photoelectric cell the absorption of light by two such ordinary glass mirrors placed at right angles. The actual mirrors used in the experiment unfortunately were not available, but he experimented with three different pairs of mirrors of a similar kind and found $28.8,30.0$ and $30.5 \%$ absorption respectively, or an average of $29.8 \%$.

The mirror side graph tends in general towards being an inverted 'mirror image' of the standard side graph, the main difference being that the points in the former are more widely dispersed and more irregular. A further explanation and discussion of this irregular dispersal, which appears to be only of secondary importance, is given in a note in

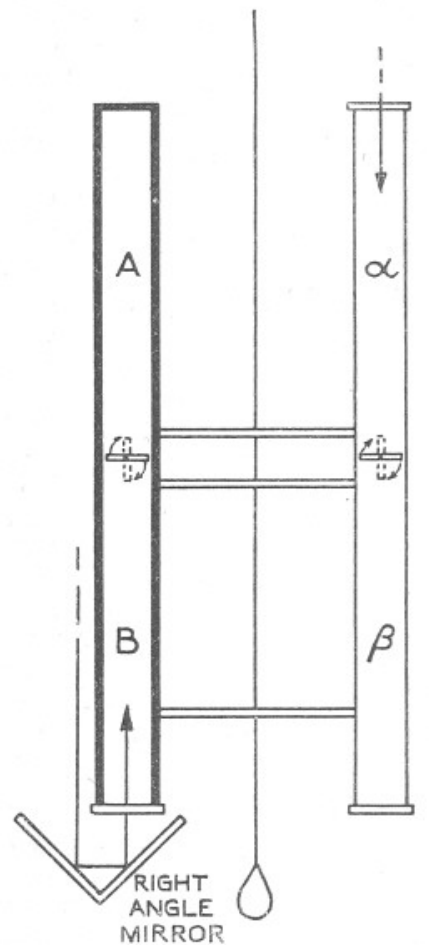

smaller type which follows. While many more such mirror experiments should be made to test these results, those here described, together with the former standard experiments, appear to indicate: $(a)$ that light more than gravity is the influence towards which or away from which the animals move at different depths, and $(b)$ that it is not the intensity of the light which determines the proportion moving towards or away from it. Such differences as there are between the two graphs, regarding them as inverted 'mirror images' of one another, can hardly be explained by the $30 \%$ reduction in the light intensity (due to the mirrors) in the one as compared with the other. In Exps. 8 and 34 the results are almost perfect inversions of one another. ${ }^{1}$

\footnotetext{
1 See however Addendum, p. $52 \mathrm{I}$.
} 
Some special though minor features concerning the dispersal of the points in the mirror side graph may now be noted. In Exps. 8 and 9 the same Calanus were used twice. In Exp. 8, 92 Calanus were put into the top compartment of the mirror side at the beginning (i.e. away from the light) and $84(9 \mathrm{I} \cdot 3 \%)$ remained there; I I I Calanus were put into the top compartment of the normal side (i.e. towards the light) and 98 $(89.2 \%)$ went down into the lower compartment (away from the light). In Exp. 9 the 84 Calanus which had stayed up (away from the light) in the mirror side of Exp. 8 were now put into the top compartment of the normal side and $77(9 \mathrm{r} \cdot 6 \%)$ went down; in the mirror side the 98 Calanus which had gone down in the normal side in Exp. 8 were put into the lower compartment (i.e. towards the light), and at the end of the experi-
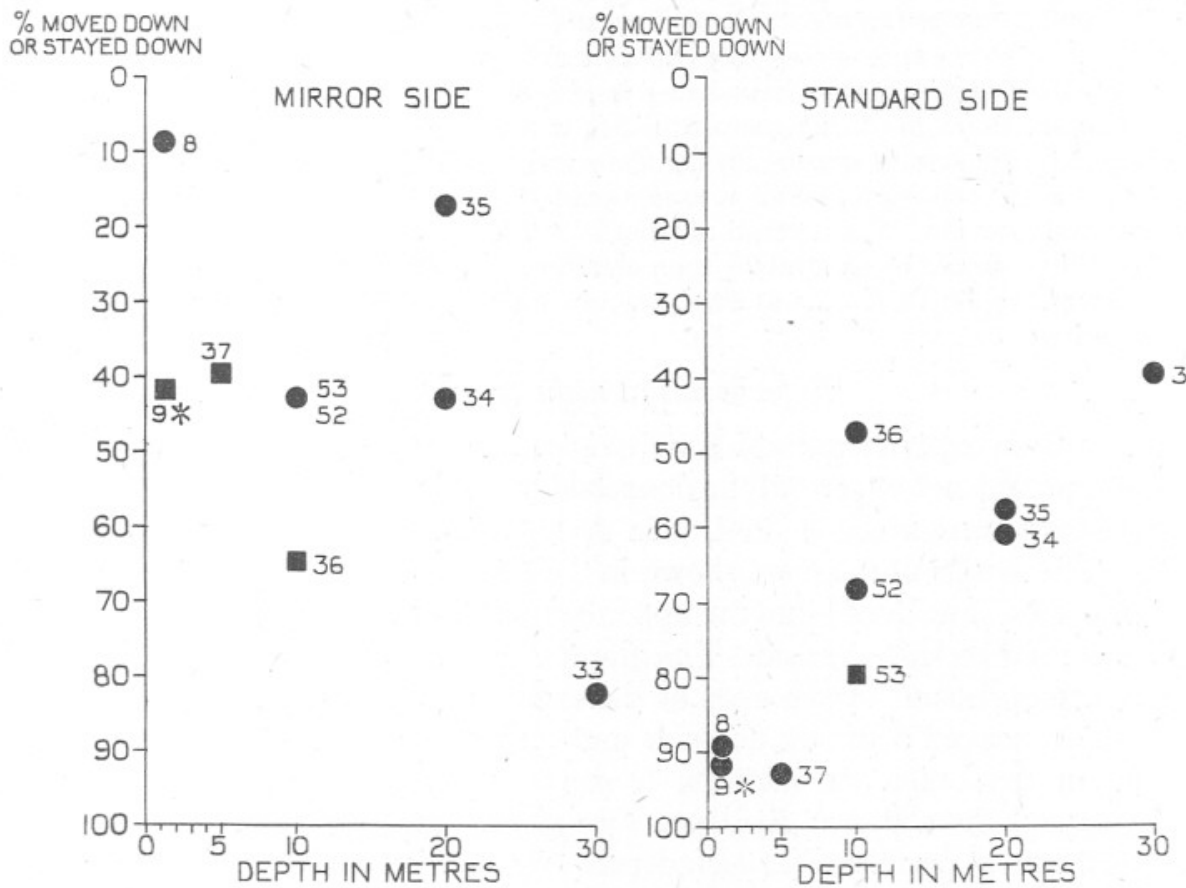

Text-fig. I6. Results of experiments with Calanus Stage V in one side of the apparatus which was blacked-out except for light reflected from a mirror below and in the other side under standard conditions. The circles represent the percentage Calanus which have moved down and the squares the percentage which have stayed down in different experiments. The figures against each indicate the reference numbers of experiments. The Calanus in Exp. 9 (marked with asterisk) were used on opposite sides of the apparatus in Exp. 8.

ment only $57(58.2 \%)$ had moved up into the compartment away from the light. It is possible that either the Calanus were suffering from fatigue or that the light intensity on the mirror side was not sufficiently high to stimulate them fully when they had previously been exposed for an hour to the greater light intensity of the open side in the former experiment. This latter suggestion implies that a good part of them had become adapted to a higher value. Johnson (1938), working on Acartia clausi, found that in the laboratory this copepod reacted rather to rate of change of light intensity than to absolute intensity, and further that a return to a random distribution occurred between changes of stimulation except when the period between them was less than half an 
hour. In other words the copepods became adapted to the presented light condition in about half an hour, but if the next alteration of stimulus occurred within 15 min. adaptation was not complete and a certain summation of reaction was noticeable. It should, however, be remembered that the present experiments must not be compared closely with laboratory experiments which do not take into account the factor of depth which would seem here to be so important. Actually in the present instance the time interval between the end of Exp. 8 and the beginning of Exp. 9 was $\mathrm{I} \mathrm{hr.} 57 \mathrm{~min}$.

In the other experiments of the series the Calanus were used only once. The percentage down on the mirror side in Exp. 35 at $20 \mathrm{~m}$. is exceptionally low; there is an experimental defect which might have given rise to this. The following is a quotation from the log-book of the experiments: 'The first messenger failed to work the trapdoor to begin with; the apparatus was hauled up and released at the surface and sent down again." ${ }^{\prime \prime}$ For a very short period the experiment began like one just below the surface and this brief exposure may have had a lasting effect through the experiment. Any such abnormalities in other experiments are few and are recorded in the Appendix. No obvious explanation appears for the abnormality of Exp. 36 at Io m. depth; on the mirror side the percentage down is exceptionally high, whereas on the other side it is correspondingly low. The reversal of values on the two sides would be expected, but not that they should be abnormally high and low; the Calanus used in this experiment were caught at the same time as those used in Exp. 35 which was performed only an hour earlier.

\section{Experiments at night and dusk}

Apart from experiments which were repeated at the same depth throughout a $24 \mathrm{hr}$. period and which will be described in the next section, a few standard experiments were made at dusk or in darkness at different depths from 5 to $50 \mathrm{~m}$. The results of these are shown in Text-fig. I7. In each experiment the Calanus were introduced into the upper compartment of one cylinder and into the lower one on the other side. The graph shows the percentages found in the lower compartments at the ends of the experiments: circles represent those which had moved down on one side and squares those which had remained down on the other. In addition to results for Stage V, those for female Calanus and the copepod Euchaeta (see p. 502) are also shown. Only one experiment was performed at each depth. The data regarding times and dates of experiments and times of sunset are shown in Table V.

There are too few experiments to discuss in detail; they are merely recorded for future reference when it is hoped many more may be made at night. They do, however, again suggest a relation with depth rather than light intensity. On the whole the percentages down are greater than those of daylight experiments when the light intensity was so much higher, but this may be due to the fact that for all experiments, except Exp. 30, the Calanus were collected between I830 and $2015 \mathrm{hr}$. from deep water when the majority of the population may have already migrated leaving below a stock 'less inclined' to move upwards (see similar suggestion in next section).

1 One could always tell whether the trapdoors had been opened by feeling on the wire for the vibration caused by the working of the springs and cranks following the striking of the messenger. 


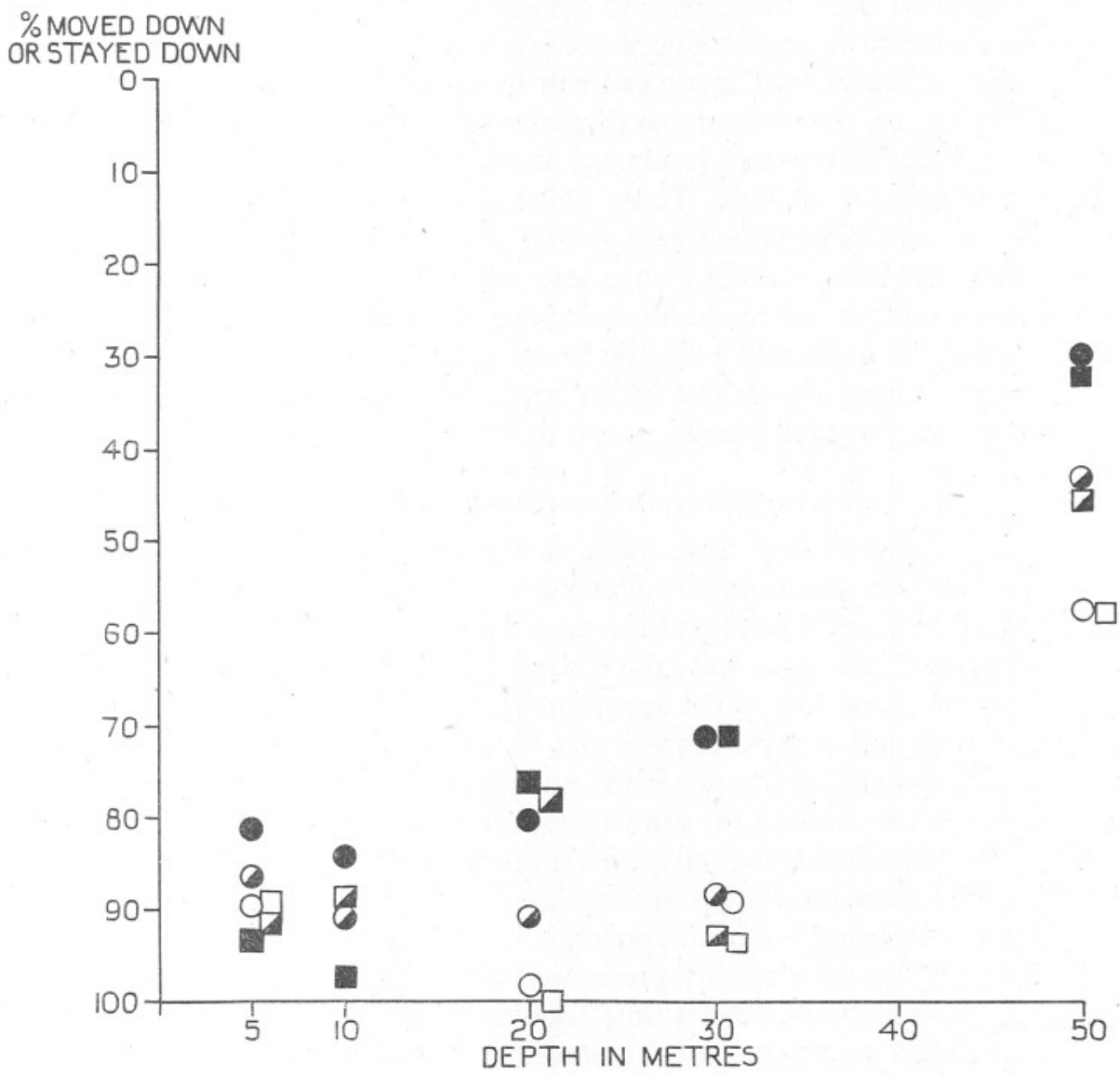

Text-fig. I7. Results of experiments made at dusk and at night with Calanus Stage V (blacked-in circles or squares), female Calanus (half-blacked circles or squares) and Euchaeta norvegica (open circles or squares). The percentage moved down shown as circles, those stayed down as squares. The experiments at 5,20 and $50 \mathrm{~m}$. were made at night and experiments at IO and $30 \mathrm{~m}$. at dusk (I9IO and I $700 \mathrm{hr}$. respectively). See Table V below.

Table V. Data for Experiments made at Night and Dusk

$\begin{array}{cccccc}\begin{array}{c}\text { Depth } \\ \text { in m. }\end{array} & \begin{array}{c}\text { Deference } \\ \text { no. of } \\ \text { exp. }\end{array} & \begin{array}{c}\text { Time of } \\ \text { exp. } \\ \text { (hr.) }\end{array} & \begin{array}{c}\text { Time of } \\ \text { collection } \\ \text { of Calanus } \\ \text { (hr.) }\end{array} & \begin{array}{c}\text { Time of } \\ \text { sunset } \\ \text { (hr.) }\end{array} \\ \text { I0 } & \text { I5. ix. } 38 & 32 & 2210 & \text { I900 } & \text { I838 } \\ 20 & \text { 23. viii. } 39 & 54 & \text { I910 } & \text { I830 } & \text { I937 } \\ 30 & \text { I4. ix. } 38 & 28 & 2108 & 2015 & \text { I840 } \\ 50 & \text { I5. ix. } 38 & 30 & \text { I700 } & \text { IIO0 } & \text { I838 } \\ \text { I5. ix. 38 } & 31 & 2039 & \text { I900 } & \text { I838 }\end{array}$


Here will be a convenient place to consider a few results obtained with the copepod Euchaeta norvegica Boeck included in these same experiments, 28, 30, 3I and 32, which were made in Loch Fyne. The results are shown in the same Text-fig. I7. It is hoped that further work will be done with Euchaeta in the future; these preliminary results are merely indications, but are thought of sufficient interest to include. Those which have moved down are shown as open circles, and those which have stayed down as open squares. It may be mentioned here that Euchaeta were also recorded in Exp. 29 made in the daytime ( $1300 \mathrm{hr}$ ) at $100 \mathrm{~m}$. depth, being introduced into $A$ on one side and $\beta$ on the other. It gave only $7.6 \%$ in $B$ and none in $\beta$ (93 were used in $A B$; sample $\alpha$ was unfortunately lost by the breakage of the cylinder so we do not know how many were originally placed in $\beta$ ).

\section{Experiments repeated over a 24-hour period}

A series of experiments were made at intervals of 3 hours from noon on 24 August 1939 to noon on the following day. These were all made at $10 \mathrm{~m}$. depth in upper Loch Fyne (over the deep water opposite Strachur pier), and were all made in the same way, the Calanus being introduced into the upper compartment of one side of the apparatus and into the lower compartment of the other, and each experiment was of I hr. duration. A Secchi disk reading was taken with each. It was not found possible to keep a sufficient single stock of Calanus to last throughout the whole period so that fresh hauls had to be taken three times during the series; while this was an unfortunate complication it has yielded some interesting indications of the behaviour of Calanus which would not otherwise have been apparent.

The results are most readily presented in graphic form and are shown in Text-fig. I8. The base-line is a time scale on which are marked the times of each experiment and the vertical co-ordinate is an inverted scale indicating the percentage Calanus found in the lower compartments in each experiment. The percentage values for the Calanus that have moved downwards in each experiment are shown as usual as blacked-in circles and those which, in the opposite cylinders of the apparatus, have stayed down are shown as blacked-in squares. The percentage values of those moved down (circles) in experiments made with Calanus collected at the same time are linked by a continuous line; the results of the opposite sides of the same experiments are linked by a broken line. At the top of the figure an indication of the variation in light penetration is given by a series of triangles the varying depths of which correspond to the depths (in metres) at which the Secchi disk disappeared from view.

The Calanus for the first three experiments were collected at $0830 \mathrm{hr}$. from a depth of $60-70 \mathrm{~m}$. and kept in the dark until required. The first experiment at noon yielded similar results in each side of the apparatus, $67.2 \%$ moving down and $70.3 \%$ remaining down. At I $500 \mathrm{hr}$. the results of the two sides were again closely similar to each other, but the values down were considerably 
higher, $87.4 \%$ moving down and $83.1 \%$ remaining down. In the third experiment at $1800 \mathrm{hr}$. there was a marked change, only $59.3 \%$ moved down and only $50 \%$ remained down on the other side. This clearly shows a change in behaviour with the passage of time as evening approaches: from noon to I $500 \mathrm{hr}$. an increasing proportion of the population were moving downwardat $\mathrm{I} 800 \mathrm{hr}$. the proportion moving up had greatly increased.

After the experiment at $1800 \mathrm{hr}$. it was found that the remaining stock of Calanus was insufficient for another experiment, and a fresh supply was collected at $1900 \mathrm{hr}$. again from $60-70 \mathrm{~m}$. depth. The catch was now a very much smaller one, only sufficient for one experiment, that made at $2100 \mathrm{hr}$.

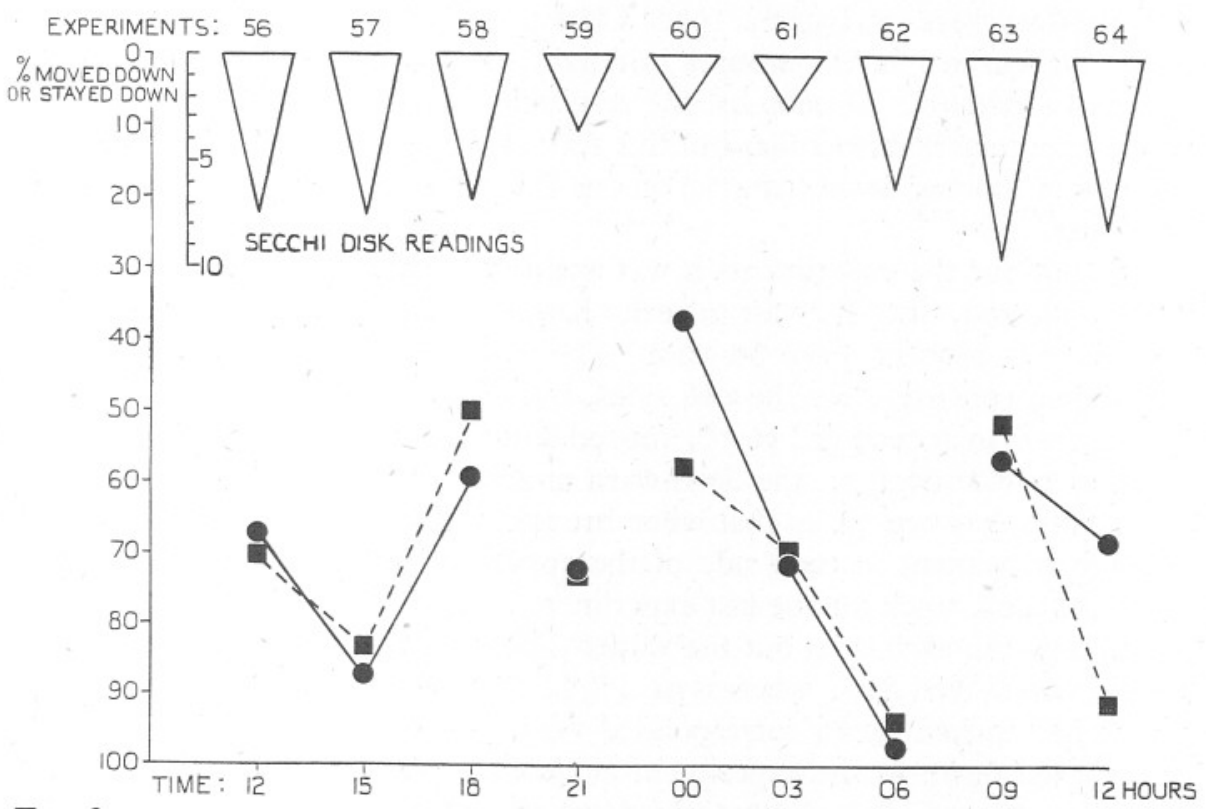

Text-fig. I8. Results of Exps. 56-64 made at Io m. depth throughout a $24 \mathrm{hr}$. period; for explanation see text.

Here the results with this new stock of Calanus gave $72 \cdot 3 \%$ moved down and $73.4 \%$ remained down; almost identical results but markedly different from those obtained with the former stock at $1800 \mathrm{hr}$. An explanation of this is suggested: at $1900 \mathrm{hr}$. the number of Calanus was very much less than was caught before, they would be those left below when the majority had begun their upward evening migration and so might be expected to yield a large proportion moving down or staying down when experimented with at $10 \mathrm{~m}$. Sunset was at $1935 \mathrm{hr}$.

It was now necessary to obtain yet a further stock of Calanus and, since the majority had apparently left the lower layers, a fresh haul was made at $2200 \mathrm{hr}$. from $20 \mathrm{~m}$. depth; now sufficient were again obtained to last for the next three 
experiments, those at midnight, 0300 and $0600 \mathrm{hr}$. At midnight only $37 \cdot \mathrm{I} \%$ moved down, whereas $57.8 \%$ stayed down; this suggests that at midnight there may be little tendency to go up or down, perhaps a general scattering effect (cf. Russell, I925), with a slight majority on each side tending to remain in the compartments into which they were introduced at the beginning of the experiment. At $0300 \mathrm{hr}$. there was once more a striking similarity in the results of the two sides of the apparatus, $71 \cdot 6 \%$ moving down and $69.5 \%$ remaining down. This tendency for the majority to move down had set in well before sunrise (which was at $0505 \mathrm{hr}$.), and when there was no increase in light penetration indicated by the Secchi disk reading. This agrees with the findings of several workers (cf. Esterly, I912; Clarke, I936, p. Io) that Calanus tend to leave the surface layers around midnight, although the light has not yet started to increase. At $0600 \mathrm{hr}$. the results in the two sides of the apparatus were again remarkably similar but this time showing nearly the whole population either moving down $(97.4 \%)$ on one side or remaining down $(93.6 \%)$ on the other.

To continue the experiments it was again necessary to collect a fresh stock of Calanus and, since the vast majority had been moving downward, the haul was made at $0800 \mathrm{hr}$. from $60-70 \mathrm{~m}$. The results of the $0900 \mathrm{hr}$. experiment were again consistent for the two sides, but the percentages down were very much less than at $0600 \mathrm{hr}$., $56 \cdot 7 \%$ moved down and $5 \mathrm{I} \cdot 6 \%$ stayed down. This suggests that at $0900 \mathrm{hr}$. the downward migratory impulse of those collected at $60-70 \mathrm{~m}$. had ceased, so that when brought up to Io $\mathrm{m}$. there was almost a random movement in each side of the apparatus. However, using Calanus from the same stock for the last experiment at noon a greater percentage was found down in each side; but the values differed markedly from one another, $68 \cdot 4 \%$ had moved down whereas $9 \mathrm{I} \cdot 2 \%$ had remained down. The percentage which had moved down corresponded very closely with the percentage that had moved down in the experiment at noon the previous day $(67 \cdot 2 \%)$, but the percentage which had remained down was very different.

Clearly more experiments on these lines must be performed before one can draw many conclusions; they do, however, give definite evidence of a change in the behaviour of Calanus throughout the $24 \mathrm{hr}$., changes in the proportions of the population moving upward or downward at different times, not the whole population rising and falling together. They also show that the downward migration begins before there can be any marked increase in the light intensity.

\section{Experiments with 'fed' and 'starved' Calanus}

In the hypothesis of 'animal exclusion' already referred to on p. 468 , it was suggested that the vertical migration of plankton animals might be modified by varying concentrations of phytoplankton in the upper layers. Apart from effects on the environment brought about by the plants such as the known 
changes in $\mathrm{pH}$ and oxygen content of the water, or possibly by their excreting some at present unrecognized substance, it was thought that perhaps the behaviour of the animals might be modified according to whether they were well or poorly fed. If the phytoplankton was abundant so that they obtained sufficient food in a short time they might remain for a shorter period in the phytoplankton zone than when it was scarce; or if they had recently been well fed they might not show the same tendency to migrate upwards as those that were 'hungry'. A few experiments were made to compare the vertical migrational behaviour of Calanus which were well fed and those which had been starved. They were preliminary experiments, exploring for the most suitable method, intended to prepare for more systematic ones, and are only included to give a complete record of the work. The results are quite inconclusive and indeed impossible to interpret, both because of the number of variables in so few experiments and because it has later been shown, on p. 508 , that keeping Calanus in the laboratory may have a most disturbing effect upon their behaviour. They do, however, give some indications suggesting future lines of work.

The following was the general procedure in preparing the cultures of 'fed' and 'starved' Calanus, the details of variations being given in Table VI. For a stock of ' $\mathrm{fed}$ ' Calanus about 200 were picked out and placed in about Io 1. of outside sea water to which was added, for different experiments, varying quantities from 50 to I000 c.c. of a medium strength culture of the diatom Nitzschia. The container was darkened and cooled by standing in running water. They were kept for varying periods from 35 to $90 \mathrm{hr}$. For the 'starved' stocks the Calanus were washed in several changes of sea water which had been filtered through a Berkefeld filter and were then placed in a container in about Io 1. of the filtered sea water darkened and kept cool as for the 'fed' stock. In Exps. I0, 23 and 24 both sets were kept in plunger jars instead of ordinary containers.

In Exps. I9 and 24 the behaviour of the 'fed' Calanus was compared with that of outside Calanus collected just before the experiment.

The results are shown in Table VI. With so many variables and in view of the already referred to effect of keeping Calanus in the laboratory, it is not surprising that they are somewhat inconsistent. Three features may be pointed out. The deviations in the results of members of a pair from their mean are more often than not considerably larger (average in $\cdot 8$ ) than the deviations due to the random sampling, the experimental error, found in standard experiments (averaging 4.6 ); their treatment, whether due to feeding and starving or not, has influenced their vertical migrational behaviour. Secondly, it will be seen that four out of five stocks of starved Calanus give very similar results $(6 \mathrm{I} \cdot \mathrm{O}$, $6 \mathrm{I} \cdot 6,6 \mathrm{I} \cdot 8$ and $67 \cdot 4 \%$ ) in spite of being experimented with at different depths of 5 , Io and $30 \mathrm{~m}$. Does starving tend to produce an 'apathy' towards different conditions? Lastly, at $10 \mathrm{~m}$. depth there is seen what might appear to be a 
Table VI. Data Regarding Experiments with 'Fed' and 'Starved' Calanus

\begin{tabular}{|c|c|c|c|c|c|c|c|c|c|}
\hline \multirow{2}{*}{$\begin{array}{l}\text { Reference } \\
\text { no. of } \\
\text { exp. }\end{array}$} & \multirow{2}{*}{$\begin{array}{l}\text { Time and date } \\
\text { of capture of } \\
\text { Calanus }\end{array}$} & \multirow{2}{*}{$\begin{array}{l}\text { Strength of } \\
\text { culture } \\
\text { for 'fed' } \\
\text { Calanus: } \\
\text { c.c. of } \\
\text { Nitzschia } \\
\text { added to } \\
\text { Iol. of } \\
\text { water }\end{array}$} & \multirow{2}{*}{$\begin{array}{l}\text { Length of } \\
\text { time in } \\
\text { culture } \\
\text { in hr. }\end{array}$} & \multirow[b]{2}{*}{$\begin{array}{l}\text { Time and date } \\
\text { of exp. }\end{array}$} & \multirow{2}{*}{$\begin{array}{l}\text { Depth } \\
\text { of exp. } \\
\text { in } \mathrm{m} \text {. }\end{array}$} & \multicolumn{3}{|c|}{$\begin{array}{l}\text { Percentage found in lower compartments. } \\
\text { (The letters } U \text { or } L \text { indicate that the } \\
\text { Calanus were introduced into upper } \\
\text { or lower compartments) }\end{array}$} & \multirow{2}{*}{$\begin{array}{l}\text { Deviation } \\
\text { of the } \\
\text { two per- } \\
\text { centages } \\
\text { from their } \\
\text { mean }\end{array}$} \\
\hline & & & & & & $\begin{array}{c}\text { 'Fed' } \\
\text { Calanus }\end{array}$ & $\begin{array}{l}\text { 'Starved' } \\
\text { Calanus }\end{array}$ & $\begin{array}{l}\text { Outside } \\
\text { Calanus }\end{array}$ & \\
\hline 7 & I030, 9 Aug. & 50 & $45^{\frac{1}{2}}$ & I036, II Aug. & Io & $5 \mathrm{I} \cdot 7(\mathrm{~L})$ & $8 \mathrm{I} \cdot 2(\mathrm{~L})$ & - & $14 \cdot 8$ \\
\hline IO & 0830, 23 Aug. & 100 & $72^{\star}$ & I055, 26 Aug. & Io & $59 \cdot 8(\mathrm{U})$ & $-t$ & - & - \\
\hline 18 & I330, 29 Aug. & 200 & 66 & I032, I Sept. & Io & $85 \cdot 1(\mathrm{~L})$ & $6 \mathrm{I} \cdot 6(\mathrm{~L})$ & - & II $\cdot 8$ \\
\hline 19 & 1330, 29 Aug. & 200 & 68 & I22I, I Sept. & Io & $87 \cdot 2(\mathrm{U})$ & - & $65 \cdot 6(\mathrm{U}) \ddagger$ & $10 \cdot 8$ \\
\hline 23 & I600, 8 Sept. & 200 & $89^{\star}$ & II39, I2 Sept. & 30 & $3 \mathrm{I} \cdot \mathrm{O}(\mathrm{U})$ & $6 \mathrm{I} \cdot 8(\mathrm{U})$ & - & 15.4 \\
\hline 24 & I60o, 8 Sept. & 200 & $9 I^{\star}$ & 1326, I2 Sept. $\$$ & 5 & $77 \cdot 9(\mathrm{U})$ & - & $69 \cdot \mathrm{I}(\mathrm{U}) \ddagger$ & 4.4 \\
\hline 26 & 0930, I2 Sept. & 1000 & $35 \|$ & 1325, I4 Sept. & 30 & $35 \cdot 0(\mathrm{U})$ & $67 \cdot 4(\mathrm{U})$ & - & $16 \cdot 2$ \\
\hline 27 & 0930, I2 Sept. & 1000 & $40 \|$ & I720, I4 Sept. $\S$ & 5 & $50 \cdot 7(\mathrm{U})$ & $6 \mathrm{I} \cdot 0(\mathrm{U})$ & - & $5 \cdot 2$ \\
\hline & & 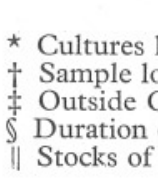 & Calanus ke & $\begin{array}{l}\text { er jars'. } \\
\text { cident to contain } \\
\text { ed on same mor } \\
\text { only } \frac{1}{2} \mathrm{hr} \text {., rema } \\
\text { for } \mathrm{I} 2 \mathrm{hr} \text {. in lab }\end{array}$ & ry b & being 1 & Mean & deviations & $\overline{I I} \cdot 8$ \\
\hline
\end{tabular}


correlation between the behaviour of the 'fed' Calanus and the strength of the Nitzschia culture in which they were kept: the stronger the culture added (50, 100 or 200 c.c.), the larger is the percentage that have moved down or stayed down; this, however, is not supported by the results at 5 and $30 \mathrm{~m}$.

\section{Experiments with waters of different alkalinity}

Loeb (I906) showed that Copepoda became positively phototropic with a reduction in the alkalinity of the water. Rose (1925), however, found that the natural range of $p \mathrm{H}$ had little effect on their reactions to light, though artificial ranges did. He says that the maximum sensitivity to light appears very clearly in the neighbourhood of neutrality. Marshall et al. (1935) found that Calanus can withstand ranges of $p \mathrm{H}$ from 6.7 to 8.5 and that changes in $p \mathrm{H}$ did not affect their respiration rate.

Two experiments were made with artificially produced $p \mathrm{H}$ : Exps. 38 and 39, both at $10 \mathrm{~m}$. depth. In the former Calanus were introduced on one side into more alkaline sea water $(p \mathrm{H} 8.75)$ produced by adding drops of $\mathrm{N} /$ Io solution of $\mathrm{NaOH}$ and their behaviour compared with that of Calanus in outside sea water $\left(p \mathrm{H}^{*} 7 \cdot 90\right)$ in the other side of the apparatus. In the second experiment they were put into less alkaline water $(p \mathrm{H} 7.57)$ and compared with those in outside sea water; the former condition was produced by bubbling $\mathrm{CO}_{2}$ into the sea water and shaking till the required $p \mathrm{H}$ was obtained. In each experiment the Calanus were introduced into the top compartments of the apparatus. The percentages of the populations found down in the lower compartments of each experiment were as follows:

$$
\begin{array}{cll}
\text { Exp. 38: In alkaline water } & p \mathrm{H} 8.75, & 84.0 \% \\
\text { In outside water } & p \mathrm{H} 7.90,80 . \mathrm{I} \% \\
\text { Exp. 39: In less alkaline water } & p \mathrm{H} 7.57,86 . \mathrm{I} \% \\
\text { In outside water } & p \mathrm{H} 7.92, & 78.5 \%
\end{array}
$$

The deviations are well within the experimental error; it is clear that, in spite of the small number of experiments, such differences in $p \mathrm{H}$ do not markedly affect their behaviour.

\section{Experiments with surface and deeper water}

In all the experiments hitherto described the sea water used was obtained from the surface, or as in a few cases, when heavy rain in Loch Fyne or Loch Striven had produced a layer of less saline water at the surface, it was obtained with closing water bottles from $10 \mathrm{~m}$. below the surface. Unless otherwise stated all the Calanus for the experiments have been collected from a depth of $60 \mathrm{~m}$. or more. Two experiments, Nos. 66 and 67, at 10 m. depth, were made to compare the behaviour of Calanus in water from the surface with the behaviour of those in water taken by a water bottle from $30 \mathrm{~m}$. In one 
experiment (No. 66) the Calanus were introduced into the upper compartments of both sides of the apparatus and in the other into the lower compartments. The two experiments were made on the same day at III2 and I3IO hr. The percentages in the lower compartments at the ends of the experiments were as follows:

Exp. 66: in surface water, $85.1 \%$; in 30 metre water, $72.3 \%$ Exp. 67 : in surface water, $83.4 \%$; in 30 metre water, $74.2 \%$

The difference in the results of the two sides is not large, well within the range of experimental error; the fact, however, that the two sides in the two experiments should give such closely similar results suggests that the difference in the nature of the water may have some slight effect: another matter to be investigated further.

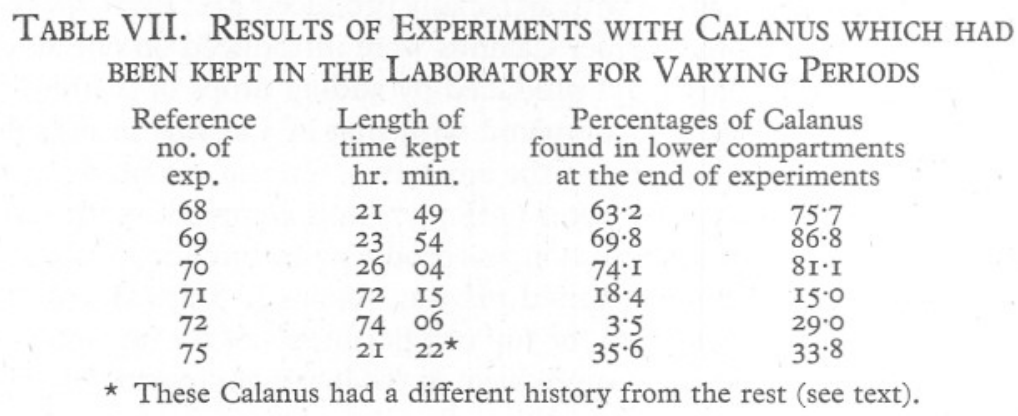

\section{Experiments with Calanus kept for a day or more in the laboratory}

In November 1939, when it was difficult to collect sufficient in the Cumbrae Deep, a quantity of Calanus was caught in Loch Striven, brought to the Millport Station laboratory and kept in large containers until required for experiments. They were kept under similar conditions as those used in the 'fed' and 'starved' experiments except that they were given two changes of outside water each day, the bulk of the old water being siphoned off through a gauze, concentrating the Calanus for a very short time before the fresh sea water was added.

The experiments made with them are those referred to on p. 489; all were made at $10 \mathrm{~m}$. depth, and in each the Calanus were introduced into the upper compartments of the two sides of the apparatus. The results are shown in Table VII together with those of Exp. 75, the Calanus of which had a somewhat different history. Exps. 68-72 were made with Calanus caught on I7 November, brought to the laboratory and kept as described; those used in Exp. 75 were also caught in Loch Striven but on 2I November and kept till the next day in a darkened accumulator jar, with two changes of water, in the cabin laboratory of the station's research boat Nautilus. 
In the series 68-72 we see a marked change in the behaviour of those Calanus kept in the laboratory for more than $70 \mathrm{hr}$. when compared with those kept in a similar manner but for only $2 \mathrm{I}-26 \mathrm{hr}$. In Exp. 75 the Calanus, which were kept under rather different conditions on the boat, but again for only 2I hr. 22 min., gave results more approaching those of the Calanus kept for $70 \mathrm{hr}$. in the main laboratory. This change of behaviour does not appear to be due merely to a lowering of their vitality since the whole of the remainder of the stock, from which the Calanus for Exps. 68-72 were taken, lived healthily in the laboratory for a fortnight and many of them lived for as long as 6 weeks.

\section{Experiments with Calanus in complete darkness}

In these experiments (Nos. 49-5I), which were performed in the daytime in August 1939, the top, bottom and sides of one cylinder were completely covered with black paper so that all light was excluded from it, while the other was left open and normal as a control. It is most unfortunate that only three such experiments were made, and all at $10 \mathrm{~m}$. depth. It was our intention to

\section{Table VIII. Results of Blacked-out Cylinder Experiments}

(Data for blacked-out cylinder in heavy type, for control cylinder in normal type)

\begin{tabular}{|c|c|c|c|c|}
\hline $\begin{array}{c}\text { Reference } \\
\text { no. of } \\
\text { exp. }\end{array}$ & $\begin{array}{l}\text { Total } \\
\text { Calanus } \\
\text { in control } \\
\text { cylinder }\end{array}$ & $\begin{array}{c}\text { Total } \\
\text { Calanus } \\
\text { in blacked-out } \\
\text { cylinder }\end{array}$ & \multicolumn{2}{|c|}{$\begin{array}{l}\text { Percentages of Calanus } \\
\text { found in lower compartments } \\
\text { at the end of exps. }\end{array}$} \\
\hline $\begin{array}{l}49 \\
50 \\
51\end{array}$ & $\begin{array}{l}68 \\
68 \\
36\end{array}$ & $\begin{array}{r}74 \\
157 \\
200\end{array}$ & $\begin{array}{l}72 \cdot 1 \\
73 \cdot 5 \\
75 \cdot 0\end{array}$ & $\begin{array}{l}59 \cdot 7 \\
8 \mathrm{r} \cdot 5 \\
8 \mathrm{r} \cdot 0\end{array}$ \\
\hline & & Averas & 73.5 & $74 \cdot I$ \\
\hline
\end{tabular}

carry out many more at different depths, but the war intervened. In Exps. 49 and 50 the Calanus were put into the top compartment of each cylinder, and in Exp. $5 \mathrm{I}$ into the bottom compartments. The results are given in Table VIII, where the data relating to the blacked-out cylinder are shown in heavy type. Each experiment was of $\mathrm{I} \mathrm{hr}$. duration.

Exp. 49 was made at I04I hr. off Millport with Calanus caught at $0830 \mathrm{hr}$. from $60-70 \mathrm{~m}$. in the Cumbrae Deep; Exps. 50 and $5 \mathrm{I}$ were made at II $39 \mathrm{hr}$. in Upper Loch Fyne with Calanus caught also at $0830 \mathrm{hr}$. from $60-70 \mathrm{~m}$. In spite of the difference in the origin of the stocks used the percentage down in the open control cylinder in all three experiments is remarkably similar; the behaviour of the two stocks in complete darkness is markedly different: $59 \cdot 7 \%$ down for the Cumbrae stock as compared with $8 \mathrm{I} \cdot 5$ and $8 \mathrm{I} \cdot 0 \%$ down for the Loch Fyne stock.

With either stock, however, there is really no very marked difference between the results of the control and darkened sides: with the Cumbrae stock the percentage down on the darkened side is $\mathrm{I}^{2} \cdot 4$ less than that of the control, in Loch Fyne those of the darkened side are 8.0 and 6.0 more than those of the 
control side. The average deviations of the pairs from their mean is only $4: 4$, no more than the average experimental error of standard experiments. Further, the averages of the percentages of Calanus moved down or stayed down in the darkened side of the apparatus is $74 \cdot \mathrm{I} \%$; this compares very closely with the average of the percentages of Calanus moved down or stayed down in the control sides of these experiments, $73.5 \%$, and with a similar average for all standard experiments at $\mathrm{I0} \mathrm{m} ., 7 \mathrm{I} \cdot 8 \%$.

In spite of this the results of Exps. 50 and $5 \mathrm{I}$ appear to show quite clearly that the distribution of the Calanus in the dark is not just a chance one due to movement at random. In Exp. 50, being introduced into the lower compartment, $8 \mathrm{I} .5 \%$ of the Calanus stayed down and $18.5 \%$ actively moved up; in Exp. 5I, being introduced into the upper compartment, $19.0 \%$ stayed up and $8 \mathrm{I} \cdot 0 \%$ moved down. The same stock gave just as close results in the open side but showed slightly higher values for those having moved up or stayed up. The difference between the presence of light and its complete absence has made a real difference, but not a very marked one. It is surely very significant that in complete absence of light a population of Calanus will still segregate into two groups of individuals: one moving up and the other moving down-and that in two experiments with the same stock at the same depth the proportions up and down vary only by $0.5 \%$.

These results, which are very puzzling in view of the mirror experiments, if confirmed by others, would seem to show that light has only a little to do with the proportions found up or down at the end of an experiment. It will be important to find out what happens when such black-out experiments are repeated at depths of $\mathrm{I}, 5,20$ and $30 \mathrm{~m}$. as we had originally intended. Actually there are two experiments which were made with the long-tube Apparatus No. 2, when the whole tube was blacked-out, and may in fact be taken to correspond to experiments made with the blacked-out cylinder of Apparatus No. I; these were performed just below the surface. Further discussion of the dark-cylinder results just given will therefore be reserved until those with the long tube have been examined in the next section.

\section{Experiments with the long-tube Apparatus No. 2}

Only five experiments, Nos. 40-44, were made with Calanus in the longtube Apparatus No. 2, the construction of which has been described on pp. 474-5, and illustrated in Pl. XI, figs. I, 2. They were made off Millport on 20, $2 \mathrm{I}$ and $22 \mathrm{July}$, 1939 with Calanus collected from $60-70 \mathrm{~m}$. in the Cumbrae Deep on the morning of each day at $0830 \mathrm{hr}$.; in each experiment the top of the apparatus was sunk just below the surface. Many more such experiments must be made at different depths and would have been but for the war; few as they are these five experiments are included here because it is considered that their results must be taken into account in any attempt to interpret the results with Apparatus No. I. 
Apparatus No. 2, it will be remembered, consists essentially of a long vertical tube made up of seven sections, each being a glass cylinder corresponding in diameter and length to one of the upper or lower compartments of Apparatus No. I. We will denote these seven consecutive compartments by the letters $A, B, C, D, E, F$ and $G$; they are linked to one another by a series of short connecting pieces fitted with gauze trapdoors which can all be opened or closed together by a control wire. The Calanus may be introduced into any one compartment, and then by opening the trapdoors at the beginning of an experiment they are free to migrate up and down the whole length of the tube; by closing the trapdoors at the end of the experiment we can separate any migration column into seven parts for subsequent analysis. The method of extracting the Calanus at the end of an experiment has already been described (p. 475).

The results of the five experiments are shown in Table IX and Text-fig. I9; each was of I hr. duration. Throughout the figures refer only to Calanus Stage V; the numbers of adults and other stages were too small to be considered.

At the start of Exp. 40 the Calanus, 98 of them, were placed in the top compartment $A$ and none in the lower ones; at the end of the hour only eighteen remained in $A$, smaller numbers in $B$ to $F$ and thirty-nine in the bottom compartment $G$. The numbers in each compartment, together with the percentage proportion of the whole column that they represent, are given for each experiment in the table.

In the next experiment 340 Calanus were put into the bottom compartment $G$. After an hour it was found that 322 had remained there and small numbers had moved up into all the others, four reaching the top compartment $A$; the total length of the tube is just $\mathrm{I} 2 \mathrm{ft}$.

In Exp. 42 the whole tube was blacked out so that the column of water was in complete darkness, and 137 Calanus were put at the start into the bottom compartment $G$. At the end I33 $(97.0 \%)$ remained in $G$ and only one went up as far as $D$, none was found in $E$ but three in $F$.

Exp. 43 was blacked out just as in Exp. 42, but the Calanus, I25, were introduced at the start into the top compartment $A$; at the end only four remained in $A$, small numbers in $B, C, D, E$ and $F$, and ninety-six had gone down to $G$.

Exps. 40 and 4I were carried out on the same day with Calanus from the same sample; Exps. 42 and 43 were made the next day with Calanus from another sample but caught at the same place, depth and time of day. It was impossible to do all four experiments with Calanus from the same sample on the same day because of the time necessary to prepare the completely blacked-out tube. The object of Exps. 40 and 4I, as planned, was to compare the vertical movement of Calanus upward and downward, as had been done in the two sides of Apparatus No. I, but through a greater range of depth; to do this it was 


\section{Table IX. Showing the Distribution of Calanus Stage V in the DifFerent COMpartments $A-G$ IN the Long-Tube Apparatus No. 2 AT the BeginNing (a) AND END $(b)$ of Exps. 40-44.}

The whole tube in Exps. 42 and 43, and compartments $A, B, C$ and $D$ in Exp. 44, were covered with black paper to exclude all light.

Exps....

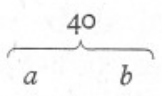

Time (hr.)... IIII I2II

Compartments

$$
A
$$

$B$

$C$

$D$

E

F

G

$\begin{array}{rr}98 & 18 \\ \mathbf{1 0 0} \% & \mathbf{1 8 . 4} \%\end{array}$

8

9

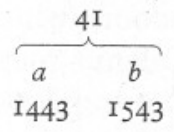

6
$-\quad 6 \%$

$\begin{array}{r}8.1 \% \\ -\quad 9 \% \\ \hline 9.2 \%\end{array}$

\begin{tabular}{c}
$9.9 \%$ \\
$-\quad 9.2 \%$ \\
\hline
\end{tabular}

9.2 \%

$$
\begin{array}{r}
39 \% \\
-\quad 39 \%
\end{array}
$$

$94.7 \%$

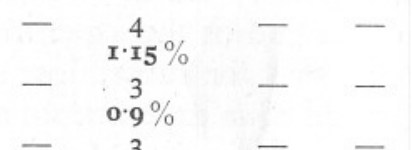

0. $9 \%$

2

0.6\%

o. $6 \%$

4
$\mathbf{r} \cdot \mathbf{5}$

\section{2}

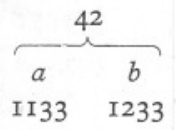

$\stackrel{\text { I }}{0.75 \%}$

075
$-\quad-$

-

I37 $\quad 2.25$

100 \% $97.0 \%$

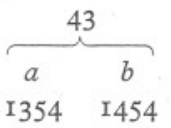

$\begin{array}{cc}\text { I25 } & 4 \\ \text { I00 } \% & 3 \cdot 2 \% \\ - & 7\end{array}$ 7
$5.6 \%$

2
$+.6 \%$

I. $6 \%$

. 1 \%

I0

$8 \cdot 0 \%$

5
$4.0 \%$

46

96
$76.8 \%$

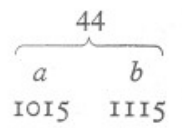

- 25 25
I $8.8 \%$ IO 14 10.5\% I6 $\mathbf{1 0 0} \% \mathbf{1 2} \cdot \mathbf{0} \%$ 35
$\mathbf{2 6 . 4} \%$ 8 $6.0 \%$ $-\quad 25$
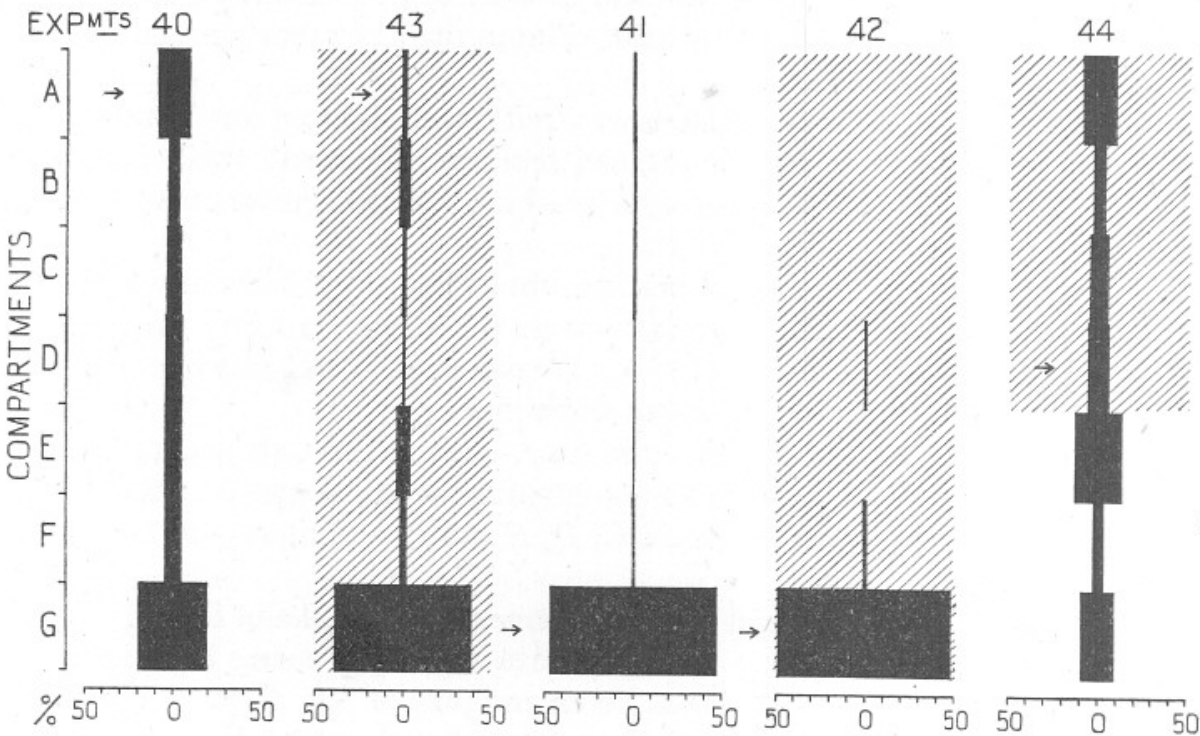

Text-fig. 19. Results of Exps. 40-44 made with Apparatus No. 2. The arrows point to the compartment into which the Calanus were introduced at the beginning of each experiment. The width of each blacked-in histogram represents the percentage of the population found in each compartment at the end of an experiment. The shaded areas indicate that the whole apparatus or part of it was blacked out for purposes of the experiment. Exp. 43 is placed next Exp. 40 to make comparison easier. For further explanation see text. 
necessary to use the same stock of Calanus for such a pair of experiments. Since Exps. 40 and 4I were taken with Calanus from one stock, and Exps. 42 and 43 with those from another, the differences between their behaviour in Exps. 40 and 43 or again between $4 \mathrm{I}$ and 42 may be due either to the effect of light and darkness or to the Calanus being of different origin. In future such experiments must be made with Calanus from the same stock, but to do this satisfactorily two separate long tubes would be necessary, one uncovered as a control, the other already blacked out. The blacking out of the tube sections and the precautions taken to cut out light with baffle plates and screens, as it was assembled and the Calanus introduced without being exposed to light, need not be described in detail; the difficulties, however, were considerable and the process took time.

Exp. 44 was of a special kind and will be more conveniently dealt with after we have considered the relation of the results of the four experiments just described to those obtained with Apparatus No. I.

If we compare Exp. 40 with a standard one using Apparatus No. I which has only the two compartments, upper $A$ and lower $B$ (or $\alpha$ and $\beta$ ), then the top compartments $A$ of each, into which the Calanus have been introduced, will correspond; further, all the Calanus found in the sections $B, C, D, E, F$ and $G$ in Apparatus No. 2 will correspond to those which would be found at the end of an experiment in the lower compartment $(B)$ of Apparatus No. I. This would correspond to an Apparatus No. I result of $8 \mathrm{I} \cdot 6 \%$ moved down. Had the tube of Apparatus No. 2 been still longer it seems likely that many of the thirty-nine found in $G$ would have descended deeper. The long tube amplifies the information provided by Apparatus No. I: the population is not simply analysed into those which stay up and those which go down-but the latter are seen to be made up of individuals graded in their reactions during a I hr. period.

Similarly, if we compare Exp. 4I to a standard experiment with Apparatus No. I, then the compartment $G$, into which the Calanus were introduced, will correspond to the compartment $\beta$ of No. I and the Calanus found in the compartments $F, E, D, C, B$ and $A$ of No. 2 will correspond to those that would be found in compartment $\alpha$ at the end of an experiment. We would have a result in Apparatus No. I of 94.7\% having stayed down and 5.3\% having moved up. Since the results of these two experiments (Nos. 40 and 4 I) can be considered to provide data strictly comparable with those from standard experiments, these percentages have been inserted into the graphs in Textfigs. 7 and 8, shown as squares instead of circles to distinguish them from the rest, Exp. 40 being entered as at $\frac{1}{2} \mathrm{~m}$. depth and Exp. $4 \mathrm{I}$ as at $3 \frac{1}{2} \mathrm{~m}$. depth. ${ }^{1}$

\footnotetext{
1 In these experiments the top of the apparatus was just below the surface so that the bottom of compartment $A$ and the top of compartment $G$ will respectively be $\frac{1}{2}$ and $3 \frac{1}{2} \mathrm{~m}$. below the surface; it is these points which correspond to the middle of Apparatus No. I when the experiments are compared.
} 
If we treat the darkened Exps, 42 and 43 in the same way we have results for comparison with those of Apparatus No. I as follows: Exp. 42 gives $97.0 \%$ stayed down $(=\beta)$ and $3 \%$ moved up $(=\alpha)$; Exp. 43 gives $96.8 \%$ moved down $(=B)$ and $3.2 \%$ stayed up $(=A)$. The two populations were from the same stock, but selected at random; it is remarkable that the percentages should be so closely similar. Exp. 42 corresponds to an experiment with Apparatus No. I at $3 \frac{1}{2} \mathrm{~m}$. and Exp. 43 with one at $\frac{1}{2} \mathrm{~m}$., as just explained. The three experiments with blacked-out cylinders performed with Apparatus No. I (described in the preceding section) were all at $\mathrm{IO} \mathrm{m}$. depth and gave percentage values for Calanus, moved down or stayed down, having an average of $74.1 \%$; this we have seen corresponded closely with the average for their control sides which was $73.5 \%$. The results of the two blacked-out experiments (Nos. 42 and 43) just described, regarded as results with Apparatus No. I, at $3 \frac{1}{2}$ and $\frac{1}{2} \mathrm{~m}$., give percentages down of 97.0 and 96.8 respectively compared with those of the uncovered cylinders at the same depths of $94 \cdot 7$ and $8 \mathrm{r} \cdot 6 \%$. These results, so expressed, again show no significant difference. Although one can see some difference between the behaviour of the Calanus over the whole length of the long tube when it is uncovered and when it is blacked out, one is led once more to doubt if light is in fact a predominating influence; yet how can such a view be reconciled with the results of the mirror experiments? The results of the fifth long-tube experiment (No. 44) may now be considered.

In Exp. 44 the four compartments $A, B, C$ and $D$ were blacked out, but the lower three, $E, F$ and $G$, were uncovered. The Calanus, 133 of them, were introduced into compartment $D$. At the end of the hour's experiment they were distributed as shown in the last column of Table IX; $12.0 \%$ remained in $D, 36.8 \%$ had moved upwards (10.5\% into $C, 7.5 \%$ into $B$ and $18.8 \%$ reached the top compartment $A$ ) and $51 \cdot 2 \%$ moved downwards ( $26 \cdot 4 \%$ into $E$, $6.0 \%$ into $F$ and $18.8 \%$ into the bottom compartment $G$ ). Certainly this peculiar distribution must be due to the distribution of light and shade which is peculiar to the experiment. Light could only enter the darkened part of the tube from below; here conditions were similar to those in the mirror experiments except that the light was scattered light and not the direct overhead illumination reflected upwards. Some of the Calanus apparently responded to this and moved upwards away from the light, for far more moved up than did so in a completely blacked-out tube; others, the largest number in any compartment $(26 \cdot 4 \%)$, were found in $E$ in the shade just below the darkened part; the rest went further down into compartments $F$ and $G(6.0$ and $18.8 \%$ respectively).

Exp. 44, adding support to the evidence from the mirror experiments with Apparatus No. I, certainly shows that light is a factor influencing the vertical migrational behaviour of Calanus. Schallek (1943), as the result of his laboratory experiments with the copepod Acartia tonsa, has put forward the view that such animals only react to direct light and in diffuse light sink passively under 
the influence of gravity. Our Exp. 44 does not support this in regard to Calanus. In any further consideration of the problem, we must bring together in review the results of all the experiments with both types of apparatus; the place for this is in the general discussion which follows.

\section{General Discussion and Conclusions}

The standard experiments in the daytime, between 0800 and I $600 \mathrm{hr}$., with Apparatus No. I (pp. 480-95), showed that populations of Calanus, caught at depths of 60 or more metres and experimented with at depths of I, 5, IO, 20, 30 and $40 \mathrm{~m}$., behaved in the following manner: at each successive depth the members of the population segregated into those which moved upwards and those which moved downwards. The proportions of those moving upwards or downwards, while showing considerable variation between results on different days, on an average increased or decreased respectively in direct relation to depth and not in relation to diminished light intensity. ${ }^{1}$

This would appear to indicate that Calanus, and possibly other animals which show a similar vertical migration, have a sense of depth. Whether they have some as yet undiscovered pressure organ for this purpose or whether there is some metabolic chemical reaction the rate of which varies with pressure remains to be investigated. The possibility that they react to chemical differences in the water which vary with depth seems unlikely from experiments made with waters either of different alkalinity or taken from different depths (pp. 507-8). It is likely that chemical differences in the water may modify their behaviour-but hardly that such differences will form a regular gradient sufficiently often to produce an average behaviour reaction directly correlated with depth.

The mirror experiments (pp. 495-500), in which the natural overhead illumination was reflected vertically upwards into an otherwise darkened cylinder, showed that light is an important factor: that it is towards or away from the light that Calanus moves at the different depths rather than in response to gravity. But again these experiments do not support the view that the response varies in relation to differences in the intensity of the light.

Experiments performed at night or dusk (pp. 500-2) showed results very similar to those of daylight experiments, again suggesting that the difference in the intensity of the light is of little significance.

Experiments repeated at 3-hourly intervals at Io m. depth (pp. 502-4) showed that there is a change in the behaviour of Calanus with the passage of time through a $24 \mathrm{hr}$. period. They showed a marked increase in the proportion of Calanus moving up with the approach of night, and an equally marked downward movement after midnight but before any apparent increase in light intensity. At $0600 \mathrm{hr}$. some $95 \%$ were moving downward.

\footnotetext{
1 See however, Addendum, p. 52 r.
} 
Experiments with 'fed' and 'starved' Calanus (pp. 504-7) were too few and too varied; they gave inconclusive results, but suggested that physiological changes may alter the animal's more normal behaviour to some extent. Experiments with Calanus kept for periods of $\mathrm{I}-3$ days in the laboratory showed marked changes in the behaviour of those kept longest (pp. 508-9).

Two outstanding puzzles are presented. First, how is it that a population of Calanus, which was known to have been caught at a depth of some $60 \mathrm{~m}$. or more at 0800 or $0900 \mathrm{hr}$., should segregate out into proportions apparently positively and negatively phototactic when experimented with at varying depths much nearer the surface, i.e. from I to $40 \mathrm{~m}$. deep, and further that the positive and negative proportions should vary directly with depth? How is it that in nature they did not take up a depth distribution in accordance with these phototactic tendencies, being invariably found by us at these times in deep water?

The second outstanding puzzle is that in experiments, made with both Apparatus No. I and No. 2, in which the Calanus were in complete darkness, there was no fundamental difference between their behaviour in darkness and their behaviour in the control uncovered cylinders at the two ranges of depth at which the experiments were made: $0.5-3.5$ and Io m. (pp. 509-I4). How can these results be reconciled with those of the mirror experiments and of Exp. 44 with the long tube (p. 5I4) which clearly show the importance of light?

As already stated in the introduction, the experiments would have been carried very much further before the publication of results if the war had not intervened. It is not our intention at present to elaborate a theory to cover all the results; this must wait until a number of hypotheses suggested by the work have been tested by further experiment. It may be of interest, however, to outline one such tentative hypothesis, and valuable if it provokes discussion and criticism.

May it not be possible that the Calanus have a diurnal rhythmic habit of vertical migration: that as evening approaches, whether or not started off by a change of light intensity which is most rapid at sunset (cf. Clarke's experiments with Daphnia, 1930), they move upwards, and after a certain time spent nearer the surface make their descent to deeper water again where they remain until the upward urge sets in once more? Now if this is so, and if artificially they are removed from their normal depth in the daytime and carried upwards, is it not possible that they may react as if they had themselves made the migration, endeavouring to distribute themselves in relation to depth as they would have done if they had made the journey upwards in the evening? May it not be that in nature, having started this migration, they move upwards towards the light, irrespective of its intensity, until certain lesser depths are reached which satisfy the migrational urge of different particular individuals on that particular day? 
If this hypothesis is correct then we could reconstruct from our results a general picture of their more normal distribution at night. From Table I we see the average percentage proportions moving or staying up at each successive depth; thus between I $\mathrm{m}$. and the surface would be $\mathrm{I}_{4} .6 \%$ of the population, between 5 and I $\mathrm{m}$. II $4 \%$ or $2.85 \%$ per $\mathrm{m}$. of depth, between Io $\mathrm{m}$. and $5 \mathrm{~m}$. $2.2 \%$ or $0.44 \%$ per m. of depth, and so on. These percentage values per metre depth are shown graphically in Text-fig. 20 down to a depth of $40 \mathrm{~m}$. Nicholls (1933), using vertical closing nets in the Clyde sea area (Loch Fyne) in July,

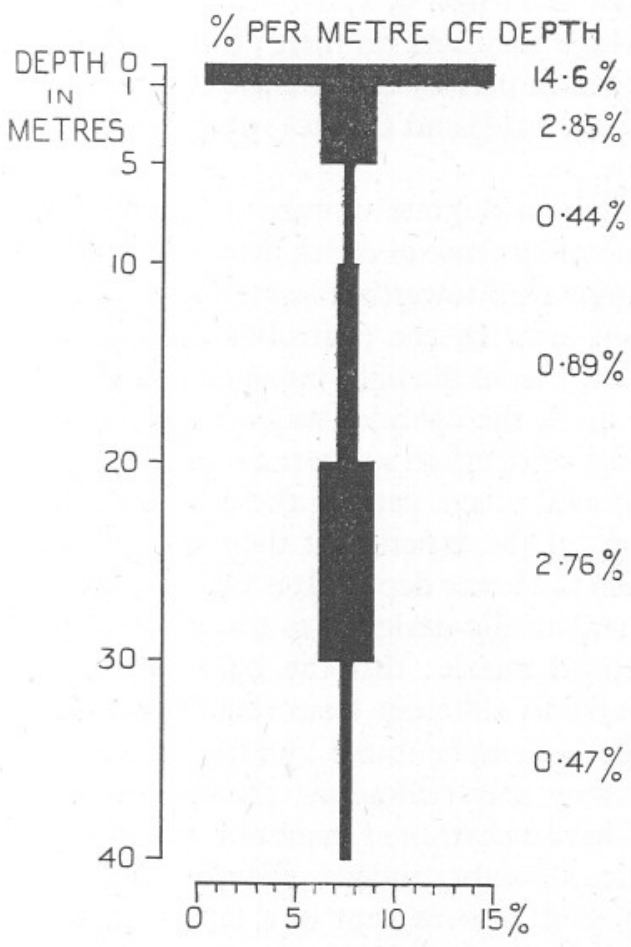

Text-fig. 20. Hypothetical distribution at night. For explanation see text.

found the distribution of Calanus Stage V at $2200 \mathrm{hr}$. as follows: $\mathrm{I} 7 \cdot \mathrm{I} \%$ between 0 and $30 \mathrm{~m}$., $0.6 \%$ between 30 and $60 \mathrm{~m} ., 0.9 \%$ between 60 and $80 \mathrm{~m} ., 6.4 \%$ between 80 and $100 \mathrm{~m} ., 45.2 \%$ between I0O and I $20 \mathrm{~m}$. and $29.5 \%$ below I $20 \mathrm{~m}$. At oIO0 hr. for similar ranges of depth he found percentages as follows: I6.7, 7.3, 0.9, 4.7, 54.5 and I5.9. The bulk of his Calanus Stage V remained below I00 $\mathrm{m}$. throughout his $24 \mathrm{hr}$.; but the distribution he found in his population above $80 \mathrm{~m}$., the region from which our samples were taken, on the whole was not unsimilar to our hypothetical reconstruction suggested above.

Physiological changes may govern the variation in depth to which individuals may go on different days; the 'fed' and 'starved' experiments have given a 
hint of such a modification of behaviour. It may be that if light plays the part of attracting them upwards when once the evening migrational urge has set in, they may be inclined, if anything, to go slightly farther up in a higher light intensity than they would in a lower. Such a view might be supported by (I) the slight but positive correlation found between the percentages in the lower compartments of the apparatus at 5 or $10 \mathrm{~m}$. depth and the Secchi disk readings (p. 494), and (2) the fact that the percentages in the lower compartments at night were on the whole higher than those in the daytime at corresponding depths (cf. Text-figs. 9, I7).

The depth to which they sink on their downward morning migration may indeed be determined in part by the intensity of the light as suggested by the work of Russell (1926, 1934) and Clarke (1933); we have no evidence from our work regarding this.

If when they begin to migrate upward it is movement towards the light which guides them until a sense of depth determines how far they go, how is it that they go still higher up towards a lesser depth in the mirror experiments when normally, as shown by the control side of the apparatus, they would move downwards away from the light into a greater depth? It is possible that, with the reversed light, the cylinder was not long enough to allow them to appreciate the change of depth in so short a range. Their movement away from the light would normally have carried them to a greater depth-under the abnormal conditions of the experiment their movement away from the light actually carried them to a lesser depth. It is idle to speculate; more experiments must be made systematically designed to test the various points suggested.

What of the second puzzle: that the behaviour of Calanus in complete darkness is not markedly different from their behaviour in light? Again we can suggest an hypothesis to be tested by experiment. In the absence of light it is possible that they may still adjust themselves to depth by reaction to gravity. They may have a rhythm of migration which will assert itself for some time in the absence of light; indeed, Esterly (19I7) demonstrated such a rhythm in the copepod Acartia kept in a tall jar in darkness all day in the laboratory. We may recall other similar rhythms recorded for marine animals, e.g. the tidal rhythm in Convoluta roscoffensis observed by Gamble \& Keeble (I903) for several days after specimens had been removed to the laboratory or the diurnal rhythm of luminescence observed by Moore (1909) in plankton animals kept in the dark. There is perhaps some evidence in support of this hypothesis from the results of the long-tube experiments shown in Table IX (p. 5I2). Comparing Exps. 4I and 42, in which the Calanus were introduced into the bottom compartment of each, we see that practically the same proportion has moved up from this compartment in each, 5.3 and $3 \%$; but that in the uncovered tube some have travelled to the very top towards the light, whereas in the complete darkness of Exp. 42 none has travelled more than half-way. Similarly in Exps. 40 and 43, in which the Calanus were introduced 
into the top compartment of each, $8 \mathrm{I} \cdot 6 \%$ moved down from that compartment in the uncovered tube and $96.8 \%$ in the completely blacked-out tube, but in the former only $39.8 \%$ reached the bottom compartment, whereas in the latter, in the dark, $76.8 \%$ went to the bottom. In Text-fig. I9 (p. 5I2) the percentage proportions in the different compartments at the end of Exps. 40-44 are shown graphically, the arrows indicating the compartments into which they were originally introduced; Exp. 43 is placed next to Exp. 40 with which it compares, Exp. 42 comparing with Exp. 4 I. It is seen that in general their behaviour in the darkened tubes (Exps. 43 and 42) is similar to that in the uncovered tubes, but that they tend to go somewhat deeper in the absence of light. Again this seems to fit in with the suggestion that, while it is the depth itself which is the major factor in determining their upward distribution, they may tend to be a little higher up in a greater light intensity than in a lesser. The distribution in Exp. 43 is more like that in Exp. 40; they have not all sunk from compartment $A$ in spite of the complete absence of light. The distribution in Exp. 42 is most like that in Exp. $4 \mathrm{I}$; in spite of the darkness some have migrated upwards.

The problem is a complex one, but that it can in time be solved by experimental analysis cannot be doubted. It would seem that the experiments must be made in the sea itself since depth appears to be such an important factor and since other conditions in the laboratory present so many artificialities. The experiments here described are to be regarded as but the beginning of such an approach.

\section{SUMMARY}

Experiments were made with apparatus, largely of glass, specially designed to study the vertical movements of plankton animals under as natural conditions as possible at various depths in the sea. The animals were introduced in darkness into the apparatus which was kept covered with a black cloth until it was lowered below the surface so that from the time they were caught, in the opaque tow-net bucket, to the time they were returned to the sea in the apparatus, they were never subjected to above-surface illumination. The experiments were begun and ended at the required depth by the dispatch of messenger weights down the suspending wire from above. The copepod Calanus finmarchicus (Gunn.) was used, but a few experiments were also made with another copepod, Euchaeta norvegica Boeck.

The apparatus is described in detail; it takes two forms. No. I consists of two vertical parallel glass cylinders $A B$ and $\alpha \beta$ closed at the top by a glass plate and at the bottom by a metal one, and having trapdoors at the middle of each which divide them into upper and lower compartments, $A$ and $B$ in one, and $\alpha$ and $\beta$ in the other. They were filled with sea water and the copepods were introduced into only one compartment of each cylinder, in standard 
experiments into $A$ on one side and $\beta$ on the other. The apparatus was now lowered to the required depth and the trapdoors opened so that the copepods were free to move up or down the whole length of the cylinders. At the end of an experiment the trapdoors were closed again so that the percentage proportions that have moved up or down under different conditions could be estimated. In experiments other than standard, one side was left normal as a control and in the other the conditions were altered for the purpose of the experiment, e.g. darkened or the $\mathrm{pH}$ of the water increased or decreased. Apparatus No. 2 is a modification, a long tube of seven compartments each separated by a controlled trapdoor.

Standard experiments in the daytime (between 0800 and I600 hr.) made at depths of I, 5, IO, 20, 30 and $40 \mathrm{~m}$. showed that populations of Calanus, caught at a depth of $60 \mathrm{~m}$. or more, segregated into those moving upwards and those moving downwards, and that their proportions on an average increased and decreased respectively in direct relation to depth and not to light intensity. Calanus would appear to have a sense of depth. ${ }^{1}$ Experiments at 50 and $100 \mathrm{~m}$. were too few to give conclusive results.

Mirror experiments, in which the natural overhead illumination was reflected vertically upwards from below (against gravity) into an otherwise darkened cylinder, showed that light is an important factor. It is towards or away from light that Calanus moves rather than in response to gravity.

Experiments at night showed results on the whole similar to those in the daytime.

Experiments repeated at 3-hourly intervals at $10 \mathrm{~m}$. depth showed that there is a marked change in the behaviour of Calanus with the passage of time through a $24 \mathrm{hr}$. period: an upward movement with the approach of night and a downward movement with the approach of day.

In other experiments those made with 'fed' and 'starved' Calanus were too few and varied to give conclusive results. Those made with waters of different $p \mathrm{H}$ and waters from different depths revealed no significant difference in the behaviour of Calanus.

A few experiments made in complete darkness are puzzling in that the behaviour of Calanus is not markedly different in the dark from that in the light: a tentative explanation is suggested in the general conclusions.

The few experiments made with the long-tube Apparatus No. 2 enable the vertical migrational behaviour of Calanus to be analysed in greater detail.

The experiments must be continued further before a theory can be elaborated to cover all the observations; some tentative hypotheses are, however, suggested in the general conclusions. This account, to record the results so far obtained, was thought desirable since the work was interrupted by the war, and it is uncertain when it may be continued (see the preface).

\footnotetext{
1 See however Addendum on next page.
} 


\section{ADDENDUM}

The late Lieut. Neil Paton made some experiments on freshwater plankton animals with both Apparatus No. I and No. 2 in Lake Windermere in the summer of 1939, but was not able to analyse the results before taking his commission in the R.N.V.R. Since going to press Mr D. H. Cushing in my Laboratory (at Oxford) has completed their analysis. $\mathrm{He}$ finds that Cyclops strenuus (but not Diaptomus gracilis) has a very similar behaviour to that of Calanus in that the proportions moving up or down in different experiments (in Apparatus No. I) appear directly correlated with the depths at which the experiments are made. Some results with Cyclops in Apparatus No. 2 however seem to tell against the 'sense of depth' hypothesis. He suggests however that instead of behaving in direct relation to depth, the animals are reacting in relation to the logarithm of the light intensity at the different depths and so giving the appearance of a straight line correlation with depth. While at present it does not seem possible to reconcile such a view with some of the Calanus experiments described in the foregoing paper, this note is added to emphasize that the 'sense of depth' hypothesis must be regarded as entirely tentative until both it and that suggested by $\mathrm{Mr}$ Cushing have been tested by further experiments specially designed for the purpose. It is hoped that these will be made in the coming year.

\section{REFERENCES}

Clarke, G. L., I930. Change in phototropic and geotropic signs in Daphnia induced by changes in light intensity. Fourn. Exper. Biol., Vol. 7, pp. I09-3I.

- 1933. Diurnal migration of plankton in the Gulf of Maine and its correlation with changes in submarine irradiation. Biol. Bull., Vol. 65, pp. 402-36.

- I934a. Further observations on the diurnal migration of copepods in the Gulf of Maine. Biol. Bull., Vol. 67, pp. 432-55.

- I934b. The diurnal migration of copepods in St George's Harbour, Bermuda. Biol. Bull., Vol. 67, pp. 456-6o.

- 1936. Light penetration in the western North Atlantic and its application to biological problems. Cons. Perm. Internat. Explor. Mer, Rapp. et Proc. Verb., Vol. IOI, 2ne partie, No. 5 .

Esterly, C. O., I9II. Diurnal migrations of Calanus finmarchicus in the San Diego region during 1909. Intern. Rev. Hydrobiol. Hydrogr., Vol. 4, pp. I40-5I.

- I9I2. The occurrence and vertical distribution of the Copepoda of the San Diego region. Univ. Calif. Public. Zool., Berkeley, Vol. 9, pp. 253-340.

- I917. Specificity in behaviour and relation between habits in nature and reactions in the laboratory. Univ. Calif. Public. Zool., Berkeley, Vol. I6, pp. 38192.

- I9I9. Reactions of various plankton animals with reference to their diurnal migrations. Univ. Calif. Public. Zool., Berkeley, Vol. I9, pp. I-83. 
Gamble, F. W. \& Keeble, F., I903. The bionomics of Convoluta roscoffensis. Quart. fourn. Micro. Sci., Vol. 47, pp. 363-43I.

Gardiner, A. C., I933. Vertical distribution in Calanus finmarchicus. Fourn. Mar. Biol. Assoc., Vol. I8, pp. 576-6ro.

Hardy, A. C., I936. Plankton ecology and the hypothesis of animal exclusion. Proc. Linn. Soc., Session 1935-6, Pt. 2, pp. 64-70.

- 1938. Change and choice: a study in pelagic ecology. In Evolution: Essays on Aspects of Evolutionary Biology. Oxford: Clarendon Press.

HARDY, A. C. \& Gunther, E. R., I935. The plankton of the South Georgia whaling grounds and adjacent waters, I926-7. Discovery Reports, Vol. XI, pp. I-456.

Johnson, W. H., 1938. The effect of light on the vertical movements of Acartia clausi (Giesbrecht). Biol. Bull., Vol. 75, pp. I06-I8.

LoEB, J., I906. Ueber die Erregung von positivem Heliotropismus durch Saure, insbesondere Kohlensaure und von negativem Heliotropismus durch ultraviolette Strahlen. Arch. ges. Physiol., Vol. II5, pp. 564-8I.

Marshall, S. M., Nicholls, A. G. \& OrR, A. P., I935. On the biology of Calanus finmarchicus. Part IV. Oxygen consumption in relation to environmental conditions. Fourn. Mar. Biol. Assoc., N.S., Vol. 20, pp. I-27.

Michael, E. L., I9II. Classification and vertical distribution of the Chaetognatha of the San Diego region. Univ. Calif. Public. Zool., Berkeley, Vol. 8, pp. 2 I-I86.

- I913. Vertical distribution of the Chaetognatha of the San Diego region in relation to the question of isolation versus coincident distribution. American Naturalist, Vol. 47, pp. 17-49.

MOORE, B., I909. Observations on certain marine organisms of (a) variations in relation to light and $(b)$ a diurnal periodicity of phosphorescence. Biochemical Fournal, Vol. 4, pp. I-29.

Murray, J. \& HJort, J., I9I2. The Depths of the Ocean. London: Macmillan and Co.

Nicholls, A. G., I933. On the biology of Calanus finmarchicus. III. Vertical distribution and diurnal migration in the Clyde Sea-area. Fourn. Mar. Biol. Assoc., N.S., Vol. I9, pp. 139-64.

Poole, H. H. \& Atkins, W. R. G., I926. On the penetration of light into sea water. Fourn. Mar. Biol. Assoc., N.S., Vol. I4, pp. I77-98.

Rose, M., I925. Contribution à l'étude de la biologie du plankton, le problème des migrations verticales journalières. Archiv. Zool. Expér. Génér., Vol. 64, Fasc. S, pp. 387-542.

RUSSELL, F. S., I925. The vertical distribution of marine macroplankton. An observation on diurnal changes. Fourn. Mar. Biol. Assoc., N.S., Vol. I3, pp. 769-809.

- I I26. The vertical distribution of marine macroplankton IV. The apparent importance of light intensity as a controlling factor in the behaviour of certain species in the Plymouth area. Fourn. Mar. Biol. Assoc., N.S., Vol. I4, pp. 4I540.

- - 1927. The vertical distribution of plankton in the sea. Biological Reviews, Vol. 2, pp. $213-62$.

- I I $28 a$. The vertical distribution of marine macroplankton VI. Further observations on diurnal changes. Fourn. Mar. Biol. Assoc., N.S., Vol. I5, pp. 8I-I03.

- I $1928 b$. The vertical distribution of marine macroplankton. VII. Observations on the behaviour of Calanus finmarchicus. Fourn. Mar. Biol. Assoc., N.S., Vol. I5, pp. 429-54.

I93I $a$. The vertical distribution of marine macroplankton. X. Notes on the behaviour of Sagitta in the Plymouth area. Fourn. Mar. Biol.Assoc., N.S., Vol. I7, pp. 39I-4I4. 
Russell, F. S., I93I $b$. The vertical distribution of marine macroplankton. XI. Further observations on diurnal changes. Fourn. Mar. Biol. Assoc., N.S., Vol. I7, pp. $767-84$.

I934. The vertical distribution of marine macroplankton. XII. Some observations on the vertical distribution of Calanus finmarchicus in relation to light intensity. Fourn. Mar. Biol. Assoc., N.S., Vol. I9, pp. 569-84.

SOUTHERn, R. \& GARDINER, A. C., I932. The diurnal migrations of the Crustacea of the plankton in Lough Derg. Proc. Roy. Irish Acad., Vol. 40, B, pp. I2 I-59.

SCHALLEK, W., I943. The reaction of certain crustacea to direct and diffuse light. Biol. Bull., Vol. 84, pp. 98-105.

Worthington, E. B., I93I. Vertical movements of freshwater macroplankton. Int. Rev. Hydrobiol. Hydrogr., Vol. 25, pp. 394-436.

\section{EXPLANATION OF PLATES}

\section{Plate X}

Fig. I. Apparatus No. I covered with a black cloth about to be sent down for an experiment; the cloth is removed when the apparatus is below the surface.

Fig. 2. The apparatus on the 'stretcher' being lowered into the cabin at the end of an experiment.

Fig. 3. Details of trigger mechanism of Apparatus No. I, the trapdoors (in their original form) are in the open position.

\section{Plate XI}

Fig. I. Apparatus No. 2 suspended attached to cable as in an experiment below the surface.

Fig. 2. Details of the levers and wire operating two of the trapdoors of Apparatus No. 2; the trapdoors are in the open position. 


\section{APPENDIX}

\section{Table I. Showing the Conditions and Type of each Experiment}

Unless otherwise stated in a footnote all experiments were of $\mathrm{I}$ hr. duration, and the Calanus used were caught from a depth of 6o-90 m. The compartments into which the Calanus were introduced $(A$ or $B$ and $\alpha$ or $\beta$ ) are shown with the results of each experiment in Table II

\begin{tabular}{|c|c|c|c|c|c|c|c|c|c|c|}
\hline $\begin{array}{c}\text { No. } \\
\text { of } \\
\text { exp. }\end{array}$ & $\begin{array}{l}\text { Date } \\
\text { I938 }\end{array}$ & $\begin{array}{l}\text { Depth } \\
\text { in } \mathrm{m} .\end{array}$ & $\begin{array}{l}\text { Time of } \\
\text { beginning } \\
\text { of exp. } \\
\text { G.M.T. }\end{array}$ & $\begin{array}{l}\text { State of } \\
\text { weather: } \\
\text { Beaufort } \\
\text { symbols }\end{array}$ & $\begin{array}{c}\text { State } \\
\text { of } \\
\text { sea }\end{array}$ & $\begin{array}{l}\text { Trans- } \\
\text { parency } \\
\text { of sea: } \\
\text { Secchi } \\
\text { disk } \\
\text { reading } \\
\text { in } \mathrm{m} \text {. }\end{array}$ & $\begin{array}{l}\text { Tem- } \\
\text { perature } \\
\text { of sea } \\
\text { at } \\
\text { surface } \\
{ }^{\circ} \mathrm{C} \text {. }\end{array}$ & $\begin{array}{c}\text { Time } \\
\text { at } \\
\text { which } \\
\text { Calanus } \\
\text { were } \\
\text { caught }\end{array}$ & $\begin{array}{c}\text { Date on } \\
\text { which } \\
\text { Calanus } \\
\text { were } \\
\text { caught }\end{array}$ & Type of exp. \\
\hline I & 2. viii. & 20 & $\mathrm{IIOO} \mathrm{O}^{c}$ & b.z. & o & - & - & 0830 & 2. viii. & Standard \\
\hline 2 & 2. viii. & 20 & $1236^{c}$ & o. & 0 & $8 \cdot 5$ & - & 0830 & 2. viii. & Standard \\
\hline 3 & 8. viii. & 20 & 1029 & o.p. & $I-2$ & $-7 \cdot 75$ & - & 0800 & 8. viii. & Standard \\
\hline 4 & 8. viii. & 5 & 1306 & o. & 2 & $7 \cdot 0$ & - & 0800 & 8. viii. & Standard \\
\hline 5 & ro. viii. & 30 & 1032 & b.z. & o & $8 \cdot 25$ & $15 \cdot 3$ & 0800 & Io. viii. & Standard \\
\hline 6 & I0. viii. & $\mathrm{I}^{b}$ & 1256 & b.z. & o & & 15.6 & 0800 & Io. viii. & Standard \\
\hline 8 & Ir. viii. & & 1006 & b. & o & $8 \cdot 4$ & 14.6 & & $-f$ & 'Fed' and 'starved' Calanus \\
\hline $\begin{array}{l}8 \\
9\end{array}$ & $\begin{array}{l}\text { 12. vili. } \\
\text { 12. viii. }\end{array}$ & $\begin{array}{l}\mathbf{I}^{b} \\
\mathbf{I}^{b}\end{array}$ & $\begin{array}{l}1054 \\
\text { I35I }\end{array}$ & $\begin{array}{c}\text { c. } \\
\text { b.c. }\end{array}$ & $I_{-2}^{I}$ & $6 \cdot 25$ & 13.9 & 0800 & I2. viii. & Mirror \\
\hline I0 & 26. viii. & 10 & 1025 & b.c.z. & ${ }^{1} 7^{2}$ & $\begin{array}{r}7.5 \\
11.0\end{array}$ & $\begin{array}{l}13.5 \\
14.6\end{array}$ & $\stackrel{0800}{-f}$ & I2. viii. & $\begin{array}{l}\text { Mirror } \\
\text { 'Fed' and 'starved' Calanus }\end{array}$ \\
\hline II & 26. viii. & 40 & $1225^{c}$ & b.c.z. & o & 9.5 & 14.6 & $\overrightarrow{0800}$ & 26. viii. & Standard \\
\hline 12 & 26. viii. & 30 & $1353^{c}$ & b.c.z. & o & II. 5 & 14.6 & 0800 & 26. viii. & Standard \\
\hline $14^{a}$ & 30. viii. & 40 & 1140 & b. & o & 10.5 & & 0730 & 3o. viii. & Standard \\
\hline 15 & 30. vili. & 30 & 1349 & b.c. & $\mathrm{I}-2$ & $8 \cdot 5$ & - & 0730 & 30. viii. & Standard \\
\hline 16 & 3I. viii. & Io & 1020 & b. & $0-1$ & 10.5 & 13.6 & 0730 & 3I. viii. & Standard \\
\hline 17 & 3r. viii. & 20 & 1200 & b. & I & II. O & & 0730 & 31. viii. & Standard \\
\hline 18 & I. ix. & Io & 1002 & b.c. & o & $8 \cdot 0$ & 13.8 & $-f$ & $-f$ & 'Fed' and 'starved' Calanus \\
\hline I9 & I. ix. & I0 & II5I & b.c. & $0-1$ & $8 \cdot 5$ & 14.0 & $-f$ & $-f$ & 'Fed' and outside Calanus \\
\hline 20 & I. ix. & 10 & $1330^{c}$ & c.p. & I & 8.25 & 14.0 & 0730 & I. ix. & Standard \\
\hline $2 \mathrm{I}$ & 7. ix. & 20 & 1030 & c.z. & $\mathrm{I}$ & $7 \cdot 25$ & 13.8 & 0800 & 7. ix. & Standard \\
\hline $23^{a}$ & 12. ix. & 30 & 1109 & o. & $I-2$ & 6.5 & 13.8 & $-f$ & $-f$ & 'Fed' and 'starved' Calanus \\
\hline 24 & 12. ix. & 5 & $13 \mathrm{II}^{c}$ & c.z. & $2-3$ & 8.0 & $\begin{array}{l}13.8 \\
13.8\end{array}$ & $-f$ & $-f$ & 'Fed' and outside Calanus \\
\hline 25 & I2. ix. & 5 & $1433^{c}$ & c.z. & $2-3$ & $7 \cdot 75$ & I 3.8 & 0830 & 12. ix. & Standard \\
\hline 26 & 14. ix. & 30 & 1255 & b.c. & $\mathrm{I}$ & - & $\begin{array}{r}13.8 \\
13-8\end{array}$ & $-f$ & $-f$ & 'Fed' and 'starved' Calanus \\
\hline 27 & I4. ix. & 5 & 1705 & b. & o & $7 \cdot 5^{d}$ & 12.6 & $-f$ & $z^{f}$ & 'Fed' and 'starved' Calanus \\
\hline 28 & I4. ix. & 20 & 2108 & b. & 0 & - & - & 2015 & I4. ix. & Standard \\
\hline 29 & 15. ix. & 100 & $1245^{c}$ & c.p. & $0-I$ & - & - & I $100 \mathrm{~g}$ & I5. ix. & Standard \\
\hline 30 & I5. ix. & 30 & 1700 & b.c. & I & $6 \cdot 0$ & - & I IOOg & I5. ix. & Standard \\
\hline $3 \mathrm{I}$ & I5. ix. & 50 & 2039 & b.c. & o & - & - & 1900 & I5. ix. & Standard \\
\hline 32 & I5. ix. & 5 & 2210 & b.c. & 0 & - & - & 1900 & I5. ix. & Standard \\
\hline 33 & I9. $x$ & 30 & II 58 & b.c.z. & I & $8 \cdot 0$ & II 6 & 1025 & I9. $x$. & Mirror \\
\hline 34 & I9. $x$. & 20 & 1358 & c. & I & 8.0 & II 6 & 1025 & I9. $x$. & Mirror \\
\hline 35 & 25. x. & 20 & 1202 & b.z. & I & $7 \cdot 25$ & II 99 & 1030 & 25. x. & Mirror \\
\hline 36 & $25 . x$. & I0 & 1355 & b.z. & $\mathbf{I}$ & 7.0 & II ${ }^{\circ} 9$ & 1030 & 25. x. & Mirror \\
\hline 37 & 27. $x$ & 5 & 1153 & b.c. & I & 6.5 & II 6 & $1030^{b}$ & $25 . \mathrm{x}^{b}$ & Mirror \\
\hline
\end{tabular}

\begin{tabular}{|c|c|}
\hline \multicolumn{2}{|c|}{$\begin{array}{l}\text { Origin of the water used } \\
\text { in the two cylinders }\end{array}$} \\
\hline$A B$ & $\alpha \beta$ \\
\hline & Surface water \\
\hline & Surface water \\
\hline water & Surface water \\
\hline water & Surface water \\
\hline e water & Surface water \\
\hline water & Surface water \\
\hline water $f$ & Filtered water $f$ \\
\hline $\begin{array}{l}\text { water } \\
\text { water }\end{array}$ & $\begin{array}{l}\text { Surface water } \\
\text { Surface water }\end{array}$ \\
\hline ure water $f$ & Filtered water $f$ \\
\hline water & Surface water \\
\hline water & Surface water \\
\hline water & Surface water \\
\hline water & Surface water \\
\hline water & Surface water \\
\hline water & $\begin{array}{l}\text { Surface water } \\
\text { Filtered water } f\end{array}$ \\
\hline $\begin{array}{l}\text { e water } \text { e water }^{f} \\
\text { ent }\end{array}$ & $\begin{array}{l}\text { Filtered water } \\
\text { Surface water }\end{array}$ \\
\hline e water & Surface water \\
\hline $\begin{array}{l}\text { wate } \\
\text { wate }\end{array}$ & Surface water \\
\hline e water $f$ & $\begin{array}{l}\text { Filtered water } f \\
\text { Surface water }\end{array}$ \\
\hline & Surface water \\
\hline re water $f$ & $\begin{array}{l}\text { Filtered water } \\
\text { Filtered water }\end{array}$ \\
\hline water & Surface water \\
\hline $10 \mathrm{~m}$. & From ro m. \\
\hline$\circ \mathrm{m}$. & From Io $\mathrm{m}$. \\
\hline & From io m. \\
\hline e water & $\begin{array}{l}\text { From Io m. } \\
\text { Surface water }\end{array}$ \\
\hline wi & $\begin{array}{l}\text { Surface water } \\
\text { Surface water }\end{array}$ \\
\hline - & Surface water \\
\hline$y$ & urface wate \\
\hline
\end{tabular}




\begin{tabular}{|c|c|c|c|}
\hline 38 & 9. xi. & IO & 45 \\
\hline 39 & II. xi. & I0 & 1215 \\
\hline 40 & 20. vii. & 0.5 & IIII \\
\hline $4 \mathrm{I}$ & 20. vii. & 0.5 & 1443 \\
\hline 42 & 2I. vii. & 0.5 & II 33 \\
\hline 43 & 2I. vii. & 0.5 & 1354 \\
\hline 44 & 22. vii. & 0.5 & IOI5 \\
\hline $49^{\circ}$ & 2I. viii. & Io & IO4I \\
\hline 50 & 23. viii. & IO & 0944 \\
\hline 51 & 23. viii. & IO & II 39 \\
\hline & 23. viii. & IO & 1356 \\
\hline 5 & 23. viii. & I0 & I556 \\
\hline 54 & 23. viii. & 10 & 1910 \\
\hline 55 & 24. viii. & 100 & 0939 \\
\hline 56 & 24. viii. & I0 & II39 \\
\hline 57 & 24. viii. & IO & I 439 \\
\hline 58 & 24. viii. & I0 & 1732 \\
\hline 59 & 24. viii. & Io & 2035 \\
\hline 60 & 24. viii. & IO & 2333 \\
\hline II & 25. viii. & I0 & 0230 \\
\hline & 25. viii. & 10 & 0537 \\
\hline & 25. viii. & IO & 0834 \\
\hline & 25. viii. & IO & $\begin{array}{l}\mathrm{I} 133 \\
\end{array}$ \\
\hline & 25. viii. & 50 & 1332 \\
\hline & 30. viii. & I0 & 1042 \\
\hline & 30. viii. & I0 & 1240 \\
\hline & 18. xi. & IO & 0949 \\
\hline 69 & 18, xi. & ro & 1154 \\
\hline 70 & 18. xi. & I0 & 1404 \\
\hline $7 x$ & 20. xi. & I0 & 1215 \\
\hline 72 & 20. xi. & IO & I 406 \\
\hline & 21. xi. & 5 & \\
\hline & 2I, xi & 5 & 1356 \\
\hline & 22, xi. & I0 & 1042 \\
\hline
\end{tabular}

\begin{tabular}{|c|c|c|c|c|}
\hline $\begin{array}{c}\text { o. } \\
\text { b.z. }\end{array}$ & $\stackrel{\mathrm{I}-2}{\mathrm{I}}$ & $\begin{array}{r}5.5 \\
5.5\end{array}$ & $=$ & ${ }^{093}{ }^{\circ}$ \\
\hline b.z. & o & 5.5 & - & 0830 \\
\hline o. & 0 & 50 & 13.9 & 0830 \\
\hline o. & 0 & - & - & 0830 \\
\hline o. & 0 & - & - & 0830 \\
\hline o.p. & $\mathrm{I}-2$ & $5 \cdot 5$ & 12.5 & 0830 \\
\hline b.c. & & 50 & I3.8 & 0800 \\
\hline b. & & $8 \cdot 5$ & $15 \%$ & 0900 \\
\hline b. & $\circ$ & $9^{\circ} 0$ & 15.6 & 0900 \\
\hline b. & o & 7.5 & c. I5 & 0900 \\
\hline b. & 0 & & c. 15 & 0900 \\
\hline b. & 0 & 6.5 & c. I5 & I830 \\
\hline o. & I & 7.5 & 15.6 & 0730 \\
\hline & I & $7 \cdot 5$ & I 4.8 & 0730 \\
\hline b. & I & $7 \cdot 5$ & c. 15 & 0730 \\
\hline b. & I & 7.0 & c. I5 & 0730 \\
\hline b.c. & 0 & 3.5 & 15.4 & 1900 \\
\hline b.c. & 0 & $2 \cdot 5$ & $16 \%$ & $2230^{\circ}$ \\
\hline b.c. & o & 2.5 & 15.6 & $2230^{\prime}$ \\
\hline b.c. & 0 & 6.25 & 15.7 & $2230^{3}$ \\
\hline b.z. & 0 & 9.5 & I6.4 & 0730 \\
\hline & 0 & 8.0 & I4.8 & 0730 \\
\hline & 0 & 6.5 & 15.8 & 0730 \\
\hline b.c. & 0 & $4 \cdot 5$ & & 0830 \\
\hline o. & 0 & 4.0 & - & 0830 \\
\hline c. & 0 & $5 \cdot 25$ & - & 1200 \\
\hline c. & 0 & 6.0 & - & 1200 \\
\hline c. & o & 5.5 & - & 1200 \\
\hline c. & 0 & $5 \cdot 25$ & - & 1200 \\
\hline c. & o & 50 & - & 1200 \\
\hline o.r. & I & 4.5 & - & 1030 \\
\hline o.r. & I & 4.5 & - & I030 \\
\hline o.r. & 2 & 5.5 & - & $1300^{k}$ \\
\hline
\end{tabular}

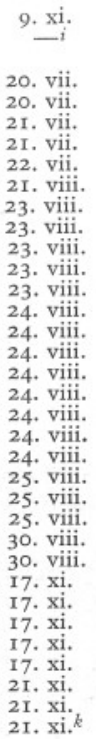

\section{Alkaline
Acid}

Long-tube experiment

Long-tube experiment

Long-tube experiment

Long-tube experiment

$\alpha \beta$ completely darkened

$\alpha \beta$ completely darkened

$\stackrel{\alpha \beta \operatorname{com}}{\text { Mirror }}$

Mirror

Standard

Standard

Standard

Standarc

Standard

Standard

Standard

Standard

Standard

Standard

Deep $v$. surface water

Deep $v$. surface water

Standard (control)

Standard (control)

Standard (control) see p. 506

Standard (control

Standard (control)
Standard (control)

See p. 507

See p. 507

Surface water

Surface water

Surface water

Surface water

Surface water

From $10 \mathrm{~m}$.

From ro m.

Surface water

Surface water

Surface water

Surface water

Surface water

Surface water

Surface water

Surface water

Surface water

Surface water

Surface water

Surface water

From $30 \mathrm{~m}$.

Surface water

Surface water

Surface water

From ro m.

From $10 \mathrm{~m}$.

From Io $\mathrm{m}$.

Surface water
Surface water Surface water

二

Surface water From ro $\mathrm{m}$.

From $10 \mathrm{~m}$.

Surface water

Surface water

Surface water

Surface water

Surface water

Surface water

Surface water

Surfer

Surface water

Surface water

Surface water

Surface water

Surface water

Surface water

Surface water

Surface water

From $10 \mathrm{~m}$.

From $10 \mathrm{~m}$

From ro m.

From $10 \mathrm{~m}$.

a Exps. 13 and 22 were done with Thysanoessa and are not included in this paper.$$
\text { . }
$$

${ }_{b}^{a}$ Exps. 13 and 22 were done with
$c$ Middle of apparatus I m. (top $\frac{1}{2} \mathrm{~m}$.) below surface.
$c$ Experiment of 30 min. duration instead of usual $60 \mathrm{~min}$.
$d$ Experiment in shallow water, Secchi disk seen resting on bottom at $7.5 \mathrm{~m}$.

Exps. 45-48 were invalidated by toxic effects (see p. 473 ).

$f$ For details of origin and treatment of Calanus in these experiments see Table VI in the text.

$g$ Calanus caught at $100-120 \mathrm{~m}$.
$b$
$i$ Calanus had been kept in jar standing in running water and fed on Nitzschia.

$i$ Calanus in $A B$ were from same stock as those used in Exp. 38 and had been kept 2 days in the laboratory; those used in $\alpha \beta$ were caught on the morning of the experiment.

$j$ Calanus caught at $20 \mathrm{~m}$. (see p. 503 ).
$k$ Calanus kept in darkened jar on boat with two changes of water. 


\section{Table II. Showing the Numbers of Calanus (Total, Stage V and Female) USED IN CYLINDERS $A B$ AND $\alpha \beta$ IN EACH EXPERIMENT TOGETHER WITH THE Percentage OF THOSE FOUND IN THE LOWER COMPARTMENTS $B$ AND $\beta$ AT THE END OF THE EXPERIMENTS.}

The experiments are grouped according to depth; particulars of date, time, weather conditions, origin of Calanus, etc., for each experiment will be found in Table I. The Calanus were introduced into compartments $A$ or $B$ and $\alpha$ or $\beta$ in each experiment as shown in columns 3 and IO.

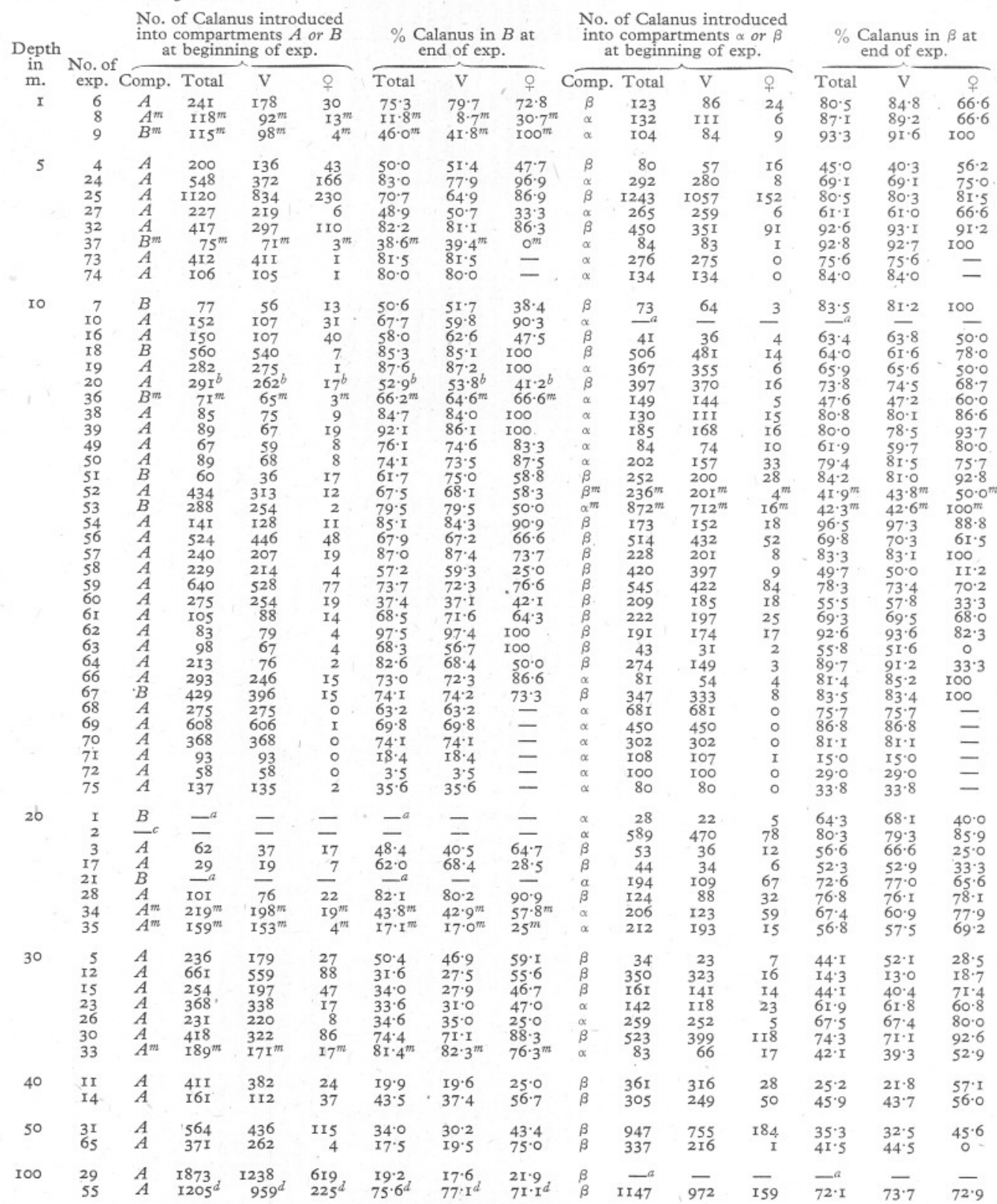

a Sample discarded (or lost) due to faulty working of apparatus.

$b$ Some of the Calanus from compartment $B$ were lost making the percentage in $B$, also estimate of numbers introduced into $A$, too low

$c$ Cylinder $A B$ out of action.

$d$ Cork came out of cylinder $A$ on the way up (at end of experiment) so that a few Calanus may have escaped.

Mirror experiments: the cylinder indicated $(A B$ or $\alpha \beta)$ was blacked out at top and sides and provided with a mirror system below reflecting light upwards (see p. 495). 